Portland State University

PDXScholar

\title{
Understanding Residential Location Choices for Climate Change and Transportation Decision Making: Phase 2 Report
}

Kelly J. Clifton

Portland State University, kclifton@pdx.edu

Steven R. Gehrke

Portland State University

Kristina Marie Currans

Portland State University, curransk@gmail.com

Follow this and additional works at: https://pdxscholar.library.pdx.edu/cengin_fac

Part of the Civil Engineering Commons, and the Mechanical Engineering Commons Let us know how access to this document benefits you.

\section{Citation Details}

Clifton, Kelly J., Steven R. Gehrke, and Kristina M. Currans. Understanding Residential Location Choices for Climate Change and Transportation Decision Making: Phase 2 Report. SPR 745 NITC-RR-543. Portland, OR: Transportation Research and Education Center (TREC), 2015. http://dx.doi.org/10.15760/ trec.118

This Report is brought to you for free and open access. It has been accepted for inclusion in Civil and Environmental Engineering Faculty Publications and Presentations by an authorized administrator of PDXScholar. Please contact us if we can make this document more accessible: pdxscholar@pdx.edu. 

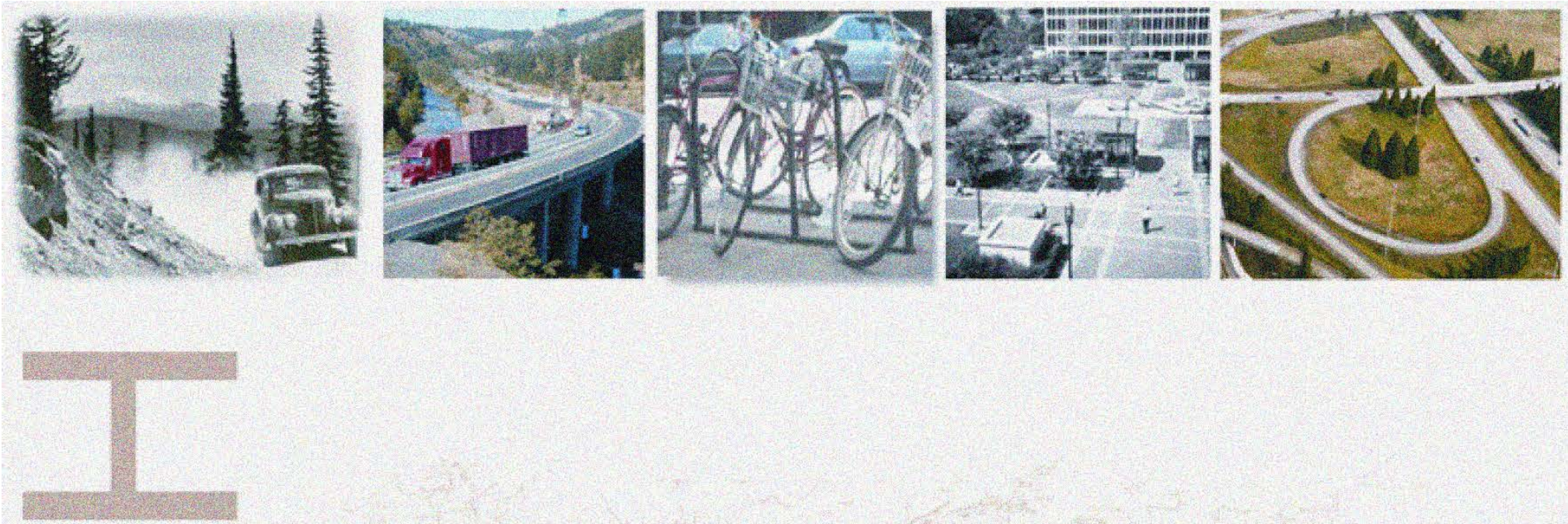

\section{UNDERSTANDING RESIDENTIAL LOCATION CHOICES FOR CLIMATE CHANGE AND TRANSPORTATION DECISION MAKING}

\section{PHASE 2 REPORT}

SPR 745

NITC-RR-543
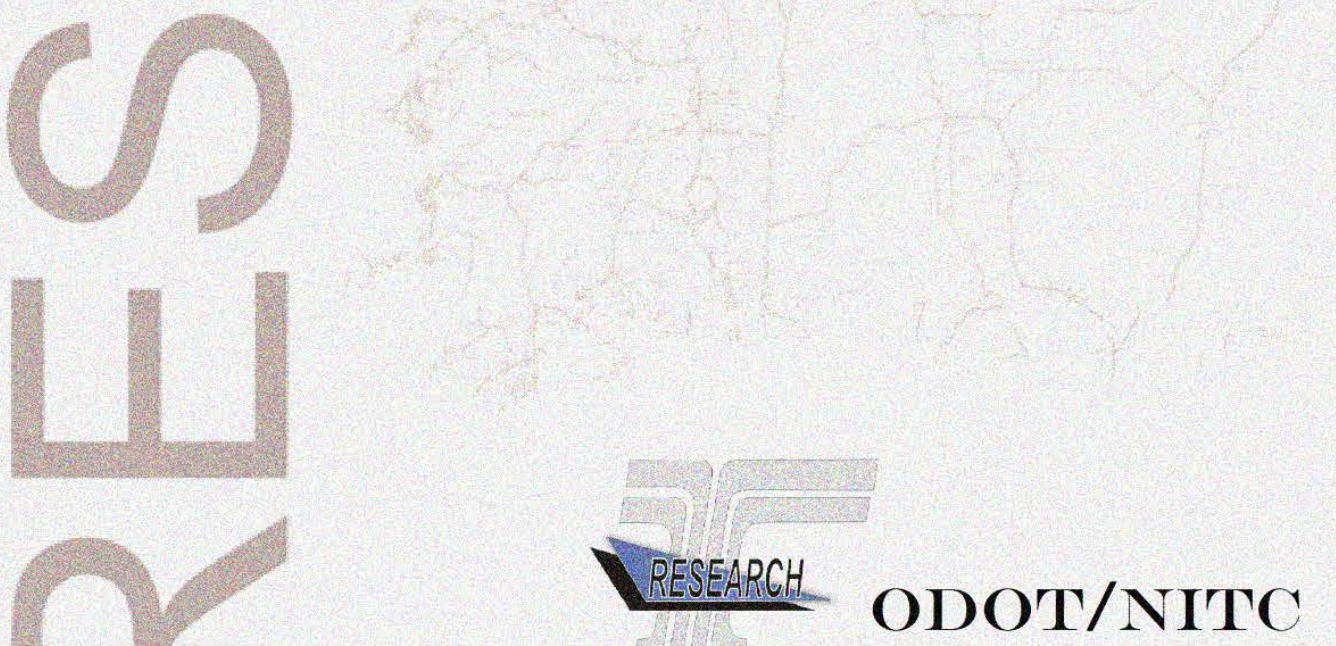

This publiction is a result of joint funding by Oregon Department of Transportation (ODOT) National Institute for Transportation and Communities (NITC)

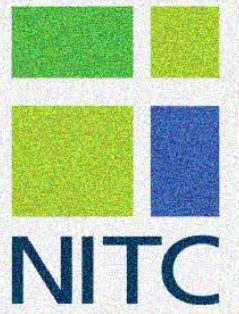





\title{
UNDERSTANDING RESIDENTIAL LOCATION CHOICES FOR CLIMATE CHANGE AND TRANSPORTATION DECISION MAKING
}

\author{
Phase 2 Report
}

\author{
SPR 745 \\ NITC-RR-543
}

\author{
by \\ Kelly J. Clifton, PhD; Steven R. Gehrke; Kristina M. Currans \\ Department of Civil \& Environmental Engineering \\ P.O. Box 751 \\ Portland State University \\ Portland, OR 97207 \\ for \\ Oregon Department of Transportation \\ Research Section \\ $55513^{\text {th }}$ Street NE, Suite 1 \\ Salem OR 97301 \\ and \\ Federal Highway Administration \\ 400 Seventh Street, SW \\ Washington, DC 20590-0003
}

February 2015 

Technical Report Documentation Page

\begin{tabular}{|c|c|c|c|}
\hline & \multicolumn{2}{|c|}{ 2. Government Accession No. } & 3. Recipient's Catalog No. \\
\hline \multirow{2}{*}{\multicolumn{3}{|c|}{$\begin{array}{l}\text { 4. Title and Subtitle } \\
\text { UNDERSTANDING RESIDENTIAL LOCATION CHOICES } \\
\text { FOR CLIMATE CHANGE AND TRANSPORTATION } \\
\text { DECISION MAKING }\end{array}$}} & \\
\hline & & & $\begin{array}{ll}\text { 6. } & \text { Performing Org } \\
\text { Code }\end{array}$ \\
\hline \multicolumn{3}{|c|}{$\begin{array}{l}\text { Author(s): } \\
\text { Kelly J. Clifton, PhD; Steven R. Gehrke; Kristina M. Currans }\end{array}$} & 8. $\begin{array}{l}\text { Perfo } \\
\text { Repo }\end{array}$ \\
\hline \multicolumn{3}{|c|}{$\begin{array}{l}\text { 9. Performing Organization Name and Address } \\
\text { Oregon Department of Transportation } \\
\text { Research Section } \\
55513^{\text {th }} \text { Street NE, Suite } 1 \\
\text { Salem, OR } 97301\end{array}$} & \begin{tabular}{|l|} 
10. Work \\
11. Cont
\end{tabular} \\
\hline \multicolumn{3}{|c|}{$\begin{array}{l}\text { 12. Sponsoring Agency Name and Address } \\
\text { Oregon Dept. of Transportation } \\
\begin{array}{ll}\text { Research Section and Federal Highway Admin. } \\
55513^{\text {th }} \text { Street NE, Suite } 1 & \text { 400 Seventh Street, SW } \\
\text { Salem, OR 97301 } & \text { Washington, DC 20590-0003 }\end{array}\end{array}$} & $\begin{array}{l}\text { 13. Type of Report and Period } \\
\text { Covered: SPR } 745 \text { Phase } 2 \\
\text { NITC-RR-543 }\end{array}$ \\
\hline \multicolumn{4}{|l|}{ 5. Supplementary Notes } \\
\hline \multicolumn{4}{|c|}{$\begin{array}{l}\text { 6. Abstract: This research builds on the related Phase } 1 \text { project. In this second phase, we continue to } \\
\text { study neighborhood and housing preferences that shape the residential location decision process. An } \\
\text { online experimental survey tool is developed to investigate lifestyle preferences and tradeoffs that } \\
\text { households make in their location decisions. This computer-aided experimental survey draws upon } \\
\text { stated preference methods to engage participants in questions about residential location and } \\
\text { transportation options. The survey infrastructure was extensively piloted (6-10\% response rate). The } \\
\text { 10-minute survey can be deployed for future investigations. This infrastructure is a contribution for } \\
\text { the integration of visualized neighborhood typologies, or concepts, which were objectively defined } \\
\text { using data from } 25 \text { of the most populous metropolitan regions from around the United States. The } \\
\text { construct of neighborhoods is based upon national data to account for potential options not currently } \\
\text { available in Oregon. These visualizations help ground the survey respondents in the same reality and } \\
\text { were carefully crafted to convey various attributes of the built and transportation environment. The } \\
\text { initial analysis of the preference data collected in this survey }(\mathrm{N}=1,035) \text { indicates that the } \\
\text { preferences for neighborhood, housing, and transportation characteristics have a greater influence on } \\
\text { the preferred neighborhood concept than the more typically used socio-economic characteristics } \\
\text { (income, household size, age). Another interesting preliminary finding is that } 27 \% \text { of respondents } \\
\text { would prefer to live in a more urban neighborhood than they currently reside. These "urban seeking" } \\
\text { respondents had no particular demographic trend, providing little evidence that specific } \\
\text { socioeconomic markets had specific preferences for the built environment. }\end{array}$} \\
\hline $\begin{array}{l}\text { 17. Key Words: Residential choic } \\
\text { choice, stated preference, experin }\end{array}$ & & & $\begin{array}{l}\text { ution Statement } \\
\text { ble from NTIS, and online at } \\
\text { regon.gov/ODOT/TD/TP_RES/ }\end{array}$ \\
\hline $\begin{array}{l}\text { 9. Security Classification ( } \\
\text { ais report) } \\
\text { Unclassified }\end{array}$ & $\begin{array}{l}\text { Security Clas } \\
\text { this page) }\end{array}$ & cation (of & \begin{tabular}{l|l} 
21. No. of Pages & 22. Price
\end{tabular} \\
\hline
\end{tabular}




\begin{tabular}{|c|c|c|c|c|c|c|c|c|c|}
\hline \multicolumn{10}{|c|}{ SI* (MODERN METRIC) CONVERSION FACTORS } \\
\hline \multicolumn{5}{|c|}{ APPROXIMATE CONVERSIONS TO SI UNITS } & \multicolumn{5}{|c|}{ APPROXIMATE CONVERSIONS FROM SI UNITS } \\
\hline Symbol & $\begin{array}{c}\text { When You } \\
\text { Know }\end{array}$ & $\begin{array}{c}\text { Multiply } \\
\text { By }\end{array}$ & To Find & Symbol & Symbol & $\begin{array}{c}\text { When You } \\
\text { Know }\end{array}$ & $\begin{array}{l}\text { Multiply } \\
\text { By }\end{array}$ & To Find & Symbol \\
\hline \multicolumn{5}{|c|}{ LENGTH } & \multicolumn{5}{|c|}{ LENGTH } \\
\hline in & inches & 25.4 & millimeters & $\mathrm{mm}$ & $\mathrm{mm}$ & millimeters & 0.039 & inches & in \\
\hline $\mathrm{ft}$ & feet & 0.305 & meters & $\mathrm{m}$ & $\mathrm{m}$ & meters & 3.28 & feet & $\mathrm{ft}$ \\
\hline yd & yards & 0.914 & meters & $\mathrm{m}$ & $\mathrm{m}$ & meters & 1.09 & yards & yd \\
\hline $\mathrm{mi}$ & miles & 1.61 & kilometers & $\mathrm{km}$ & $\mathrm{km}$ & kilometers & 0.621 & miles & $\mathrm{mi}$ \\
\hline \multicolumn{5}{|c|}{$\underline{\text { AREA }}$} & \multicolumn{5}{|c|}{$\underline{\text { AREA }}$} \\
\hline in $^{2}$ & square inches & 645.2 & $\begin{array}{l}\text { millimeters } \\
\text { squared }\end{array}$ & $\mathrm{mm}^{2}$ & $\mathrm{~mm}^{2}$ & $\begin{array}{l}\text { millimeters } \\
\text { squared }\end{array}$ & 0.0016 & square inches & $i^{2}$ \\
\hline $\mathrm{ft}^{2}$ & square feet & 0.093 & meters squared & $\mathrm{m}^{2}$ & $\mathrm{~m}^{2}$ & meters squared & 10.764 & square feet & $\mathrm{ft}^{2}$ \\
\hline $\mathrm{yd}^{2}$ & square yards & 0.836 & meters squared & $\mathrm{m}^{2}$ & $\mathrm{~m}^{2}$ & meters squared & 1.196 & square yards & $\mathrm{yd}^{2}$ \\
\hline $\mathrm{ac}$ & acres & 0.405 & hectares & ha & ha & hectares & 2.47 & acres & ac \\
\hline $\mathrm{mi}^{2}$ & square miles & 2.59 & $\begin{array}{l}\text { kilometers } \\
\text { squared }\end{array}$ & $\mathrm{km}^{2}$ & $\mathrm{~km}^{2}$ & $\begin{array}{l}\text { kilometers } \\
\text { squared }\end{array}$ & 0.386 & square miles & $\mathrm{mi}^{2}$ \\
\hline \multicolumn{5}{|c|}{ VOLUME } & \multicolumn{5}{|c|}{ VOLUME } \\
\hline $\mathrm{fl} \mathrm{oz}$ & fluid ounces & 29.57 & milliliters & $\mathrm{ml}$ & $\mathrm{ml}$ & milliliters & 0.034 & fluid ounces & fl oz \\
\hline & gallons & 3.785 & liters & $\mathrm{L}$ & $\mathrm{L}$ & liters & 0.264 & gallons & gal \\
\hline $\mathrm{ft}^{3}$ & cubic feet & 0.028 & meters cubed & $\mathrm{m}^{3}$ & $\mathrm{~m}^{3}$ & meters cubed & 35.315 & cubic feet & $\mathrm{ft}^{3}$ \\
\hline $\mathrm{yd}^{3}$ & cubic yards & 0.765 & meters cubed & $\mathrm{m}^{3}$ & $\mathrm{~m}^{3}$ & meters cubed & 1.308 & cubic yards & $\mathrm{yd}^{3}$ \\
\hline \multirow{2}{*}{\multicolumn{5}{|c|}{$\begin{array}{l}\text { NOTE: Volumes greater than } 1000 \mathrm{~L} \text { shall be shown in } \mathrm{m}^{3} \text {. } \\
\text { MASS }\end{array}$}} & \multirow{2}{*}{\multicolumn{5}{|c|}{ MASS }} \\
\hline & & & & & & & & & \\
\hline $\mathrm{oz}$ & ounces & 28.35 & grams & g & g & grams & 0.035 & ounces & $\mathrm{oz}$ \\
\hline $\mathrm{lb}$ & pounds & 0.454 & kilograms & $\mathrm{kg}$ & $\mathrm{kg}$ & kilograms & 2.205 & pounds & $\mathrm{lb}$ \\
\hline $\mathrm{T}$ & $\begin{array}{l}\text { short tons (2000 } \\
\text { lb) }\end{array}$ & 0.907 & megagrams & $\mathrm{Mg}$ & $\mathrm{Mg}$ & megagrams & 1.102 & short tons (2000 lb) & $\mathrm{T}$ \\
\hline \multicolumn{5}{|c|}{ TEMPERATURE (exact) } & \multicolumn{5}{|c|}{ TEMPERATURE (exact) } \\
\hline${ }^{\circ} \mathrm{F}$ & Fahrenheit & $\begin{array}{l}(\mathrm{F}- \\
32) / 1.8\end{array}$ & Celsius & ${ }^{\circ} \mathrm{C}$ & ${ }^{\circ} \mathrm{C}$ & Celsius & $\begin{array}{l}1.8 \mathrm{C}+3 \\
2\end{array}$ & Fahrenheit & ${ }^{\circ} \mathrm{F}$ \\
\hline
\end{tabular}




\section{ACKNOWLEDGEMENTS}

The authors would like to acknowledge our technical advisory committee for their comments and feedback throughout the process of both stages of this project. Funding from the Oregon Department of Transportation and the National Institute for Transportation and Communities was also provided for the Phase II of this study.

\section{DISCLAIMER}

This document is disseminated under the sponsorship of the Oregon Department of Transportation and the United States Department of Transportation in the interest of information exchange. The State of Oregon and the United States Government assume no liability of its contents or use thereof.

The contents of this report reflect the view of the authors who are solely responsible for the facts and accuracy of the material presented. The contents do not necessarily reflect the official views of the Oregon Department of Transportation or the United States Department of Transportation.

The State of Oregon and the United States Government do not endorse products of manufacturers. Trademarks or manufacturers' names appear herein only because they are considered essential to the object of this document.

This report does not constitute a standard, specification, or regulation. 


\section{EXECUTIVE SUMMARY}

This report describes the design, development, administration, and empirical application of an experimental survey infrastructure built to associate a household's residential location choice and their housing, neighborhood, and transportation preferences. The primary goal of the phase of the project described in this report is to develop an online experimental survey tool to investigate lifestyle preferences and tradeoffs that households make in their location decisions. This computer-aided experimental survey draws upon stated preference methods and integrates visualized neighborhood concepts to engage survey participants in the questions about residential location and transportation options. The infrastructure can be used to collect information regarding residential neighborhood, housing, and transportation choices and preferences, which may include targeting to specific market segments, examining current or changing preferences, emphasizing policy directives or needs, and aiding in the supplementation of existing transportation-land use models and tools.

The infrastructure developed also includes the definition and visualization of a universal set of neighborhood types. The development and testing of the six, nationally defined, neighborhood concepts can be found within Section 3.1 (satisfying Task \#4 and \#5). The testing of our visualized neighborhood concepts included a pilot survey administered online, and recruited through US Postal Service postcards. This survey allowed the research team to (a) pilot the main components of the survey instrument, (b) test the response rate from a survey administered from a single postcard, and (c) validate the visualized survey respondents, testing the ability for respondents to "get on the same page" when viewing our neighborhood concept image sets.

To test the online infrastructure developed by the research team (Tasks \#7 and \#8), neighborhood choice and commute (mode and travel time) tradeoffs were investigated within a full-factorial choice-based conjoint experiment. With three neighborhood levels (Central District, Urban District Neighborhood, and Urban Neighborhood), three commute mode levels (car, public transit, and bike/walk), and three levels of travel times (15, 30, and 60). Each experimental survey respondent completed the five choice scenarios required to conduct experimental analysis - choosing between two "cards"-and then they were given the option to complete five additional choice scenarios. The 10-12 minutes survey was administered via Qualtrics online, and recruited from two sample frames: (a) a random sample of Portland residents from the ReferenceUSA database (N1=8,000; 6\% response rate) and (b) all non-Portland 2009-2011 Oregon Household Activity Survey respondents who agreed to be contacted again for a followup survey (N2=5,249; $10 \%$ response rate). Although the experimental survey had a low average response rate (approximately 8\%), 83\% of respondents who completed the experimental portion of the survey choose to complete ten tasks, instead of the minimum requested five choice scenarios. This indicates that although the response rate is lower, respondents are more willing to "burden" themselves by completing additional hypothetical choice questions.

The experimental analysis of the collected stated neighborhood preference survey (see Section 3.3) indicates more influence of the preferences for a variety of neighborhood, housing, and transportation characteristics, rather than the more typically used land use-transportation attributes: income, household size, and age. Ideas for future research or analysis of the collected data are included in this section. 
The Phase II conclusions in Section 4.0 consist of a discussion of the lesson's learned from development and piloting of the survey infrastructure, a summary of the major findings suggested from the experimental analysis of the piloted survey, and information about potential future work related to the this project. This section concludes with a discussion of the ways in which this survey infrastructure might help to inform policy needs and directives, as well as how it might be applied to supplement and improve the representation of residential neighborhood and transportation choices within existing models and tools in Oregon. 


\section{TABLE OF CONTENTS}

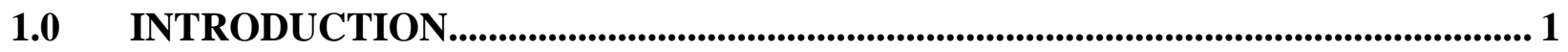

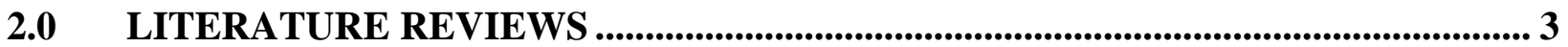

$2.1 \quad$ LITERATURE REVIEW OF NEIGHBORHOOD CONCEPTS.................................................... 3

2.1.1 Conceptualizing Neighborhood .......................................................................................................

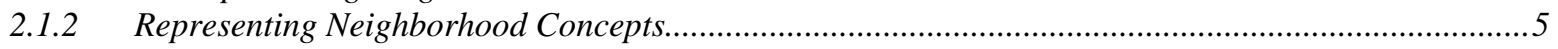

2.1.3 Literature Review of Influential Residential Location Attributes .............................................................

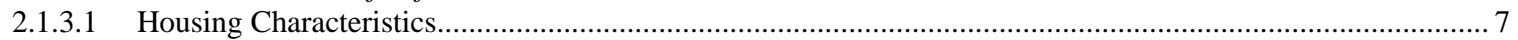

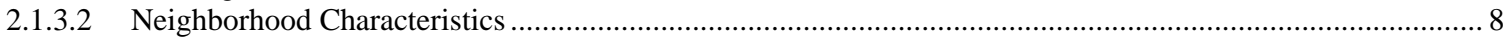

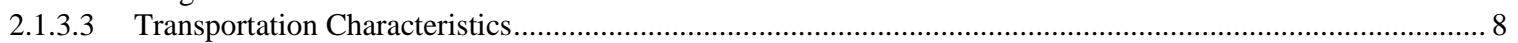

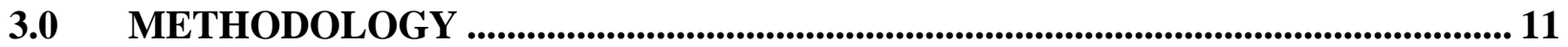

3.1 DEVELOPING NEIGHBORHOOD CONCEPTS ………................................................ 12

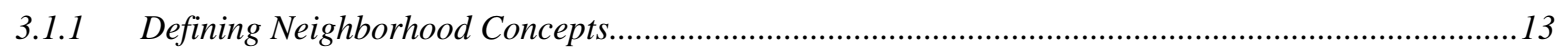

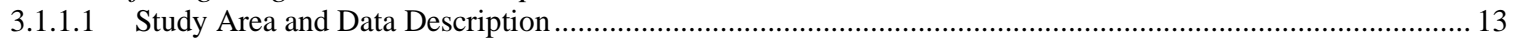

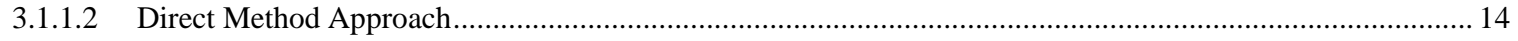

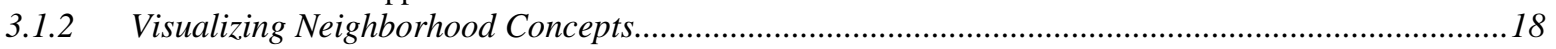

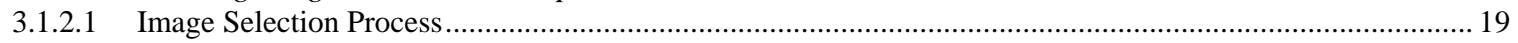

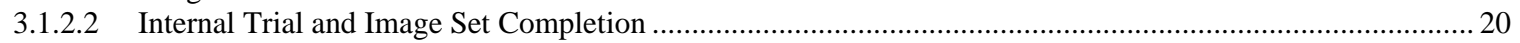

3.1.3 Validating Neighborhood Concepts..................................................................................20

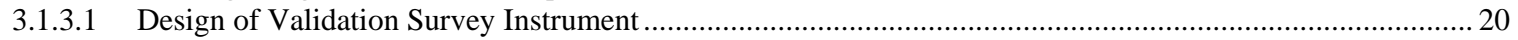

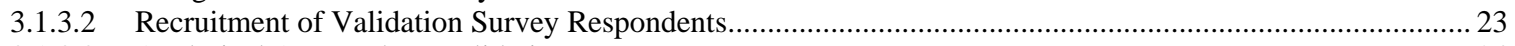

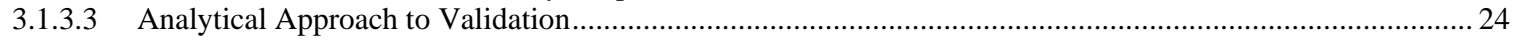

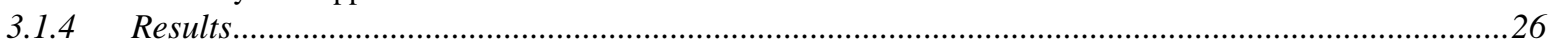

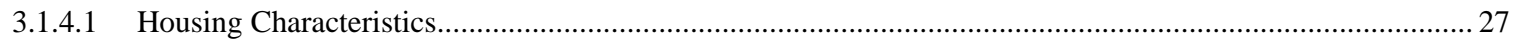

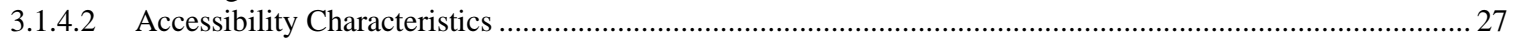

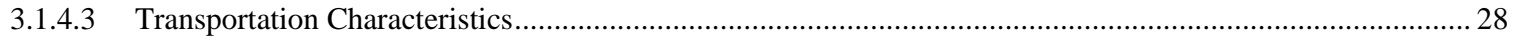

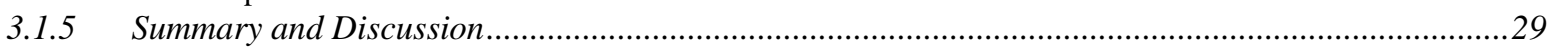

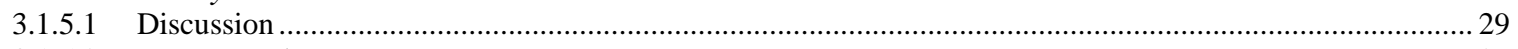

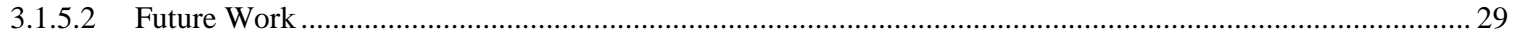

3.2 RESIDENTIAL LOCATION PREFERENCES AND CHOICES................................................ 30

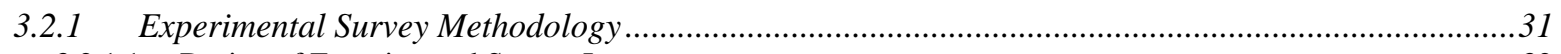

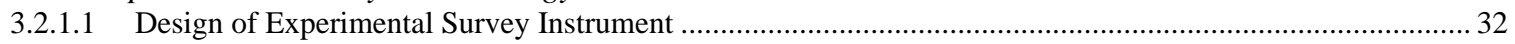

3.2.1.2 Survey Component: Background Information............................................................................... 32

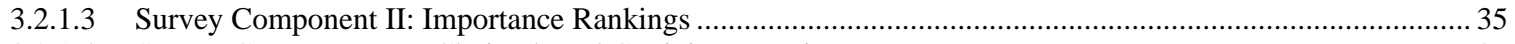

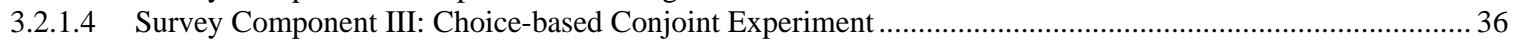

3.2.1.5 Recruitment of Experimental survey Respondents......................................................................... 37

3.2.1.6 Summary Statistics of Experimental Survey Respondents ..................................................................... 38

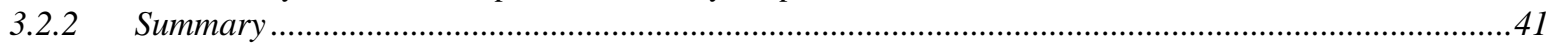

3.3 NEIGHBORHOOD PREFERENCE ANALYSIS ………….................................................. 41

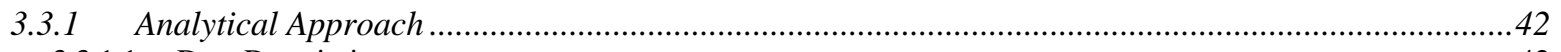

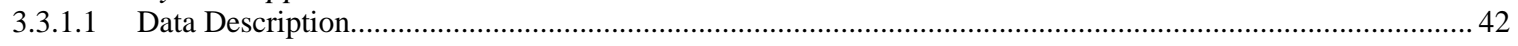

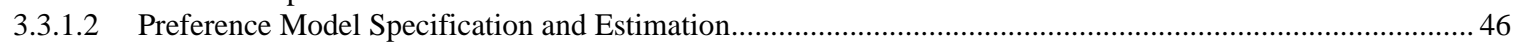

3.3.2 Neighborhood Preference Model Estimation Results ................................................................49

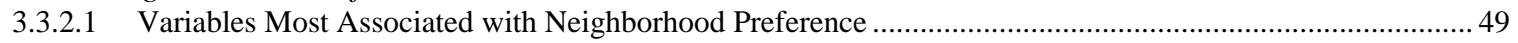

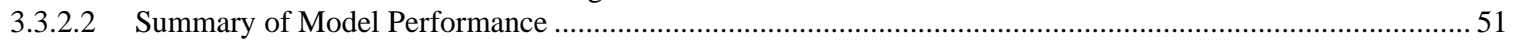

3.3.2.3 When do People Prefer Neighborhood C: Urban Residential Districts .....................................................56

3.3.2.4 When do People Prefer Neighborhood D: Urban Neighborhoods.............................................................58

3.3.3 Future Work: Methodology for Stated-Choice Experiment Analysis.................................................60

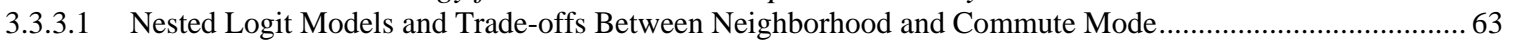

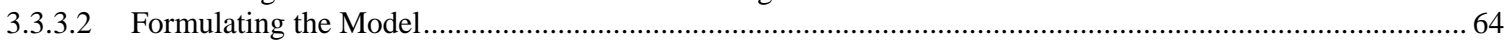

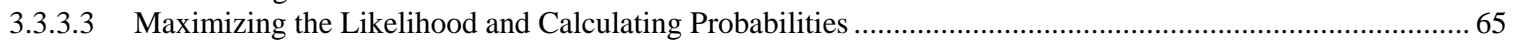

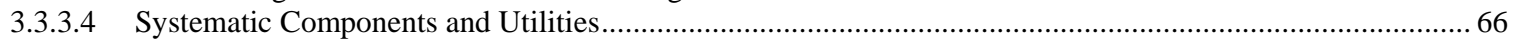

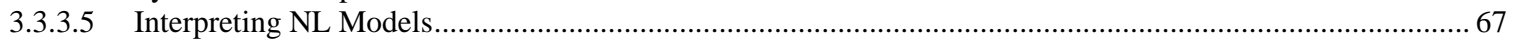


3.3.3.6 Evaluating Trade-offs in Neighborhood, Commute Mode and Travel Time................................................6 68

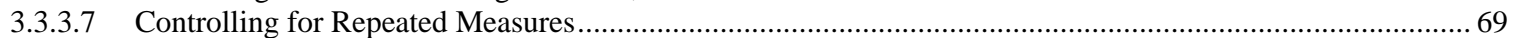

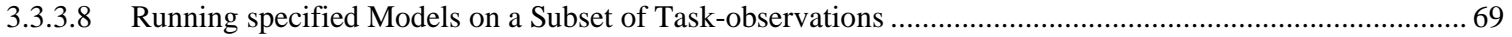

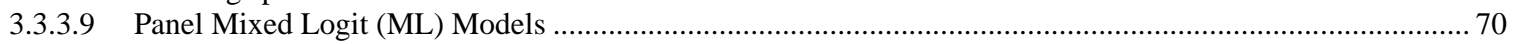

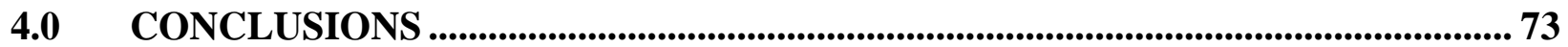

4.1 ASSESSMENT OF SURVEY INFRASTRUCTURE AND ADMINISTRATION............................. 73

4.2 OPPORTUNITIES FOR IMPLEMENTATION AND FUTURE WORK ..................................... 75

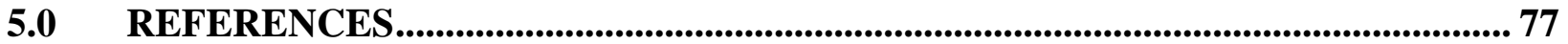

\section{LIST OF TABLES}

Table 3.1: Range of Built Environment Measure Values for Groups Defined by FNBCM ......................................15

Table 3.2: Summary Statistics of the Neighborhood Concepts for Three Built Environment Measures at the Census

Block Group Level for the 25 Most Populous US Metropolitan Regions......................................................17

Table 3.3: Proportion of Survey Responses Evaluating Neighborhood Concept Pairings: "Indicate the neighborhood

that you think is more likely to have." ...........................................................................................................25

Table 3.4: Comparison of Objective versus Respondent Evaluation Outcomes: "Indicate the neighborhood that you

(the respondent) think is more likely to have. .................................................................................................26

Table 3.5: Distribution of Sampled Oregon Residents by Neighborhood Concept and Work Status...........................39

Table 3.6: Distribution of Sampled Oregon Residents by Dwelling Type and Work Status .......................................40

Table 3.7: Distributions of Sampled Oregon Residents by Common Travel Mode and Work Status...........................41

Table 3.8: Descriptive Statistics for Socioeconomic Characteristics for Preference Dataset .......................................43

Table 3.9: Descriptive Statistics for Residential Location Characteristics for Preference Dataset................................44

Table 3.10: Descriptive Statistics for Transportation Characteristics for Preference Dataset .....................................45

Table 3.11: Importance Ranking of Residential Location Choice Items for Preference Dataset.................................46

Table 3.12: Neighborhood Concept Preference Model Estimation (Base $=$ Suburban Neighborhood/EF) ..................47

Table 3.13: Neighborhood Concept Preference Model Estimation (Base = Suburban Neighborhood/EF) - Continued

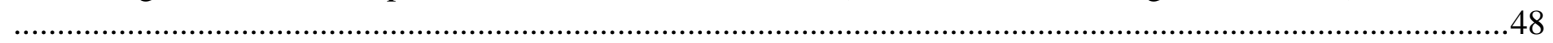

Table 3.14: Comparison of Current and Stated Neighborhood Preference...................................................................50

Table 3.15: Neighborhood Preference Model Accuracy_Predicted versus Stated Preferences ...................................52

\section{LIST OF FIGURES}

Figure 3.1: Illustration of Aggregation Process used to define the Neighborhood Concepts .....................................16

Figure 3.2: Spatial Distribution of Neighborhood Concepts in Portland, San Francisco, and Seattle ..........................18

Figure 3.3: Example of Image Set Comparison found in Validation Survey Instrument ...........................................23

Figure 3.4: Neighborhood Concepts in Experimental Survey ………........................................................................34

Figure 3-5 Illustration of a Potential Task in the Choice-based Conjoint Experiment Error! Bookmark not defined.

Figure 3.6: Recruitment Postcard ..........................................................................................................................38

Figure 3.7: Observed Distribution of Stated Neighborhood Preferences by Annual Household Income....................51

Figure 3.8: Individual-Level Variables- Contribution to the Change in Probability of Neighborhood Preference, all

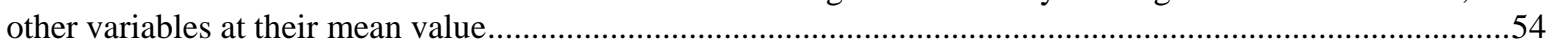

Figure 3.9: Importance Ranking Preferences - Variable Contribution to the Change in Probability of Neighborhood

Preference, all other variables at their mean value.............................................................................................55 
Figure 3.10: Fitted Probabilities for Neighborhood Preference, All Other Variables at the Mean Values.......... Error! Bookmark not defined.

Figure 3.11: Observed Distribution of Stated Neighborhood Preferences by Respondent Age..... .59

Figure 3.12: hree cards: each with one of the three alternatives for neighborhood, commute mode and commute travel time

Figure 3.13: Joint multinomial logit structure. ……….................................................................................63

Figure 3.14: Proposed nested logit structure....................................................................................................64

Figure 5-1 Neighborhood Concept Image Sets and Descriptions ............................................................................21 


\subsection{INTRODUCTION}

Understanding the changing preferences of differing market segments is key toward improving the representation of residential locations choices in integrated land use and travel demand models and more importantly fundamental to understanding the drivers for future housing, land use and transportation policies. As communities struggle to address rising challenges in public infrastructure provision, climate change preparation, energy and natural resource consumption, and the creation of a sustainable future given present economic uncertainty, transportation and land use plans have become increasingly predicated on assumptions concerning the market for various types of dwelling units, residential environments, and travel modes. However, if planners lack faith in the estimates of these travel demand models, the long range supply of housing, activity locations, and transportation facilities will be insufficient to meet future demands. In response, an added importance has been placed on the development of innovative tool sets capable of providing a robust and flexible understanding of how differing assumptions contribute to a set of planning scenarios and impact future residential location decisions.

This report describes the design, development, administration, and empirical application of an experimental survey design targeted toward assessing the multitude of connections that are associated with a household's residential location choice and their preferences for various housing, neighborhood, and transportation characteristics. An improved identification and understanding of the factors that most influence this complex residential location decision making process carries great potential for refining scenario planning exercises and providing a more policy-sensitive depiction of these influential factors in existing transportation analysis tools. Specifically, the administration of the experimental survey design and insight provided by the initial analysis of the data collected from results from its early implementation described in this report has the ability to be integrated into a variety of modeling tools available to metropolitan regions and states, including the sophisticated land use, transportation, and greenhouse gas models utilized in Oregon.

The primary goal of the phase of the project described in this report is to develop an online experimental survey tool to help understand the lifestyle preferences and key tradeoffs that households make in their location decisions. This computer-aided experimental survey will draw upon various stated preference methodologies and will integrate visualization of the physical attributes of housing choices and neighborhood types to engage survey participants in the questions about residential location and transportation options. The tool will be useful in collecting information to better understand future neighborhood, housing, and transportation preferences of key market segments.

This research is the second phase of a project examining the relationships between the residential location decisions of Oregon residents and the transportation implications of the revealed and stated choices. In the first phase of this project, the research team used revealed preference data to identify a set of lifecycle stages and model the impact of their observed residential location 
decisions on travel outcomes such as miles traveled, trip frequency, and automobile ownership ${ }^{1}$. In this second phase, the research team complements this prior Portland-based work with the design of a data collection methodology to support a stated preference analysis that will allow better understand how current residential location and transportation choices of Oregon residents relate to their preferences for certain dwelling types and neighborhoods. The design and application of the stated preference survey techniques used in this second phase further provides the infrastructure needed to enhance the ability of present policy tools to forecast the impact of hypothetical residential conditions or unrealized lifestyles on future housing, neighborhood, and transportation decisions.

More specifically, the experimental survey described hereinafter introduces an innovative tool to examine the important tradeoffs that household members make when choosing a neighborhood, dwelling type, and commute mode. In an attempt to better understand these complicated tradeoffs and provide the survey infrastructure necessary to answer other advanced residential location topics, the project includes the following innovations in this survey methodology and the outcomes:

- The development of neighborhood concepts, or typologies, that are grounded in an objective analysis of the physical attributes of neighborhoods.

- The use of a set of tested and validated imagery to convey these neighborhood concepts in the survey instrument.

- A survey instrument that integrates visual imagery and allows for online administration.

- A tested stated-preference survey methodology that is guided by a goal of collecting data to support discrete choice experiment analyses.

- An initial data set and analysis from the piloting of this methodology.

- A framework for analyzing these and future choice experiment data.

The report is divided into four major sections, including this introduction. The following section includes the literature review. The literature review has two parts. First, we discuss the concept of neighborhood and how it is defined. Then, we delve into the area of literature that discusses the influential locational attributes that determine how and why people their residential location. Section 3.0, details the three major parts of analyses within this project: Developing Neighborhood Concepts; Residential Location Preferences and Choices, and; the Neighborhood Preference Analysis. The final Section 4.0 closes with an extended design for a conjoint analysis framework for future work to examine the tradeoffs between housing, transportation and neighborhood choices.

\footnotetext{
${ }^{1}$ Information about Phase 1 of this project can be found in: Clifton et al. "Understanding Residential Location Choices for Climate Change and Transportation Decision Making Phase 1 Report”, June 2013.
} 


\subsection{LITERATURE REVIEWS}

There are two main literature reviews conducted within this study. In the first, we discuss how neighborhoods are currently defined in the literature, which supports our methodology subsection 3.1: Developing Neighborhood Concepts. This is followed by a discussion of the influential attributes determined to effect or be related to neighborhood location attributes. Both of these subsections influence the development of our experimental surveys.

\subsection{LITERATURE REVIEW OF NEIGHBORHOOD CONCEPTS}

Acceptance of the intuitive notion that residential location decisions are based on tradeoffs in housing, transportation accessibility, and neighborhood elements has been well-established (Weisbrod et al. 1980). Further, the belief that the environment surrounding one's choice of residence (neighborhood) has a significant impact on one's well-being has long been a central tenant guiding multi-disciplinary research on the topic of residential location choice (Guo and Bhat 2007). However, a proper understanding of how this element is valued in comparison to housing and transportation characteristics has proven far more elusive because of the abstract nature of the neighborhood concept. This inability to accurately convey the role of neighborhood effects has been attributed to discrepancies in the manner that neighborhood has been defined, including the dimensions that comprise the concept, in addition to the assortment of methodological strategies that have been employed to define the neighborhood concept.

\subsubsection{Conceptualizing Neighborhood}

Agreement on a single description of neighborhood has remained unreachable because of ongoing debates about whether the concept should be defined in a strictly spatial context or one that also accounts for any social dimensions (O'Campo 2003). Further complicating any consensus is the inability of researchers to agree on a term to describe a person's immediate residential environment, which has been interchangeably referred to as neighborhood, community, or area (Diez Roux 2001). However, some researchers have made distinctions between these substituted terms to restrict neighborhood to spatial dimensions that relate to the area around a residence within which people physically interact with each other and the environment (Meegan and Mitchell 2001). Galster (Galster 2001) emphasized the spatial dimension of neighborhood by defining the concept as "the bundle of spatially based attributes associated with clusters of residences, sometimes in conjunction with other land uses." The theoretical and empirical research of Grannis (Grannis 1998) underlined the additional importance of street design to spatial proximity in defining an individual's surrounding residential environment. 
As a complement to the physical aspect of the neighborhood that focuses on various attributes of the built environment, Gauvin et al. (Gauvin et al. 2007) emphasized the social aspect of neighborhood that concentrates on the interrelationships among residents of a defined area. Chaskin (Chaskin 1997) had earlier extended this pairing to also include an experiential dimension of neighborhood, which accounts for individual-level differences due to varying interpersonal networks and neighboring behavior. More idiosyncratic, Galster (Galster 2001) divided the complex neighborhood commodity into ten categories of characteristics to reflect the bundle of spatial attributes: structural, infrastructural, demographic, class status, public service package, neighborhood, environmental, proximity, political, social-interactive, and sentimental characteristics. An attempt to include individual-level differences in any neighborhood definition is likely in response to the criticism of strictly spatial reflections, which fails to portray the complex selection problem of people choosing to live in a neighborhood because of individuallevel characteristics that may relate to other behavioral outcomes (Diez Roux 2001). Unfortunately, the use of individual-level perceptive measures to aid in conceptualizations of neighborhood has proven to be a difficult proposition (Coulton et al. 2001). Moreover, the manifestation of neighborhood perceptions into individual-level attitudes has been well-noted as a challenging prospect for planners attempting to influence behavioral outcomes by campaigns to modify attitudes (McFadden 1974). In the end, any decision to define the abstract neighborhood concept by a set of physical, social, or some combination of these distinct dimensions must be established into a defensible and workable conceptualization that may be empirically measured (Cutchin et al. 2011).

Neighborhood definitions, which are not rigorously tested, will lead to poor conceptualizations of neighborhoods that misinform statistical inferences (Cutchin, et al. 2011) and limit the generalizability of results (Diez Roux 2001). A thorough operationalization of the concept will ultimately lead to an improved understanding of how various elements of the neighborhood effect residential location decisions and the behavior of those individuals living in the selected residence (Guo and Bhat 2007). Accordingly, the choice of spatial extent to measure neighborhood effects must be given adequate consideration in order to infer the role of neighborhood in these decisions. However, similar to the selection of neighborhood dimensions, there is no consensus or easy solution concerning the choice of spatial extent to define the neighborhood concept (O'Campo 2003) and its effect on behavioral outcomes. Reasons for the lack of any agreement include: (i) the idea that one areal boundary may not satisfy the needs for measuring the multitude of neighborhood processes (Galster 2001); (ii) differences in the intervention or policy-based context that neighborhoods are defined to inform (Chaskin 1997); and (iii) the restricted availability of secondary data at a pre-defined spatial extent to allow for any rigorous scale testing (O'Campo 2003).

Most frequently, the neighborhood concept has been operationalized at a statistical spatial unit (e.g., census tract) in order to empirically understand its effect on residential and travel choice behavior (Guo and Bhat 2007). Although commonplace, conceptualizing neighborhoods with this spatial definition has been criticized for creating high levels of within-area variation (Gauvin, et al. 2007) and insensitivity to perceptive neighborhood elements (Guo and Bhat 2007). However, these point may be in part resolved by the use of smaller statistical spatial units (e.g., census block groups), which may enhance within-area homogeneity (O'Campo 2003) and 
move closer to a representation approximating the scale of internal social relations (Cutchin, et al. 2011). Additionally, the adoption of a census-related spatial definition has the theoretical benefit of a nested structure reflecting the multi-level nature of different neighborhood effects (Guo and Bhat 2007).

\subsubsection{Representing Neighborhood Concepts}

Regardless of the potential theoretical advantages of one definition over another, the adoption of any conceptualization of neighborhood must be guided by the purpose of the overall study as well as the availability of data sources (Krizek 2003). In planning studies, the ability to differentiate neighborhoods based on physical aspects and place the resulting concepts along a spectrum has been useful for devising area-specific design guidelines, framing sampling strategies, measuring progress on plan implementation, and estimating the effects of neighborhood type in regression analyses (Song and Knaap 2007). Specific to this study, in developing robust and transferable residential location choice models, a greater interest is typically placed on representing neighborhood concepts by generic characteristics as opposed to using specific locations (Bagley and Mokhtarian 2002). Meanwhile, the strategies for defining these neighborhood concepts have become increasingly more complex as more disaggregate measures have been used to reflect these generic characteristics. However, while these efforts are in theory more comprehensive in their approach, there are prohibitive expenses often associated with the collection of disaggregate built environment or social data across a metropolitan region (Krizek 2003). Given this and other data limitations, a variety of strategies have been used to define different neighborhood concepts.

Previous strategies have adopted a cross-section approach or provided a historical account to generalize residential environments into a set of concepts based on development patterns. Talen and Duany (Duany 2002) proposed an arrangement of six residential environments based on a transect approach in which the relationship between different physical elements and the locational character of an area are used to provide a sense for different regional spaces (e.g., urban core, rural preserve). An alternative to this approach was later proposed by Brower (Brower 2002), which would further incorporate a social quality to the six concepts. Related strategies have discretized varying residential environments by the dominant street patterns constructed during particular historical eras. Southworth and Owen (Southworth and Owen 1993) described six neighborhood concepts (e.g., gridiron, loops and lollipops) in their study of fringe developments in the San Francisco Bay area; whereas, Wheeler (Wheeler 2003) associated prevailing street patterns to transportation improvements of the past to describe neighborhood concepts in Portland and Toronto (e.g., turn-of-the-century streetcar suburbs, 1990's New Urbanism). Similarly, Cervero and Radisch (Cervero and Radisch 1996) used physical development patterns and transportation accessibility to represent two concepts (pedestrian- and auto-oriented neighborhoods), but further incorporated the social aspect of household income to select the study areas.

Added complexity to these pattern generalization methods for representing neighborhood concepts coincided with advancements in spatial analysis software. Handy (Handy 1996) classified six Austin communities into three concepts (traditional, early-modern, and late-modern neighborhoods) through both visual distinction and the quantification of transportation and commercial access. Ten years later, Rodriguez et al. (Rodriguez et al. 2006) also examined the 
effect of neighborhood concepts on pedestrian activity. In this latter study, conventional suburban and New Urbanist neighborhood concepts were defined based on a set of physical and sociodemographic characteristics.

Instead of representing neighborhoods as a limited set of concepts, past research has utilized disaggregate built environment data sources to reflect neighborhood variation with composite indices. Lawton (Lawton 2001) examined the effect of surrounding residential environments on travel behavior in the Portland metropolitan region by combining measures of retail and local intersection density toward the development of a continuous urban index. Bagley et al. (Bagley et al. 2002) created traditional and suburban indices to describe the residential environments of San Francisco residents by performing a factor analysis on 18 objective and perceptive measures of the built environment. The use of a two-factor disaggregate index reflecting the residential environment enabled a depiction of hybrid neighborhood concepts exhibiting both traditional and suburban characteristics; however, this use of a continuous measure is not ideal in a residential location choice context favoring the production of general neighborhood concepts. Krizek (Krizek 2003) also used factor analysis to produce a neighborhood accessibility index composed of a residential density, land use mix, and street design measures, but then segmented the Puget Sound study area into gridded neighborhoods defined by either a high or low level of neighborhood accessibility.

A more sophisticated strategy for grouping neighborhood concepts was introduced by Song and Knaap (Song and Knaap 2007), who performed a factor analysis on 21 physical environment measures to produce eight dimensions (e.g., street design, density) that were then clustered to create six neighborhood concepts (e.g., sporadic rural developments, outer ring suburbs) in the Portland metropolitan region. Likewise, Shay and Khattak (Shay and Khattak 2007) employed a factor-cluster analysis strategy on 34 built environment measures in an effort to represent the Charlotte metropolitan region as eight neighborhood concepts (e.g., central business district, outer suburbs). Other studies have established spectrums of neighborhood concepts that account for elements beyond the physical environment. Recently, Jacques and El-Geneidy (Jacques and El-Geneidy 2014) performed separate factor-cluster analyses for built environment and travel behavior characteristics to quantitatively define two sets of neighborhood concepts in Montreal. In an effort to account for the social aspect of the neighborhood concept, Nelson et al. (Nelson et al. 2006) used a nationally representative sample to identify six homogenous adolescent groups sharing neighborhood characteristics (e.g., rural working class, newer suburban). Lin and Long (Lin and Long 2008) produced ten neighborhood concepts (e.g., rural, suburban retired, urban elite) across the US by adopting a factor-cluster analysis of physical, sociodemographic, and travel behavior characteristics that were measured at a census tract geography.

\subsubsection{Literature Review of Influential Residential Location Attributes}

Past stated preference experiments have theorized the residential location decision process to be most influenced by attributes related to an individual's choice in housing, neighborhood, and transportation (Borgers et al. 2008; Walker and Li 2007). In support, a recent review of the residential location literature summarized past efforts as typically modeling a decision maker's preference in terms of a set of attributes related to residential unit, location, accessibility, or socioeconomic attributes (Schirmer et al. 2014). Beyond these more easily observable characteristics, past studies have highlighted the added benefit of measuring attitudes and more 
subjective factors to better understand residential preferences (Schwanen and Mokhtarian 2007; Liao et al. 2014). In fact, an earlier study by this research team (Chen et al. 2013) reviewed this evidence base and explored the influence of lifecycle stages on the residential decisions of dwelling type and tenure. To supplement this prior review of influential socioeconomic attributes, the following subsections synthesize how past studies measured the housing, neighborhood, and transportation characteristics related to the residential location choice process.

\subsubsection{Housing Characteristics}

Arguably, the housing characteristic most explored in stated choice studies of residential location has been an individual's preference for a particular dwelling type; however, the division of this alternative has often varied based on study context. In his stated preference analysis of resident location choice in Edmonton, Alberta, Hunt (Hunt 2001) divided dwelling type into five levels (single-family, duplex, townhouse, walkup, and high rise) and found individuals to most likely prefer a single-family unit. Previously, Molin et al. (Molin et al. 1999) compared individual- and group-based conjoint models of residential preferences for survey participants in Eindhoven, the Netherlands by segmenting dwelling type into four levels: detached dwelling, semi-detached dwelling, row house, and flat or apartment. Both family and individual models in their study highlighted a preference for the detached dwelling unit. Senior et al. (Senior et al. 2006) estimated a set of binary logit models to analyze the dwelling type preference of a sample of homeowners in Cardiff, Wales. Results of this stated preference exercise found respondents most likely considered detached and semi-detached dwelling types over terraced homes or apartments. Using a similar classification for dwelling type (detached house, house in terrace, not high-rise apartment, and high-rise apartment), Katoshevski and Timmermans (Katoshevski and Timmermans 2001) conducted a conjoint experiment of residents in several Israeli cities to understand their preference for new residential developments. In another study, Olaru et al. (Olaru et al. 2011) collected stated preference data for residents of Perth, Australia by asking if they would rather reside in a one or two story dwelling type near a transit-oriented development.

Aside from the variation of different dwelling types, past stated preference research has also examined the influence of housing characteristics related to architectural character and configuration. In example, Jansen et al. (Jansen et al. 2009) estimated choice-based conjoint models to examine the influence of a set of dwelling characteristics including architectural style (traditional, modern, innovative) and number of rooms to measure the impact of image inclusion in experimental surveys of residential location. Building period (new house, secondhand house) and number of rooms was similarly examined in the Katoshevski and Timmermans (Katoshevski and Timmermans 2001) study, while Senior et al. (Senior et al. 2006) incorporated a preference for distinctive housing character as a housing feature. Meanwhile, Orzechowski et al. (Orzechowski et al. 2013) explored the influence of a seven-level housing layout attribute and a two-level attribute representing the number of bedrooms in their study into the validity and reliability of conjoint analyses of housing preference. Hoshino (Hoshino 2013) included four-level attributes for building age and dwelling size area in his design of a conjoint survey to measure residential location choice behavior in Tokyo, Japan. 


\subsubsection{Neighborhood Characteristics}

Additional built environment characteristics related to the location of a residence have also commonly been studied in stated choice experiments of residential location. These influential residential location characteristics refer to the neighborhood surrounding a dwelling unit and the accessibility afforded by a unit's relative location to land uses within this environment. Molin and Timmermans (Molin and Timmermans 2003) estimated the influence of relative location by creating an accessibility attribute with four levels: near city center, other location in the city, suburban location, and rural area. While not a direct measurement of accessibility, this measure was intended to reflect the continual decrease in accessibility to the number and variety of facilities that occurs along this neighborhood concept spectrum. Zondag and Pieters (Zondag and Pieters 2005) examined this influence of accessibility on residential location choice by developing a neighborhood type attribute with five levels: urban center, urban, local village center, green neighborhood, and countryside. Morrow-Jones et al. (Morrow-Jones et al. 2004) examined consumer preferences for two neighborhood concepts-defined as having a suburban or neotraditional neighborhood layout-by adopting a conjoint analysis framework. Walker and Li (Walker and Li 2007) also proposed a general neighborhood attribute for their Portland-based residential location choice experiment that defined a neighborhood as either being urban, mixed use, suburban, or rural.

Wang and Li (Wang and Li 2004) examined housing preference by conducting a stated choice experiment that incorporated a three-level living convenience attribute defining the relative distance of the dwelling unit to a nearby daily market. Hoshino (Hoshino 2013) similarly developed a neighborhood accessibility attribute that asked respondents to select a preferred residence while altering the proximity to a shop or supermarket as being within 500 meters, between 500 and 1,000 meters, or farther than 1,000 meters. In lieu of distance, other residential location studies depicted neighborhood accessibility as a mode-specific travel time. Olaru et al. (Olaru et al. 2011) used a three-level attribute for distance from dwelling unit to local shops based on five-minute walking increments; whereas, Walker and Li (Walker and Li 2007) applied an accessibility measure for walking time to shops that varied by 10 -minute increments. Katoshevski and Timmermans (Katoshevski and Timmermans 2001) used a measure of distance to neighborhood shops that reflected a walk of 10 or 20 minutes and a separate distance to main shopping areas measure that reflected a drive of either 10 or 20 minutes. Senior et al. (Senior et al. 2006) proposed a three-level land use mix measure that segmented walking time to non-residential land uses as being 2-5 minutes, 6-10 minutes, or not within a reasonable distance. Aside from the measurement of accessibility to shopping destinations, past residential choice experiments have also specified multilevel attributes related to the accessibility of green spaces and local parks (Katoshevski and Timmermans 2001; Walker and Li 2007; Jansen et al. 2009).

\subsubsection{Transportation Characteristics}

Beyond the accessibility of a location based on proximity to land uses, past stated choice experiments have emphasized accessibility to the surrounding transportation system as an 
influential determinant of residential location preferences (Zondag and Pieters 2005). Regarding automobile infrastructure, previous choice experiments have analyzed the impact of proximity to various road types or parking facilities on residential preferences. For instance, Hunt (Hunt 2001) estimated the sensitivity of stated preferences to the type of street in front of a dwelling unit and found that individuals preferred local streets over collector roads, local streets with speed bumps, and local streets with chicanes. Borgers and Timmermans (Borgers and Timmermans 1993) previously discovered residential preferences decreased as travel time to a major highway increased. In regard to the availability of vehicle parking facilities, Senior et al. (Senior et al. 2006) found no statistical difference in residential preferences between three parking attribute-levels (parking on-road, off-road parking space, and parking in secured garage). As for distance to a parking facility, Borgers et al. (Borgers et al. 2008) discovered that survey respondents preferred parking their vehicle near their dwelling, whether or not the parking space was secured.

Other choice experiments have examined the impact of accessibility to public transit and bicycle infrastructures in relation to residential location preferences. Wang and $\mathrm{Li}$ (Wang and Li 2007) found Beijing's residents preferred accessible neighborhoods with public transit connections to all major districts; yet, note the unique Chinese context in which public transit is the most widely selected travel mode. In a more auto-centric setting, Smith and Olaru (Smith and Olaru 2011) found the direction and significance of the proximity to rail transit station parameter to vary depending on the participant's lifestyle. Access to transit was noted as the fifth most influential factor of residential location choice by Lund (Lund 2006), which used stated preference techniques to understand why a sample of Californians chose to live in a transit-oriented development. In a study of the residential preferences among different family members, Molin and Timmermans (Molin and Timmermans 1999) found an increase in public transit frequency to have no statistically significant influence on residential preferences. Walker and Li (Walker and Li 2007) investigated accessibility to a local bike path, but found the two-level transportation attribute to have no significant influence on household location decisions. Smith and Olaru (Smith and Olaru 2011) found most of lifecycle stages to consider walking and cycling access a very important factor.

Finally, a number of stated choice experiments have analyzed the influence of an individual's commute on his/her stated residential preference. Such accessibility measures may be thought of as a transportation-related characteristic since commute mode and travel time are more strongly associated with the decision maker than the general land uses in a neighborhood. Molin et al. (Molin et al. 1999) used a three-level attribute of travel time to work/school to evaluate the differing preference structures of fathers, mothers, and children. Olaru et al. (Olaru et al. 2011) revealed a preference for reducing commute travel time by introducing a change in commuting travel time attribute to their experimental survey. Unsurprisingly, their study also found respondents to have a significant preference toward reducing travel cost. Finally, Hoshino (Hoshino 2013) examined commute time by train with a four-level attribute discretizing time by a set of ten-minute intervals. 


\subsection{METHODOLOGY}

The first major subsection, 3.1: Developing Neighborhood Concepts, describes a methodology for objectively defining and visually depicting a set of images chosen to represent the bundling of built environment characteristics that represent different neighborhood concepts. Using data reduction techniques to analyze objective, archived spatial data from Oregon and elsewhere, a set of initial neighborhood concepts were defined. The next task required careful consideration of the various physical characteristics of housing and neighborhoods (e.g. housing types, housing mix, density, transportation system, mixed use, and retail and service access). The team was also tasked with deciding the number of different neighborhood concepts to develop, trading off having more detailed and nuanced neighborhood types with survey respondents' ability to differentiate them, and the number to include in the survey design. Then the challenge for the team was how to best convey these objective measures using visual imagery, a relatively new endeavor for the land use-transportation field. This task drew largely from the marketing, urban design and architecture literature where visualization of urban concepts has been tested more broadly than in transportation. Finally, these visual images were validated using a piloting survey to test that these images are appropriate to convey the physical characteristics of these neighborhoods to a lay audience.

The next subsection, 3.2: Residential Location Preferences and Choices, includes a set of tasks to develop the survey infrastructure and methodology for conducting choice experiments aimed toward better understanding the housing, neighborhood, and transportation tradeoffs that individuals consider when undertaking a residential location decision. First the imagery associated with neighborhood concepts needed to be integrated into a computer-aided survey technology. Here several commercial survey packages, such as Qualtrics, were considered, as well as other web-based applications and the option of developing our own programming module. In the end, Qualtrics was chosen as the survey platform. In addition to including these visualizations, the online survey instrument design was guided by the desire to look at tradeoffs between neighborhood, housing and transportation attributes in a choice experimental framework. Understanding respondent preferences, and their rankings, was also desired to better understand the drivers of their current and stated preference choices. The design of the survey administration considered what sampling frames were available, populations of interest, sample size needed for desired analysis, means of recruitment, and incentives. This entire survey methodology was tested in a large piloting exercise that resulted in nearly 800 responses. These tasks are described in Section 3.2.

Finally, the last subsection, 3.3: Neighborhood Preference Analysis presents an initial analysis of some of the data collected from the large scale pilot and a design for future analysis of these data in a conjoint framework. Here, multinomial logit models (MNL) of a respondents choice of preferred neighborhood and preferred dwelling type are estimated as a function of socioeconomic characteristics, currently residential and transportation choices and their importance rankings of various neighborhoods, dwellings and transportation attributes when making residential choices. Results show that the importance rankings offer significant explanatory power over socio-economic characteristics alone and the data gathered in this 
extended pilot should be explored further for how Oregon analytical tools may best make use of this finding in their applications.

\subsection{DEVELOPING NEIGHBORHOOD CONCEPTS}

With more advanced models being developed to better inform the transportation-land use connection, an emphasis is being directed toward developing better tools to identify individual preferences for the housing, accessibility, and transportation characteristics of a neighborhood. Stated choice experiments have proven to be effective tools for identifying individual preferences for different characteristics and evaluating the tradeoffs made during the selection process. As applied to residential choice questions, stated preference experiments often evaluate the locational tradeoffs made by individuals when given a set of hypothetical scenarios. For instance, a participant in a stated choice survey may be asked about his/her preference for a particular neighborhood by trading-off the available housing, activity, and travel options inherent to the varying neighborhood concepts.

Traditionally, stated choice experiments have used text descriptions of these varying concepts; however, recent studies (Jansen et al. 2009) have noted the potential for visual imagery to better illustrate residential location characteristics. Conceptually, images likely better convey what some may interpret as abstract concepts (e.g., neighborhood, accessibility) and complement the customary use of text descriptions. In fact, image use has recently benefited survey instruments designed to examine the abstract concept of walkability when evaluating varying urban design characteristics (Ewing and Handy 2009). Images are provided to represent some item the research is presenting, but if the visualization itself is not carefully prepared, the respondent may interpret the images in a way that the researcher does not intend. Jansen et al. (Jansen et al. 2009) suggested the following seven benefits of including images in choice experiments surveys which may outweigh the potential drawbacks:

1. Images may be better suited to capture more vague concepts.

2. Images of certain characteristics may help participants better "understand and appreciate" the different options, with some evidence suggesting text alone may be inadequate in describing design or style elements.

3. Images may "enhance the realism of the task" and help participants make more realistic choices.

4. Images may reduce information overload by conveying more information with fewer words.

5. Images may reduce individual interpretation of descriptions and group individuals into a similar reality that leads to more "homogeneity of perceptions".

6. Images may provide more interesting comparisons than choice sets with a large number of sentences or words that may fatigue participants. 
7. Images may come to be expected in an evolving and technologically well informed society that is accustomed to imagery in survey designs.

Yet, despite these noted benefits and potential others, questions still remain as to how image use in stated choice surveys to improve the clarity of the concepts they represent. Specifically, if image use allows researchers to better illustrate a bundle of objectively measured characteristics (e.g., density, land use mix), then how do survey respondents identify the relative objective differences between neighborhood concepts portrayed by these images given their preferences for certain characteristics? In other words, in what ways do images "ground" stared choice survey respondents in a similar reality and in what ways are images unsuccessful in representing abstract concepts related to residential location decisions?

To address these questions, this report section describes the creation of visual images to depict the bundle of built environment characteristics comprising a neighborhood concept and the incorporation of these images into a residential location stated choice experiment. The following subsection provides a review of the literature on conceptualizing and representing varying neighborhoods. Next, the methods used to objectively define, visualize, and statistically validate a spectrum of neighborhood concepts is presented. A discussion of the validation results from our analytical approach, lessons learned from our pilot study, and importance of this research can be found in Section 4.0.

\subsubsection{Defining Neighborhood Concepts}

The adoption of statistical data reduction techniques such as the aforementioned factor-cluster analysis has been pursued in past neighborhood-related studies because of their ability to efficiently address the correlations that often exist between a set of measures representing the physical environment. Also, since individuals likely consider a bundle of attributes when conceptualizing and differentiating a set of neighborhoods, these techniques represent a statistical approach to define neighborhood concepts as a bundle of housing-, accessibility-, and transportation-related characteristics. Regrettably, the complexity and subjective nature of these techniques often hinder later attempts to replicate the defined spectrum of neighborhood concepts and directly transfer them to practice. In response, the following subsection describes the application of a direct method to quantify a set of objective built environment measures into six unique neighborhood concepts spanning the most populous American metropolitan regions.

\subsubsection{Study Area and Data Description}

In an effort to ensure a greater ease in transferability of methodology and interpretability of the resulting neighborhood concepts, the research team decided to utilize a nationally representative and publicly available secondary dataset and select a parsimonious number of built environment measures. The Smart Location Database (U.S. EPA 2014) is a nationwide geographic data source, maintained by the United States Environmental Protection Agency, which offers built environment information summarized at the census block group geography. Acknowledging the theoretical imperfections associated with the use of an administrative boundary unit to define the multifaceted concept of 
neighborhood, this spatial resolution was deemed satisfactory because of the ability to link the sociodemographic and economic information provided by other national secondary datasets in future analyses. Also of importance, the research team restricted the objective definition of a neighborhood concept to only include those data for block groups located inside the 25 most populous US metropolitan regions as of the 2010 Census. A decision to confine the study area to these geographic regions enabled the potential to devise a neighborhood concept that may be only found outside the Portland metropolitan region as well as the possibility to discover parity between neighborhoods in different urbanized areas. Furthermore, the use of these areas in defining neighborhood concepts likely incorporates most variations across the built environment spectrum except those areas reflecting the most rural contexts, which arguably has little applicability to a study examining future land use and transportation relationships.

Having settled on a data source and study area to produce the objectively defined neighborhood concepts, the next step was to determine the built environment measures needed to differentiate the 76,188 block groups into a manageable number of unique neighborhood concepts. Our choice of neighborhood concept indicators borrowed from established research on cataloging built environment measures influencing the transportation-land use connection into a 3D grouping of variables (Cervero and Kockelman 1997). Adopting this scheme, the research team chose one built environment measure from each of the three categories: activity density, employment diversity, and intersection density. Activity density describes the number of people and jobs per acre of unprotected land in a census block group; whereas, employment diversity is an entropy measure ranging in value from zero to one in which a value of one is representative of an even balance of retail, office, industrial, service, and entertainment jobs in a census block group. Intersection density is a design measure in which the number of auto-oriented intersections per square mile of a census block group is calculated as a proxy of neighborhood design. The following subsection describes how these three measures were incorporated into a direct method for objectively defining the six neighborhood concepts.

\subsubsection{Direct Method Approach}

The application of the direct measure method began by calculating the three built environment measures for all census block groups within the 25 most populous metropolitan regions. For each of the built environment measures, the Fisher's Natural Breaks Classification Method (FNBCM) (Fisher 1958) was employed to divide all block groups into tertiles based on the calculated value of the measure representing a block group's activity density, employment diversity, or intersection density. The FNBCM is a statistical approach to grouping observations into categories, similar to a univariate clustering analysis that both maximizes the total variation captured in all block groups and minimizes the within-group variation. The decision to use FNBCM to categorize the three built environment measures as well as the decision to use three categories for each of the individual measures was the result of an explorative and iterative process involving both spatial inspection and statistical examination. The range of values for each measure used to categorize the universe of block groups is provided in Table 3.1. More suburban, exurban, and rural block groups tend to be represented in "Group 1" categories, where the 
activity and intersection densities are low, and there is less diversity. More urban locations tend to be represented by "Group 2" and "Group 3".

Table 3.1: Range of Built Environment Measure Values for Groups Defined by FNBCM

\begin{tabular}{l|c|c|c|c|c|c}
\hline Built Environment & \multicolumn{2}{|c|}{ Group 1 (Low) } & \multicolumn{2}{c|}{ Group 2 (Medium) } & \multicolumn{2}{c}{ Group 3 (High) } \\
\cline { 2 - 7 } Measure & Min Value & Max Value & Min Value & Max Value & Min Value & Max Value \\
\hline $\begin{array}{l}\text { DENSITY: } \\
\text { Activity Density }\end{array}$ & 0 & 102 & 102 & 498 & 497 & 3,026 \\
\hline $\begin{array}{l}\text { DIVERSITY: } \\
\begin{array}{l}\text { Employment } \\
\text { Entropy }\end{array}\end{array}$ & 0.00 & 0.26 & 0.26 & 0.64 & 0.64 & 1.00 \\
\hline $\begin{array}{l}\text { DESIGN: } \\
\text { Intersection Density }\end{array}$ & 0 & 83 & 83 & 201 & 201 & 5,173 \\
\hline
\end{tabular}

NOTES:

Built Environment Data: Smart Location Database

Overall, every block group we analyze fits into one of 27 potential categorical combinations. For example, one block group could be very urban-falling into Group 3 for density and design — that have less land use diversity_-falling into Group 2 for diversity-like an office park or a residential development with high-rises but very little supportive land use (restaurants, retail, etc.).

The intention behind creating these neighborhood types is to find 5-10 neighborhoods that represent overall the universe of potential neighborhood environments. For modeling purposes, 27 neighborhoods provide too many alternatives. We examine the block group variation within the 27 (3D) category combinations to determine potential categorical combinations to (a) simplify the number of neighborhoods to represent and (b) place these neighborhoods on a scale from suburban/exurban/rural to urban. To do this, the research team undertook a manual aggregation process of placing these exclusive combinations into one of six categories. The collection of these 27 combinations into six categories was guided by a notion that these three characteristics of the built environment often shift together along a continuum representing the abstract concept of neighborhood design. For instance, a neighborhood located within a central business district would likely possess a high concentration of residents and jobs (high activity density), strong diversity in employment opportunities (high employment diversity), and an interconnected street network with small city block sizes (high intersection density). In contrast, the built environment of those neighborhoods located in a rural context would likely be characterized as exemplifying opposite conditions and a lower activity density, employment diversity, and intersection density.

Figure 3.1 provides an illustration of this aggregation process, which led to the development of the six objectively defined neighborhood concepts, as well as a summation of the number of block groups in each of the nationwide neighborhood concepts. These six categories provide the quantitative backdrop to the proceeding 
processes of visually depicting these neighborhood concepts as image sets to be used in a stated choice experiment.

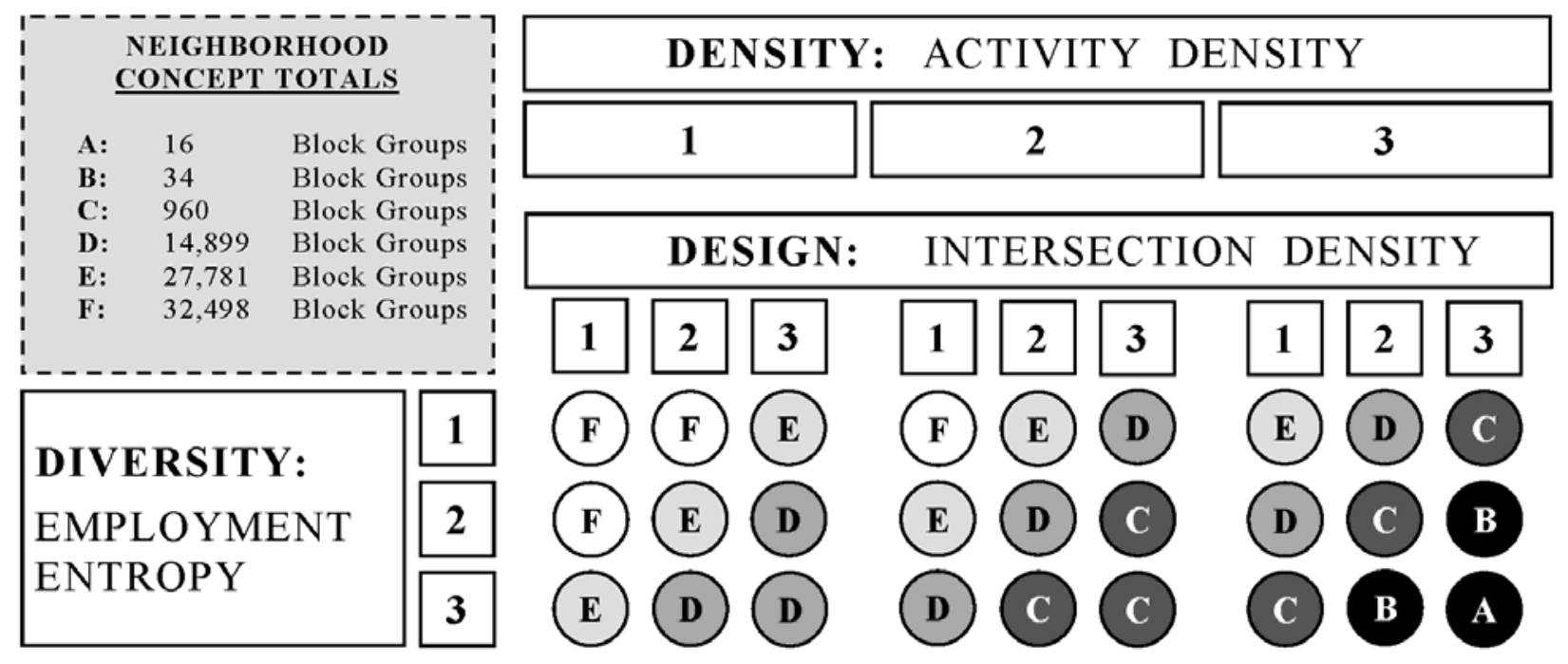

Figure 3.1: Illustration of Aggregation Process used to define the Neighborhood Concepts

Neighborhoods A and B represent very urban areas, only found in 16 different metropolitan regions (mainly New York City and Chicago, but including a few block groups in Seattle and San Francisco). Neighborhood C represents the a central district in smaller metropolitan areas and can be found in downtown Portland, as well as one block group in the central city of Eugene. For larger metro areas (like New York City), Neighborhood C appears surrounding A and B neighborhood concepts. In Oregon, Neighborhood D appears as inner East Portland, as well as smaller city centers (like Beaverton or Corvallis). Neighborhoods E and F are more suburban and rural, respectively. Table 3.2 offers the reader with summary statistics for each of the objectively defined neighborhood concepts; whereas, Figure 3.2 shows the spatial distribution of the six neighborhood concepts in the Portland metropolitan region as well as downtown San Francisco and Seattle, for contrast. 
Table 3.2: Summary Statistics of the Neighborhood Concepts for Three Built Environment Measures at the Census Block Group Level for the 25 Most Populous US Metropolitan Regions

\begin{tabular}{|c|c|c|c|c|c|c|c|c|c|c|c|}
\hline \multirow{3}{*}{$\begin{array}{l}\text { Neighborhood } \\
\text { Concept }\end{array}$} & \multicolumn{9}{|c|}{ Built Environment Measure } & \multirow{3}{*}{$\begin{array}{l}\text { Block } \\
\text { Groups }\end{array}$} & \multirow{3}{*}{$\begin{array}{l}\text { Metro } \\
\text { Regions }\end{array}$} \\
\hline & \multicolumn{3}{|c|}{ Activity Density } & \multicolumn{3}{|c|}{$\begin{array}{c}\text { Employment } \\
\text { Entropy }\end{array}$} & \multicolumn{3}{|c|}{ Intersection Density } & & \\
\hline & Avg. & Min. & Max. & Avg. & Min. & Max. & Avg. & Min. & Max. & & \\
\hline A & 667 & 497 & 986 & 0.75 & 0.65 & 0.97 & 489 & 204 & 1,156 & 16 & 7 \\
\hline $\mathrm{B}$ & 976 & 508 & 3,026 & 0.67 & 0.29 & 0.92 & 193 & 83 & 450 & 34 & 9 \\
\hline $\mathrm{C}$ & 245 & 107 & 1,685 & 0.75 & 0.00 & 0.99 & 189 & 0 & 1,268 & 960 & 22 \\
\hline $\mathrm{D}$ & 39 & 0 & 1,626 & 0.76 & 0.00 & 1.00 & 141 & 0 & 1,356 & 14,899 & 25 \\
\hline $\mathrm{E}$ & 20 & 0 & 1,467 & 0.67 & 0.00 & 1.00 & 73 & 0 & 5,173 & 27,781 & 25 \\
\hline $\mathrm{F}$ & 19 & 0 & 495 & 0.19 & 0.00 & 0.64 & 71 & 0 & 201 & 32,498 & 25 \\
\hline Overall & 27 & 0 & 3,026 & 0.48 & 0.00 & 1.00 & 87 & 0 & 5,173 & 76,188 & 25 \\
\hline
\end{tabular}

NOTES:

Built Environment Data: Smart Location Database 

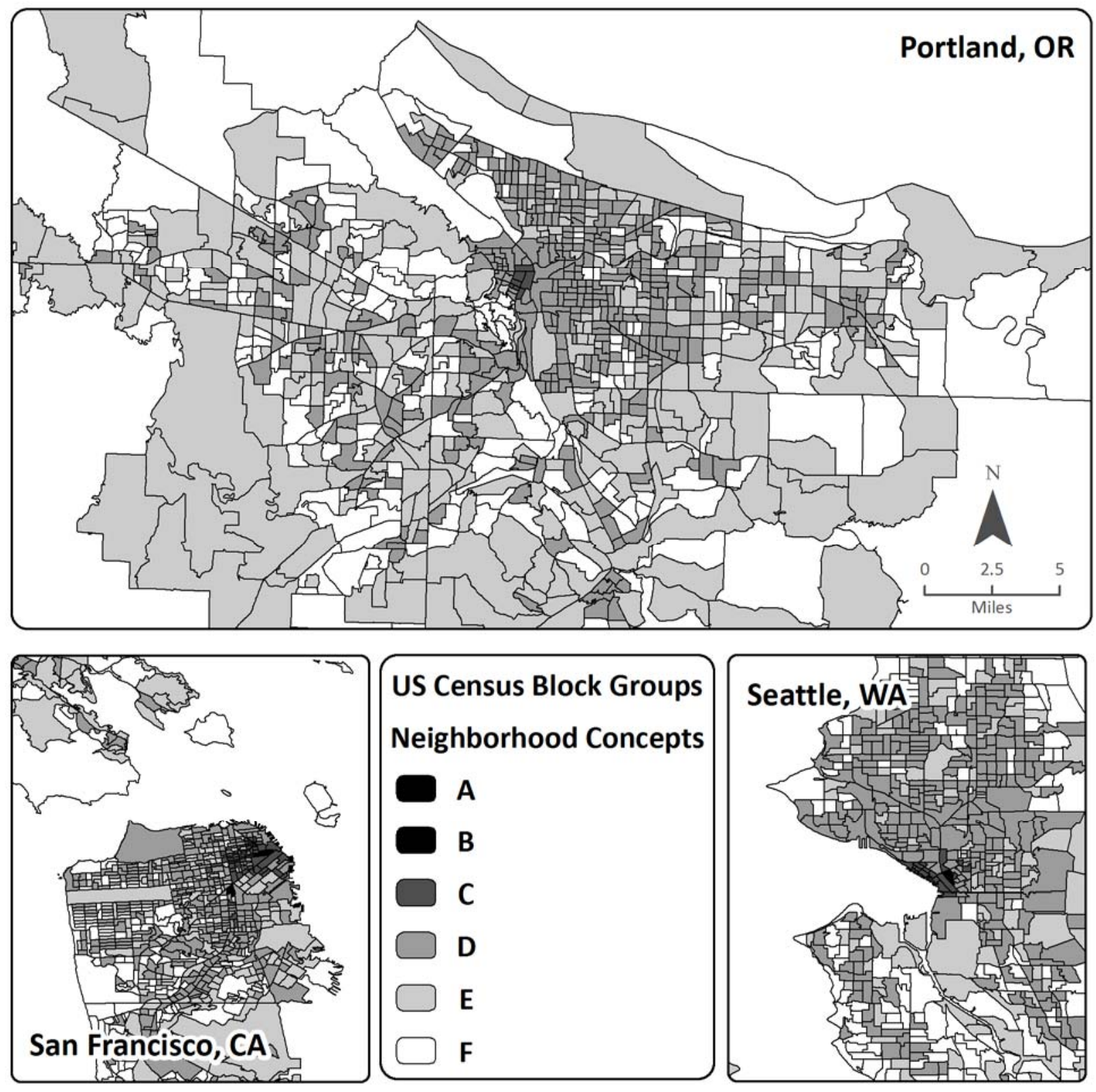

Figure 3.2: Spatial Distribution of Neighborhood Concepts in Portland, San Francisco, and Seattle

\subsubsection{Visualizing Neighborhood Concepts}

Defining the six neighborhood concepts with the use of a direct measure method and three common built environment measures was an objective exercise to define an abstract concept; however, the next phase proved to be more subjective in nature. The visual representation of six neighborhood types in image sets undoubtedly captures an infinite number of physical elements extending beyond the three measures of activity density, employment entropy, and intersection density utilized to spatially define them. Yet, instead of being regarded solely as a limitation in 
efforts to accurately portray a household's residential environment, the ability to reflect additional attributes in a visual format enables researchers to also account for a multitude of more nuanced features such as housing type, accessibility, etc. that were not originally used to define the concepts. Moreover, a validated process to visually depict these neighborhood concepts provides researchers and decision makers with an additional strategy for expressing quantifiable measures of varying built environments, which are not articulated in technical jargon like density and entropy. The following subsection outlines the set of principles used to guide the image selection process, the collection process, and the results of an internal trial that informed the final neighborhood concept image sets.

\subsubsection{Image Selection Process}

Each of the six neighborhoods was spatially defined by census block group boundaries that were initially defined in a Geographic Information Systems (GIS) environment. To ease the ability of capturing existing physical environments, the information in these spatially defined geographies was converted from a GIS file structure (e.g., shapefile) to a structure adoptable to Google Earth (e.g., KMZ file). This conversion process produced six individual neighborhood concept layers that were then imported into Google Earth and used to identify what block groups in the 25 most populous metropolitan regions belonged to a specific neighborhood concept. In this platform, the research team was able to zoom into a specific block group and capture a screen shot using the Google Street View technology featured within Google Earth. Thus, a street-level image may be selected to visually represent the six objectively defined neighborhood concepts.

Using this platform to capture photos to best reflect a particular neighborhood concept offered a number of stylistic decisions to be made by the individual analyst, which involved the decision to screen capture one image rather than another, the camera angle to capture that image, and all of the other seemingly infinite judgments related to these and other aspects of the process. As such, the research team identified a handful of principles to guide the image selection process, while understanding that it was impossible to standardize this admittedly idiosyncratic process. These guiding principles for the image selection process included:

- Portray the neighborhood in the best possible light (i.e., avoid capturing images of general blight or structural decay, which may introduce negative bias in the preference survey).

- Avoid the use of images that have specific cultural significance, uniquely identify a particular region, explicitly describe a place, or potentially elicit individual biases (i.e., avoid capturing images of churches, schools, landmarks, geographic names, etc.).

- When compiling a set of images for any given neighborhood concept, order the images in a consistent manner that transitions from residential to commercial land uses, while integrating images of the transportation and recreation options available within a given neighborhood concept. 
- Display each image in the image set for a fixed amount of time in order to control the amount of time an image may be viewed. At the recommendation of Jansen et al (Jansen et al. 2009), such dynamic transitions between images allow researchers to prevent observers from focusing on any potentially disturbing or distracting details that may be seen as unfavorable.

This process resulted in a set of 15 Google Street View images for each neighborhood concept that were then edited in Adobe Premiere Pro video editing software. The chosen images were next compiled into a set of PowerPoint slide presentations, where each image was displayed for two seconds before automatically transitioning to the next image. The end product was a set of 30 -second visual image sets intended to represent the built environment for each neighborhood concept.

\subsubsection{Internal Trial and Image Set Completion}

The completion of the image sets was an iterative process. An internal trial was initially conducted to test the image progression within our visual display technique, eliminate distracting content, minimize respondent biases and burden, and produce an overall favorable reflection for each neighborhood concept in its image set. Respondents to this internal trial were chosen at convenience and represented a non-random sample of individuals including members of the technical advisory committee, graduate students, fellow transportation faculty, and various other professions. Trial respondents were solicited to provide qualitative feedback on the selection of imagery and the understandability of select questions in the validation pilot survey (Section 3.1.3). Feedback from this trial exercise helped us better understand the number of images needed to visually convey a neighborhood concept without producing respondent burden. Additionally, open-ended responses provided during the internal trial indicated the image sets for neighborhood concepts A and B were too similar, which added difficulty to comparisons of their image sets. This informative finding resulted in the aggregation of the $A$ and $B$ neighborhood concepts into a single concept $(A B)$, reducing the overall number of concepts to five. Section 6.1 provides the final selection of images used to visualize the five objectively-defined neighborhood concepts.

\subsubsection{Validating Neighborhood Concepts}

After finalizing the visual representations of the objectively-defined neighborhood concepts, an online pilot survey was designed and administered to validate whether individuals identify the distinctions (where they exist) in the built environments portrayed by the image sets. In the following subsections, we describe the design of this survey instrument, recruitment of respondents, and analytical approach adopted to validate these visually portrayed neighborhood concepts.

\subsubsection{Design of Validation Survey Instrument}

The validation survey instrument was designed to confirm that the five neighborhood concepts differed from one another with regard to the representation of different elements 
of the physical environment. Beyond validating the image sets as being representative of different concepts, the survey instrument was also intended to:

- Familiarize the research team with the online survey software and establish a survey respondent recruitment process to later adopt for the design of the experimental survey instrument.

- Provide current socioeconomic, housing, and travel information about survey respondents and details on those characteristics that they view as most important when choosing a residence.

- Identify respondent satisfaction of current neighborhood, housing, and transportation choices.

The online survey instrument was designed using Qualtrics software and had four components (Section 6.2). The first component consisted of a set of questions intended to "prime the pump" and familiarize survey participants with the subject matter and planning-related jargon such as "type of dwelling”. Here, participants were asked to provide their current residential address and preferences. In the second component, survey respondents were asked to decide what housing, accessibility, and transportation characteristics were of importance to them when choosing a residential location. Each participant was asked to indicate whether a given characteristic was very important (must have), important but not necessary (would like to have), or not at all important (would not consider). In the third component, participants were presented with the visual representations of two of the five neighborhood concepts, which were generically labeled A and B to conceal objective differences between the compared neighborhood concepts. The pilot survey participants were then instructed to compare the two image sets based on a selection of housing, accessibility, and transportation attributes corresponding to 13 characteristics derived from a review of neighborhood attributes found in stated preference literature.

- $\quad$ Larger private yards;

- Greater variety in types of dwelling (single-family structure, apartment building, duplex, etc.);

- $\quad$ Larger residential living spaces;

- Closer proximity to local shopping and/or retail establishments;

- Better access to parks and/or outdoor recreational facilities;

- Better access to regional shopping centers and/or big box stores;

- Greater population density;

- A greater variety of transportation options; 
- Better accommodations for car ownership;

- A greater ease for finding parking spaces;

- Better public transportation service;

- Better walking environments; and

- Better streets to ride a bicycle for transportation.

The research team assumed the most difficult evaluation for survey respondents would be between the neighborhood concepts most similar to one another. As such, the validation survey instrument only asked respondents to compare characteristics of a neighborhood concept to those in the neighborhood concept most similar to it on the AB-F (urbansuburban) spectrum. For example, neighborhood D was only compared to either neighborhood concept $C$ or $E$. Thus, four sets of comparisons were tested in the survey: $A B$ versus $C$; $C$ versus $D$; D versus $E$; and $E$ versus $F$. To reduce respondent burden, we asked each survey participant to evaluate only two of the four sets of potential neighborhood comparisons (either $\mathrm{AB} / \mathrm{C}$ and $\mathrm{C} / \mathrm{D}$ or $\mathrm{D} / \mathrm{E}$ and $\mathrm{E} / \mathrm{F}$ ).

Figure 3.3 provides a screenshot of this image set comparison in which the two concepts are generically labeled "A" and "B", but actually representing concepts "C" and " $\mathrm{D}$ ". As noted in Figure 3.3, a "no difference/could not distinguish" option was also provided to the participant during this task. Responses to these questions were used to validate the concepts by providing feedback about whether the relative scale of attributes (e.g. residential density) across neighborhoods could be properly identified from the image sets. The validation survey was designed to conclude with a set of sociodemographic and economic questions about the participant and his/her household. 


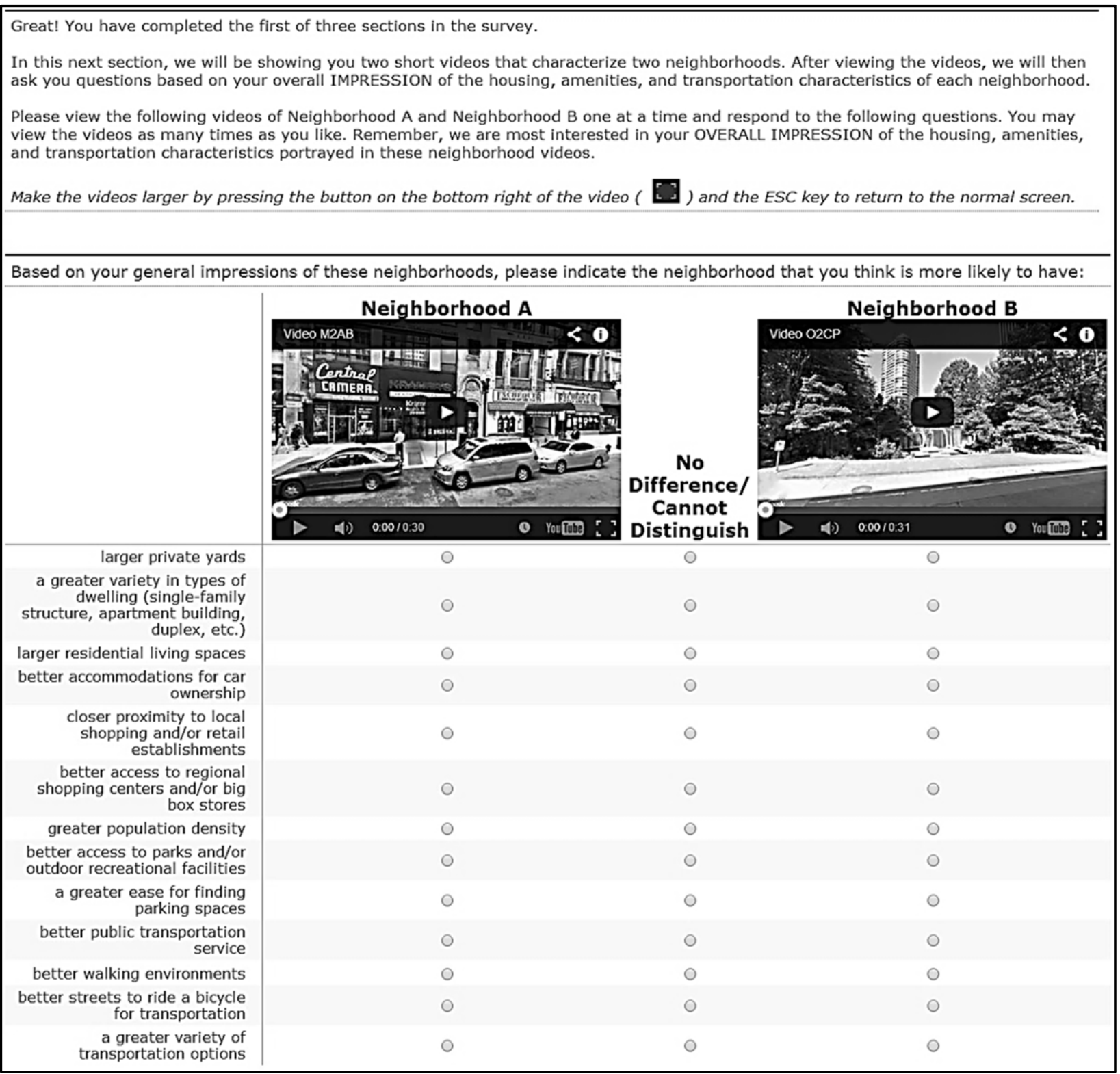

Figure 3.3: Example of Image Set Comparison found in Validation Survey Instrument

\subsubsection{Recruitment of Validation Survey Respondents}

The online survey was administered to a sample of residents from three randomly selected ZIP codes within the Portland, Oregon metropolitan region (97203, 97209, and 97086). Recruitment postcards were mailed to 2,000 household addresses obtained using ReferenceUSA (Infogroup, Inc. 2014) data. These postcards provided the selected residents with a URL link to the validation survey website. Since we questioned whether the ability to identity neighborhood characteristics varied by respondents' residential environment, we chose to stratify the sample by the neighborhood typology of the home 
address. In our study area, only four of the six neighborhood concepts existed (C, D, E, F), as was shown in Figure 3.1.

The response rate for the validation survey was 6.2 , with $4.1 \%$ of the recruitment postcards being returned due to vacancy or incorrect addresses, which resulted in a sample size of 123 individuals. Less than $6.4 \%$ of respondents "opted out" during the survey and nearly all of those individuals left after completing only the first page of the survey (less than $0.5 \%$ of all recruited households). On average, respondents completed the neighborhood validation survey in about 12 minutes, with a standard deviation of about 7 minutes.

Respondents indicated an average household income of approximately $\$ 70,000$ per year, with 1.2 vehicles per household (15\% of households reported zero vehicles). Approximately $60 \%$ of the respondents were female and the overall average respondent age was 45 years. In general, the pilot survey respondents were older, possessed fewer household automobiles, and earned a higher income than the average Portland resident ${ }^{2}$, who is 36 years old (median), has 1.7 household vehicles, and earns $\$ 71,300$ per year. In terms of housing type, a greater percentage of respondents resided in multifamily units (51\%) than the regional average (42\%). It is not clear how respondents with higher income levels may perceive the environment differently from more average individuals.

\subsubsection{Analytical Approach to Validation}

The validation survey was intended to help determine whether individuals can visualize differences between two sets of images portraying separate objectively-defined neighborhood concepts. Moreover, the research team wished to determine whether the respondent's evaluations matched our objective evaluations. We hypothesized that survey respondents would recognize consistent differences between the neighborhood concepts for all 13 housing, accessibility, and transportation characteristics - where objective differences were identified.

To test this hypothesis, a set of chi-squared contingency table tests were applied to the distribution of respondents for each neighborhood concept comparison of each characteristic. Table 3-3 notes the proportion of responses for each neighborhood concept pair evaluated. We tested the hypothesis that the proportion of responses for each neighborhood comparison — for the first neighborhood, the second neighborhood, or "no difference (ND)” between neighborhoods — was equally distributed. When statistical evidence $(\mathrm{p}<0.10)$ suggested the response proportions were not equally distributed, results indicated that at least one response produced a significantly different perception for that given respondent evaluation of neighborhood concept pairings. Any statistically significant test result was then followed by a multiple pair-wise comparison test to determine which proportion attributed to the prior statistical significance (Cox and Key 1993).

\footnotetext{
${ }^{2}$ Regional sociodemographic characteristics for households and persons; mean and median were collected from the 2008-12 5-year American Community Survey for the Portland metropolitan region.
} 
Table 3.3: Proportion of Survey Responses Evaluating Neighborhood Concept Pairings: "Indicate the neighborhood that you think is more likely to have."

\begin{tabular}{|c|c|c|c|c|c|c|c|c|c|c|c|c|}
\hline \multirow{4}{*}{$\begin{array}{c}\text { Sample Size } \\
\text { Neighborhood } \\
\text { Concept } \\
\text { Characteristics }\end{array}$} & \multirow{2}{*}{\multicolumn{3}{|c|}{$\begin{array}{c}\text { AB versus } C \\
61\end{array}$}} & \multicolumn{3}{|c|}{ C versus D } & \multicolumn{3}{|c|}{ D versus $\mathrm{E}$} & \multicolumn{3}{|c|}{ E versus $F$} \\
\hline & & & & & 61 & & & 62 & & & 62 & \\
\hline & \multicolumn{3}{|c|}{$\begin{array}{l}\text { Proportion } \\
\text { Frequency }\end{array}$} & \multicolumn{3}{|c|}{$\begin{array}{l}\text { Proportion } \\
\text { Frequency }\end{array}$} & \multicolumn{3}{|c|}{$\begin{array}{l}\text { Proportion } \\
\text { Frequency }\end{array}$} & \multicolumn{3}{|c|}{$\begin{array}{l}\text { Proportion } \\
\text { Frequency }\end{array}$} \\
\hline & $\mathrm{AB}$ & $\mathrm{C}$ & ND & C & $\mathrm{D}$ & $\mathrm{ND}$ & $\mathrm{D}$ & $\mathrm{E}$ & ND & E & $\mathrm{F}$ & ND \\
\hline \multicolumn{13}{|c|}{ HOUSING CHARACTERISTICS } \\
\hline Larger Private Yards & $7 \%$ & $33 \%$ & $61 \%$ & $2 \%$ & $90 \%$ & $8 \%$ & $5 \%$ & $89 \%$ & $7 \%$ & $3 \%$ & $81 \%$ & $15 \%$ \\
\hline $\begin{array}{l}\text { A Greater Variety in } \\
\text { Types of Dwelling }\end{array}$ & $25 \%$ & $34 \%$ & $41 \%$ & $72 \%$ & $13 \%$ & $13 \%$ & $10 \%$ & $79 \%$ & $11 \%$ & $63 \%$ & $10 \%$ & $26 \%$ \\
\hline $\begin{array}{l}\text { Larger Residential } \\
\text { Living Spaces }\end{array}$ & $7 \%$ & $39 \%$ & $54 \%$ & $0 \%$ & $92 \%$ & $8 \%$ & $10 \%$ & $74 \%$ & $15 \%$ & $2 \%$ & $58 \%$ & $39 \%$ \\
\hline \multicolumn{13}{|c|}{ ACCESSIBILITY CHARACTERISTICS } \\
\hline $\begin{array}{l}\text { Closer Proximity to } \\
\text { Local Shopping } \\
\text { and/or Retail } \\
\text { Establishments } \\
\end{array}$ & $49 \%$ & $15 \%$ & $36 \%$ & $71 \%$ & $2 \%$ & $28 \%$ & $47 \%$ & $10 \%$ & $44 \%$ & $60 \%$ & $10 \%$ & $29 \%$ \\
\hline $\begin{array}{l}\text { Better Access to } \\
\text { Parks and/or } \\
\text { Recreational } \\
\text { Facilities }\end{array}$ & $10 \%$ & $51 \%$ & $38 \%$ & $20 \%$ & $23 \%$ & $56 \%$ & $15 \%$ & $42 \%$ & $40 \%$ & $32 \%$ & $15 \%$ & $52 \%$ \\
\hline $\begin{array}{l}\text { Better Access to } \\
\text { Regional Shopping } \\
\text { Centers and/or Big } \\
\text { Box Stores } \\
\end{array}$ & $18 \%$ & $23 \%$ & $57 \%$ & $8 \%$ & $64 \%$ & $28 \%$ & $21 \%$ & $27 \%$ & $52 \%$ & $61 \%$ & $7 \%$ & $31 \%$ \\
\hline $\begin{array}{l}\text { Greater Population } \\
\text { Density }\end{array}$ & $69 \%$ & $3 \%$ & $28 \%$ & $79 \%$ & $5 \%$ & $16 \%$ & $89 \%$ & $5 \%$ & $7 \%$ & $74 \%$ & $3 \%$ & $21 \%$ \\
\hline \multicolumn{13}{|c|}{ TRANSPORTATION CHARACTERISTICS } \\
\hline $\begin{array}{l}\text { A Greater Variety of } \\
\text { Transportation } \\
\text { Options }\end{array}$ & $13 \%$ & $43 \%$ & $44 \%$ & $71 \%$ & $2 \%$ & $28 \%$ & $57 \%$ & $5 \%$ & $37 \%$ & $50 \%$ & $7 \%$ & $42 \%$ \\
\hline $\begin{array}{l}\text { Better } \\
\text { Accommodations for } \\
\text { Car Ownership }\end{array}$ & $6 \%$ & $43 \%$ & $41 \%$ & $0 \%$ & $79 \%$ & $21 \%$ & $8 \%$ & $79 \%$ & $13 \%$ & $5 \%$ & $24 \%$ & $69 \%$ \\
\hline $\begin{array}{l}\text { A Greater Ease for } \\
\text { Finding Parking } \\
\text { Spaces }\end{array}$ & $7 \%$ & $51 \%$ & $43 \%$ & $7 \%$ & $77 \%$ & $16 \%$ & $11 \%$ & $68 \%$ & $19 \%$ & $7 \%$ & $27 \%$ & $65 \%$ \\
\hline $\begin{array}{l}\text { Better Public } \\
\text { Transportation } \\
\text { Service }\end{array}$ & $18 \%$ & $43 \%$ & $39 \%$ & $72 \%$ & $2 \%$ & $26 \%$ & $68 \%$ & $3 \%$ & $27 \%$ & $61 \%$ & $3 \%$ & $34 \%$ \\
\hline $\begin{array}{l}\text { Better Walking } \\
\text { Environments }\end{array}$ & $12 \%$ & $33 \%$ & $56 \%$ & $44 \%$ & $26 \%$ & $30 \%$ & $27 \%$ & $19 \%$ & $52 \%$ & $26 \%$ & $18 \%$ & $55 \%$ \\
\hline $\begin{array}{l}\text { Better Streets to Ride } \\
\text { a Bicycle for } \\
\text { Transportation }\end{array}$ & $13 \%$ & $41 \%$ & $46 \%$ & $28 \%$ & $46 \%$ & $26 \%$ & $8 \%$ & $52 \%$ & $39 \%$ & $36 \%$ & $11 \%$ & $52 \%$ \\
\hline
\end{tabular}

To determine the ability of respondents to evaluate characteristic differences between the paired neighborhood concepts, the research team compared the proportion of responses from the survey respondent's evaluation to their own objective evaluation. Table 3.4 provides a qualitative comparison of the survey respondent and objective research team evaluations of neighborhood concept comparisons for each characteristic. This table provides a summary of the general impression of respondents, based on the chi-square comparison and post-hoc tests and compares their impression to an objective interpretation of the neighborhood concept visualizations. Ideally, respondents would see 
similar differences to the objective interpretation. The following section discusses the ways in which survey respondents (a) agreed on what they saw when evaluating neighborhood concept comparisons and (b) were able to see differences between neighborhoods where differences (objectively) existed.

Table 3.4: Comparison of Objective versus Respondent Evaluation Outcomes: "Indicate the neighborhood that you (the respondent) think is more likely to have.

\begin{tabular}{|c|c|c|c|c|c|c|c|c|}
\hline \multirow{2}{*}{$\begin{array}{c}\text { Neighborhood } \\
\text { Concept Characteristics }\end{array}$} & \multicolumn{2}{|c|}{$\mathrm{AB}$ versus $\mathrm{C}$} & \multicolumn{2}{|c|}{ C versus D } & \multicolumn{2}{|c|}{ D versus $\mathrm{E}$} & \multicolumn{2}{|c|}{ E versus $F$} \\
\hline & Obj. & Res. & Obj. & Res. & Obj. & Res. & Obj. & Res. \\
\hline \multicolumn{9}{|c|}{ HOUSING CHARACTERISTICS } \\
\hline Larger Private Yards & $N D$ & ND & $D$ & $\mathrm{D}$ & $E$ & $\mathrm{E}$ & $F$ & $\mathrm{~F}$ \\
\hline $\begin{array}{l}\text { A Greater Variety in } \\
\text { Types of Dwelling }\end{array}$ & C & --- & $D$ & $\mathrm{C}$ & $D$ & $\mathrm{E}$ & $E$ & $\mathrm{E}$ \\
\hline $\begin{array}{l}\text { Larger Residential Living } \\
\text { Spaces }\end{array}$ & C & $\mathrm{ND} / \mathrm{C}$ & $D$ & $\mathrm{D}$ & $E$ & $\mathrm{E}$ & $F$ & $\mathrm{~F} / \mathrm{ND}$ \\
\hline \multicolumn{9}{|c|}{ ACCESSIBILITY CHARACTERISTICS } \\
\hline $\begin{array}{l}\text { Closer Proximity to Local } \\
\text { Shopping and/or Retail } \\
\text { Establishments }\end{array}$ & $A B$ & $\mathrm{AB} / \mathrm{ND}$ & C & $\mathrm{C}$ & $D$ & $\mathrm{D} / \mathrm{ND}$ & $E$ & $\mathrm{E}$ \\
\hline $\begin{array}{l}\text { Better Access to Parks } \\
\text { and/or Recreational } \\
\text { Facilities }\end{array}$ & C & $\mathrm{C} / \mathrm{ND}$ & $D$ & ND & $E$ & $\mathrm{E} / \mathrm{ND}$ & $F$ & $\mathrm{ND} / \mathrm{E}$ \\
\hline $\begin{array}{l}\text { Better Access to Regional } \\
\text { Shopping Centers and/or } \\
\text { Big Box Stores }\end{array}$ & C & ND & $D$ & $\mathrm{D}$ & $E$ & ND & $F$ & $\mathrm{E}$ \\
\hline $\begin{array}{l}\text { Greater Population } \\
\text { Density }\end{array}$ & $A B$ & $\mathrm{AB}$ & C & $\mathrm{C}$ & $D$ & $\mathrm{D}$ & $E$ & $\mathrm{E}$ \\
\hline \multicolumn{9}{|c|}{ TRANSPORTATION CHARACTERISTICS } \\
\hline $\begin{array}{l}\text { A Greater Variety of } \\
\text { Transportation Options }\end{array}$ & C & $\mathrm{ND} / \mathrm{C}$ & C & $\mathrm{C}$ & $D$ & $\mathrm{D} / \mathrm{ND}$ & $E$ & $\mathrm{E} / \mathrm{ND}$ \\
\hline $\begin{array}{l}\text { Better Accommodations } \\
\text { for Car Ownership }\end{array}$ & C & $\mathrm{C} / \mathrm{ND}$ & $D$ & $\mathrm{D}$ & $E$ & $\mathrm{E}$ & $N D$ & ND \\
\hline $\begin{array}{l}\text { A Greater Ease for } \\
\text { Finding Parking Spaces }\end{array}$ & $C$ & $\mathrm{C} / \mathrm{ND}$ & $D$ & $\mathrm{D}$ & $E$ & $\mathrm{E}$ & $N D$ & ND \\
\hline $\begin{array}{l}\text { Better Public } \\
\text { Transportation Service }\end{array}$ & $A B$ & $\mathrm{C} / \mathrm{ND}$ & $C$ & $\mathrm{C}$ & $D$ & D & $E$ & $\mathrm{E}$ \\
\hline $\begin{array}{l}\text { Better Walking } \\
\text { Environments }\end{array}$ & $A B$ & ND & $C$ & --- & $D$ & $\mathrm{ND} / \mathrm{D}$ & $E$ & $\mathrm{ND} / \mathrm{E}$ \\
\hline $\begin{array}{l}\text { Better Streets to Ride a } \\
\text { Bicycle for Transportation }\end{array}$ & $C$ & $\mathrm{ND} / \mathrm{C}$ & $D$ & --- & $D$ & $\mathrm{E} / \mathrm{ND}$ & $E$ & $\mathrm{ND} / \mathrm{E}$ \\
\hline
\end{tabular}

Notes:

--- : No clear response or statistical evidence (chi square, $1 x 3$ matrix, $p>0.1$ ) between response proportions.

Obj.: Objective evaluation of concept comparisons for given characteristic, conducted by research team.

Res.: Respondent evaluation of concept comparisons for given characteristic, summarizing survey responses. Split results (e.g., “AB/ND) indicate results in which each response was represented by a large proportion of the sample. Response order indicates the larger proportion (i.e., AB had larger proportion than D).

\subsubsection{Results}

In general, the research team found the majority of responses to be consistent with the objectively measured attributes; however, variation existed in how respondents evaluated 
characteristics across the neighborhood concepts. The following subsections report the findings from our analysis for each subcategory of neighborhood characteristics (housing, accessibility, and transportation).

\subsubsection{Housing Characteristics}

Three housing characteristics were compared across neighborhood concepts: private yard space, variety of dwelling types, and size of residential living space. In the most urban neighborhood concepts, $\mathrm{AB}$ and $\mathrm{C}$, our analysis found little objective difference in yard size. In agreement, $61 \%$ of the validation survey respondents indicated "no difference". However, this concept comparison of yard size produced far less respondent agreement than the other pairings. Overall, the majority of respondents $(>80 \%)$ were able to detect differences in the size of private yards for the other image set comparisons, where average yard size increased as the neighborhood concept moved up the spectrum from $\mathrm{AB}$ to $\mathrm{F}$.

We also asked participants to compare the variety in types of dwellings between concepts (e.g. single-family detached structures, apartment buildings). Objectively, neighborhoods in the middle of the spectrum ( $\mathrm{D}$ and $\mathrm{E}$ ) tended to have the greatest variety in dwelling types, providing a mix of single family and multifamily residential buildings. Based on the presented image sets, participants responded that neighborhood concepts $C$ and $E$ had the greatest level of variety in types of dwellings (72\%, when comparing $C$ to $D$ and $79 \%$, when comparing $\mathrm{D}$ to $\mathrm{E}$ ). There was less agreement when comparing the $\mathrm{AB}$ and $\mathrm{C}$ neighborhoods, where $41 \%$ of respondents saw no difference in housing mix, $25 \%$ viewed $\mathrm{AB}$ as having a greater mix, and 34\% choosing $\mathrm{C}$. In terms of living space, which is implied by the urban density shown in the images since we do not directly show this characteristic, respondents generally agreed that more suburban neighborhoods tended to have larger residential living spaces. There was less agreement among respondents who compared concept AB to C, with 54\% stating no difference and 39\% choosing C. There was similar response variation in the more suburban comparison of concept $\mathrm{E}$ to $\mathrm{F}$.

\subsubsection{Accessibility Characteristics}

Validation survey respondents were asked to evaluate the ability for the neighborhood visualizations to convey four accessibility characteristics: proximity to local shopping and/or retail; access to parks and/or recreational facilities; access to regional shopping centers and/or big box stores; and population density. Respondent evaluations varied, with greater agreement on population density and proximity to local shopping across all paired comparisons. In general, survey participants were able to distinguish that denser neighborhood concepts had "closer proximity to local shopping and/or retail establishments"; although, participants were unable to discern differences in local accessibility to shops and retail when comparing AB to C (36\%) and D to E (44\%). As mentioned, most validation survey participants were able to identify the difference between population densities (>69\%); especially, as the neighborhoods transitioned between the inner and outer suburban concepts ( $D$ and $E$ ). 
When evaluating levels of access to "regional shopping centers and/or big box stores", many respondents did not see a difference between concept AB and C (57\%) or E and D (52\%). More survey respondents perceived $\mathrm{D}$ to have better access to regional shopping centers than concept C (64\%), as well as E relative to concept F (61\%). These findings indicated that survey respondents generally tended to only observe three levels of access to regional shopping centers: $\mathrm{AB}$ and $\mathrm{C}$ (very urban); D and $\mathrm{E}$ (urban and inner suburban); and F (outer suburban). With respect to "access to parks and/or outdoor recreational facilities" in an image set, respondents were not able to see differences between concepts. This result may be an artifact of the subjective definition of "parks" and "outdoor recreational facilities" meaning different things to different people.

\subsubsection{Transportation Characteristics}

Lastly, validation survey respondents were asked to evaluate six transportation-related characteristics: a greater variety of transportation options; better accommodations for car ownership; greater ease for finding parking spaces; better public transportation service; better walking environments; and better streets to ride a bicycle for transportation. In examining respondent evaluations for "the variety of transportation options" characteristic, we found that participants observed the image set for concept $\mathrm{C}$ as offering more variety in travel options than $\mathrm{AB}(43 \%)$, although many did not see any difference at all (44\%). For all other tested neighborhood comparisons, participants felt that the more urban concept exhibited a greater variety in transportation options $(\geq 50 \%)$.

Neighborhood comparisons were also conducted to investigate the ability of respondents to identify differences in the car-specific characteristics visualized in each concept's image set; specifically, "accommodations for car ownership" and "ease for finding parking spaces." Overall, survey participants did not see a strong difference between concepts $\mathrm{E}$ and $\mathrm{F}$ in their depiction of the two automobile-supportive characteristics; however, a more clear distinction was found in the other comparisons. In general, the more urban concept in each comparison was viewed as having worse accommodations for car ownership and greater difficulty in finding parking.

When we inquired about comparing neighborhoods with respect to non-motorized options, the respondents were less clear whether differences exist. Respondents identified $\mathrm{C}$ as having "better public transportation service" compared with $\mathrm{AB}(43 \%)$, if they saw any difference at all (39\%). This finding may be related to the subterranean transit systems more frequently found in the most urban neighborhood concepts. The research team found subways to be more difficult to represent in a static image collected from a roadway perspective. Participants were able to see higher levels of public transportation service in the more urban neighborhood for all other concept comparisons (>61\%). In our objective evaluation of the concepts, we anticipated respondents to evaluate more urban concepts as having more walkable environments; however, once again, participants did not see a significant difference between the $A B$ and $C$ concepts. Outside of the $A B$ versus $\mathrm{C}$ comparison, if respondents noted a visual difference in the walkability of the paired concepts, then the more urban neighborhood was perceived to have the greater level of walkability. Results were also largely inconclusive when survey respondents were asked to select the neighborhood concept with "better streets to ride a bicycle for 
transportation.” Image sets displaying the more suburban concept were generally viewed as having the better streets for biking, with the exception of the E versus F comparison.

\subsubsection{Summary and Discussion}

In this exercise to validate the image sets of the different neighborhood concepts, survey participants were prompted to look for differences based on housing, accessibility, and transportation characteristics of the neighborhood. In general, the image sets were found to be accurate visual illustrations of the physical environment differences found between the five objectively-defined neighborhood concepts.

\subsubsection{Discussion}

If researchers intend to use image sets to communicate the built environment characteristics related to each neighborhood concept, we recommend housing, accessibility, and transportation characteristics comprising each neighborhood bundle to be supplemented by text descriptions. For the majority of the 13 neighborhood characteristics tested, validation survey respondents tended to have some difficulty in identifying differences between the $\mathrm{AB}$ and $\mathrm{C}$ concepts. This finding underscores the specific need to either supplement these image sets with text descriptions or further collapse the two most "urban” concepts. Specifically, the choice of either suggestion would likely benefit the use of our image sets to better understand differences related to non-automobile transportation, in which survey respondents had difficulty discerning any difference. This finding may be a result of all photos in the image set being taken from the middle of the roadway; a notably car-centric perspective. To visually distinguish the differences in the neighborhood attribute bundles with respect to a variety of transportation users, a consideration should be given to the added benefit of using photos taken from a non-automobile user's perspective (e.g., sidewalk, bus stop, bike lane).

Additionally, internal trials of the validation survey infrastructure informed the research team that trial participants had difficulty establishing neighborhood differences for housing, accessibility, and transportation characteristics, which had not been previously defined or discussed in the instrument. Before participants were asked to compare the image sets of the neighborhood concepts, we "primed the pump" by asking them to rank the importance of the 13 housing, accessibility, and transportation characteristics to their own residential location decisions. This process was found to help early trial participants think about these characteristics before evaluating them in the neighborhood concept comparisons. Also, in using such image sets to reflect "bundled" neighborhood characteristics in a stated preference survey, we believe an initial ranking exercise may help prepare respondents to give more thoughtful consideration as to how these interrelated neighborhood characteristics may be individually identified.

\subsubsection{Future Work}

With respect to the use of image sets to depict a set of bundled characteristics, future work remains. As previously noted by Jansen et al. (Jansen et al. 2009), researchers may be unable to easily control for "accidental or non-systematic" details recognized by the 
survey respondent (i.e., unflattering window frames, trash, or broken-up concrete driveways). Our validation exercise attempted to control for many of these details by conducting internal trials to determine whether or not an image set placed each neighborhood concept in the best possible light (e.g., maintained landscapes). As suggested by Jansen et al. (Jansen et al. 2009), the use of multiple images or collages may better mask the occasional non-systematic detail by allowing survey participants to be grounded in the general appearance of the collection of all images instead of the specific details of a single image. In view of that, our validation survey instrument used multiple images compiled into 30-second videos, which were to be later redesigned as static image collages, and applied them with the addition of text descriptions to the design of our experimental survey. With this presented validation survey design, additional image collages could be later created to further subdivide or aggregate the presented neighborhood concepts (i.e., combining the $\mathrm{E}$ and $\mathrm{F}$ concepts).

In this study, we used qualitative observation and experience to objectively evaluate the neighborhood concept comparisons for each of the 13 different neighborhood characteristics. We intend to conduct further examination to quantify the level to which each image set varies between comparisons. This quantitative examination of neighborhood concept may help to explain the variation in the respondent's evaluation of neighborhood concept comparisons. Finally, in future iterations of this work, we intend to examine the variation in respondent evaluation on the sociodemographic and economic characteristics of the participant and his or her household. Variation in survey respondent evaluations may closely pertain to their sociodemographic characteristics or market segment, while their corresponding attitudes and preferences related to certain neighborhood concepts of housing, accessibility, and transportation characteristics.

\subsection{RESIDENTIAL LOCATION PREFERENCES AND CHOICES}

The residential location decisions of households have long been investigated in the travel behavior and transportation planning fields. Such studies generally evaluate the revealed connection between land use or location choices and travel with a focus toward better understanding themes related to the: self-selection of households into neighborhoods supporting their desired travel behaviors, representation of household taste variations in travel demand models, and various housing and transportation costs faced by these households. Yet, despite improved knowledge bases across these topic areas, questions persist about how applicable past findings of residential location studies will be in a future with ever-changing market conditions, populations, technologies, and policy assumptions. In response, choice experiments have emerged in order to evaluate a residential location context in which a revealed behavior may not accurately represent a household's preference if demand for a certain dwelling type or neighborhood concept exceeds its present supply (Louviere and Timmermans 1990).

The application of stated preference survey techniques has allowed researchers to explore the residential location choice process and examine the various housing, neighborhood, and transportation tradeoffs made by survey participants responding to hypothetical scenarios or policies. In all, Louviere and Timmermans (Louviere and Timmermans 1990) indicated the benefits of stated preference studies based on experimental design methods to include their ability to study the choice process under controlled conditions, create choice alternatives outside 
of the domain of respondent experience, and minimize the correlations across the attributes of the choice alternatives. A choice-based conjoint analysis has reflected a common stated preference technique used by researchers to measure and model tradeoffs, preferences, and choices (Hensher et al. 1999). The adoption of this technique lends itself to the type of scenario analysis being developed in Oregon at both the statewide and metropolitan level, where the planning outlook is over the long term and considers a range of conditions and policies in play.

Accordingly, this report section describes the development and preliminary administration of an experimental survey aimed toward providing a better understanding of residential location and transportation preferences and choices. The following subsection reviews the various housing, neighborhood, and transportation characteristics commonly studied in stated preference experiments. Next, the design and administration of an experimental survey instrument is offered. A subsection describing the results of an analysis of neighborhood and housing preferences of experimental survey respondents then follows. Section 3.2 of the report concludes by presenting a method for modeling the results of this experimental survey of residential location choices.

\subsubsection{Experimental Survey Methodology}

Development and administration of the validation survey discussed in Section 2.0 proved to be a valuable exercise in informing the design of an experimental survey instrument to better understand residential decisions. This previous exercise allowed testing of the proposed neighborhood concepts, exploring the flexibility of an online survey instrument, improving the presentation of survey material, and advancing the prior recruitment strategy. Beyond these methodological refinements, the employment of the validation survey instrument ultimately benefited the research agenda by apprising the team of what research questions the previous instrument was ill-suited to answer.

In response, an experimental survey was designed and administered to allow a closer examination of the housing, accessibility, and transportation tradeoffs considered by individuals during hypothetical residential choice scenarios. The research was motivated by a desire to understand the relationship between individual preferences for a certain neighborhood or dwelling type and his/her socioeconomic characteristics, attributes of his/her current residential location, and access to a set of transportation options. Specifically, the resulting experimental survey provides an innovative tool to examine the important tradeoff between commute mode or travel time and dwelling type as well as the tradeoff between these commute characteristics and varying levels of local access characteristic of the previously defined neighborhood concepts. Given this interest in commute behavior, the experimental survey was initially designed to evaluate the tradeoffs of workers and students. Respondents who were retired participated in all survey components except the choice-based conjoint analysis exercise.

Designing a conjoint analysis experiment within the survey instrument allowed the estimation of the aforementioned tradeoffs as well as residential location preferences and choices. Use of a conjoint analysis experimental design offered the ability to measure the value survey respondents placed on the housing, neighborhood, and transportation characteristics of the residential environment. The desire to examine these advanced topical areas within the context of this project and an ability to explore other areas of interest in the future (i.e., self-selection bias in 
residential location choices) further informed the adoption of this choice-based conjoint analysis. The complexity of these analyses, increased benefit of utilizing visual imagery in these experiments, and ability to recruit a diverse sample of participants led to the design of a computer-aided survey instrument in Qualtrics software with some modifications.

In the next subsection, we discuss this experimental survey by describing the three components of the instrument (Section 6.3), which enabled the collection of socioeconomic information, implementation of an importance ranking exercise, and employment of a choice-based conjoint analysis. The participant recruitment process is then discussed by outlining the selection of a study location, sampling frame, and strategy of recruiting survey participants. This subsection is followed by a summary of the experimental survey respondents according to work status, neighborhood concept, dwelling type, and travel mode. Finally, a summary of the design of the experimental survey methodology is provided.

\subsubsection{Design of Experimental Survey Instrument}

As mentioned, the experimental survey instrument was designed in an online environment by using the widely-available Qualtrics software. The visual images representing the various neighborhood concepts were integrated into the Qualtrics software; however, portions of the program code were manipulated to allow for an improved display of the collages informed by the prior piloting exercise. For instance, the image collages in the conjoint analysis component were able to be enlarged by the survey participant when he/she clicked on the thumbnail. Additionally, a need to explore the various tradeoffs considered during the residential choice process required further manipulation of the Qualtrics code to enable the proper full-profile design of a choicebased conjoint analysis.

\subsubsection{Survey Component: Background Information}

The introductory section of the survey was designed to collect background information about the respondents' personal and household sociodemographic background, employment status and commute characteristics. In addition, the first component also presented the survey participant with a series of questions related his/her present residential location characteristics. These questions were intended to serve the dual purpose of gathering information about the revealed housing, neighborhood, and transportation decisions of survey respondents and familiarizing the respondents with the terminology and concepts used in the later sections of the survey. In terms of housing information, the survey instrument asked respondents to describe their present dwelling type, size of living space, and satisfaction with either of these elements. Respondents were also asked questions regarding whether they presently rent or own their home and the type of dwelling unit they prefer via a set of visual illustrations. These questions used multiple choice and fill-in-the-blank formats.

Respondents were asked to examine the images that represent four neighborhood concepts, listed below in Figure 3.4, and select the concept they most preferred. Each of these image collages was accompanied by descriptive text of the type of dwelling units, 
level of accessibility to local services and regional centers, mix of renters and owners, and parking facilities inherent to a neighborhood concept.

In addition, the experimental survey instrument asked their current residential location permitting identification of the concept that best describes their neighborhood and future augmentation of the data collected in this survey with other spatial information from secondary sources. Respondents were asked about their current of mode of travel for work and other trip purposes and their level of satisfaction with their present travel modes. Other travel-related questions asked the total number of household vehicles or bicycles available to a survey respondent in addition to mode-specific questions related to possession of a driver's license, transit pass, or car share membership.

Finally, the background component of the experimental survey asked the respondent a question concerning their potential willingness to pay a greater housing cost (rent or mortgage) to live in a home or location better suited to their stated preferences. By using skip logic, an individual who answered the work status question with a "retired" or "other" response could forego any commute-related question as well as the choice-based conjoint experiment component. 

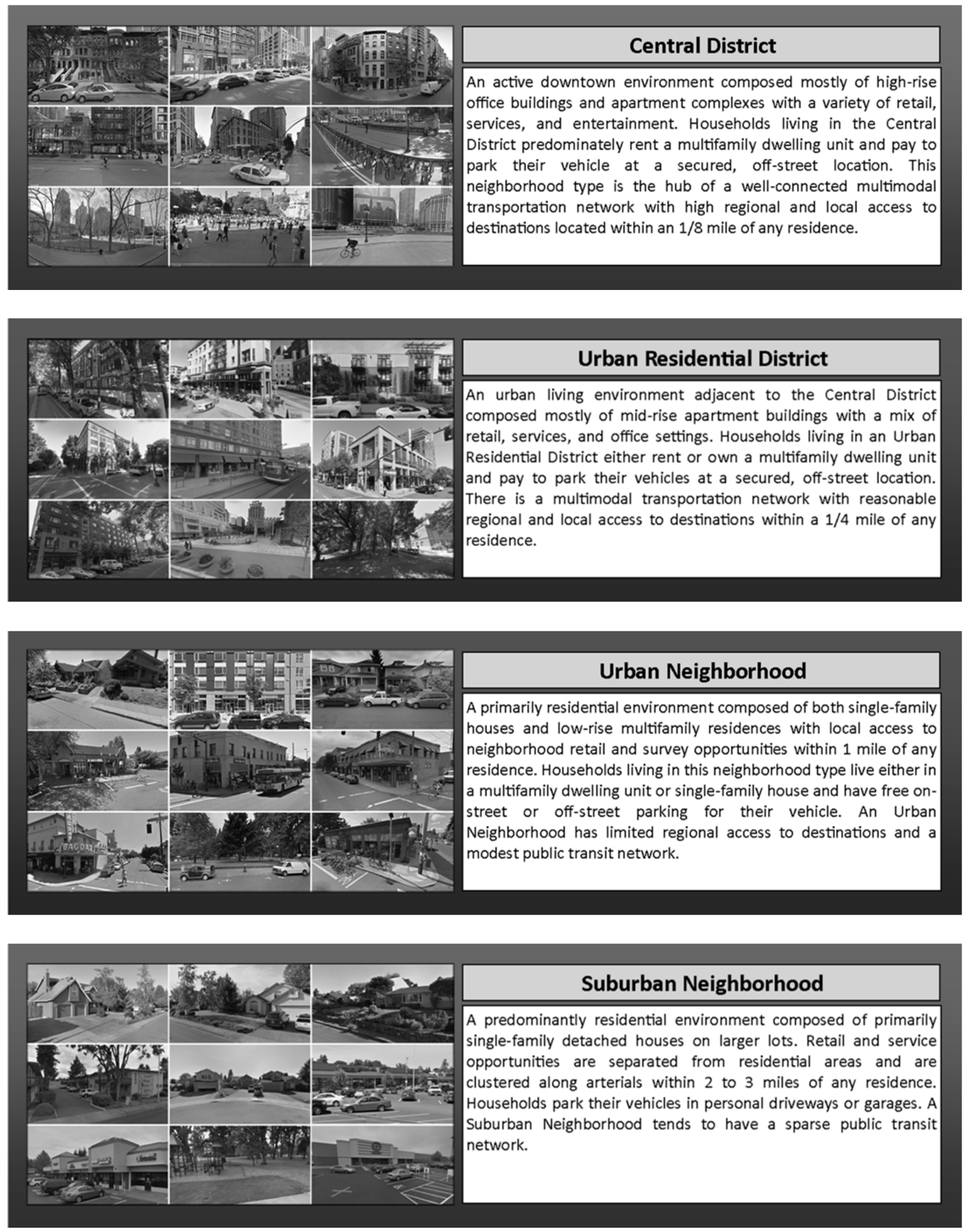

Figure 3.4: Neighborhood Concepts in Experimental Survey 


\subsubsection{Survey Component II: Importance Rankings}

The experimental survey instrument was also designed to incorporate a section in which individuals were asked to place a level of importance on a set of 17 housing, accessibility, and transportation characteristics they would likely consider in a residential location decision making process. Using a "drag and drop" method, the respondent placed each of the 17 characteristics in one of three boxes distinguishing a level of importance: very important (must have or "deal breakers"), somewhat important (nice to have or "icing on the cake"), or not important at all (no bearing on their decision).

The following 17 characteristics were included in this importance ranking component.

- Own my house/condo;

- Live in a home with a large living space;

- Live in a detached single-family home;

- Have a private yard;

- Have privacy from my neighbors;

- Living at the "center of it all";

- Being near high-quality public schools;

- Living near established, older homes;

- Access to highways/freeways;

- Having a variety of transportation options;

- Having a commute that takes 25 minutes or less;

- Walking to bus and/or rail stop;

- Having off-street parking at local destinations;

- Having dedicated parking at your residence;

- Access to parks and recreational areas;

- Walking to nearby places; and

- Biking to nearby places. 
The inclusion of these importance rankings permits a better understanding of the concerns and tradeoffs that individuals make in their housing, neighborhood, and transportation choices.

\subsubsection{Survey Component III: Choice-based Conjoint Experiment}

The final component of the experimental survey infrastructure involved the design of a choice-based conjoint experiment. Here, a set of choice attributes representing neighborhood concepts, commute mode and commute time are bundled in a "card". Each card reflects a different combination of levels of attributes. In all, 27 unique cards were developed using three levels of neighborhood concepts (central district, urban residential district, and urban neighborhood), three levels of commute modes (car, public transit, and bike or walk), and three levels of travel times (15, 30, and 60 minutes). These choices of attributes and levels were carefully considered as they have implications for the sample size needed for the analysis. Given this constraint, we opted to include only the most urban neighborhood choices, given that increasing urbanization raises more questions about future choices, than rural or suburban options. In a choice experiment, respondents are asked to choose their preference from a pair of cards. This comparison of two cards is called a task and in any given experiment, respondents can be asked to engage in a number of tasks. Figure 3.5 provides an example of one potential task that may be faced by an individual partaking in the choice-based conjoint experiment.

In this survey design, respondents are initially presented with five tasks - with two randomly selected cards (from the 27) comprising each task. The survey respondent was asked to choose the card that most closely reflected his/her preferences. Initially, respondents were asked to repeat this choice experiment five times to minimize burden; however, they were later given the option to participate in an additional five tasks after completing their initial assignment.

Further iterations of this survey may introduce additional complexity, such as adding more range to the alternative-levels (e.g., adding a "Suburban" or "Rural" neighborhood choice alternative) or varying the attribute levels that describe each alternative level (e.g., varying the available size of living space or access to transit within each neighborhood type instead of holding these descriptions static for within each type). Either of these options will add complexity to the model specification and will require additional sample size and respondent level of burden (i.e., number of tasks the respondent sees). 

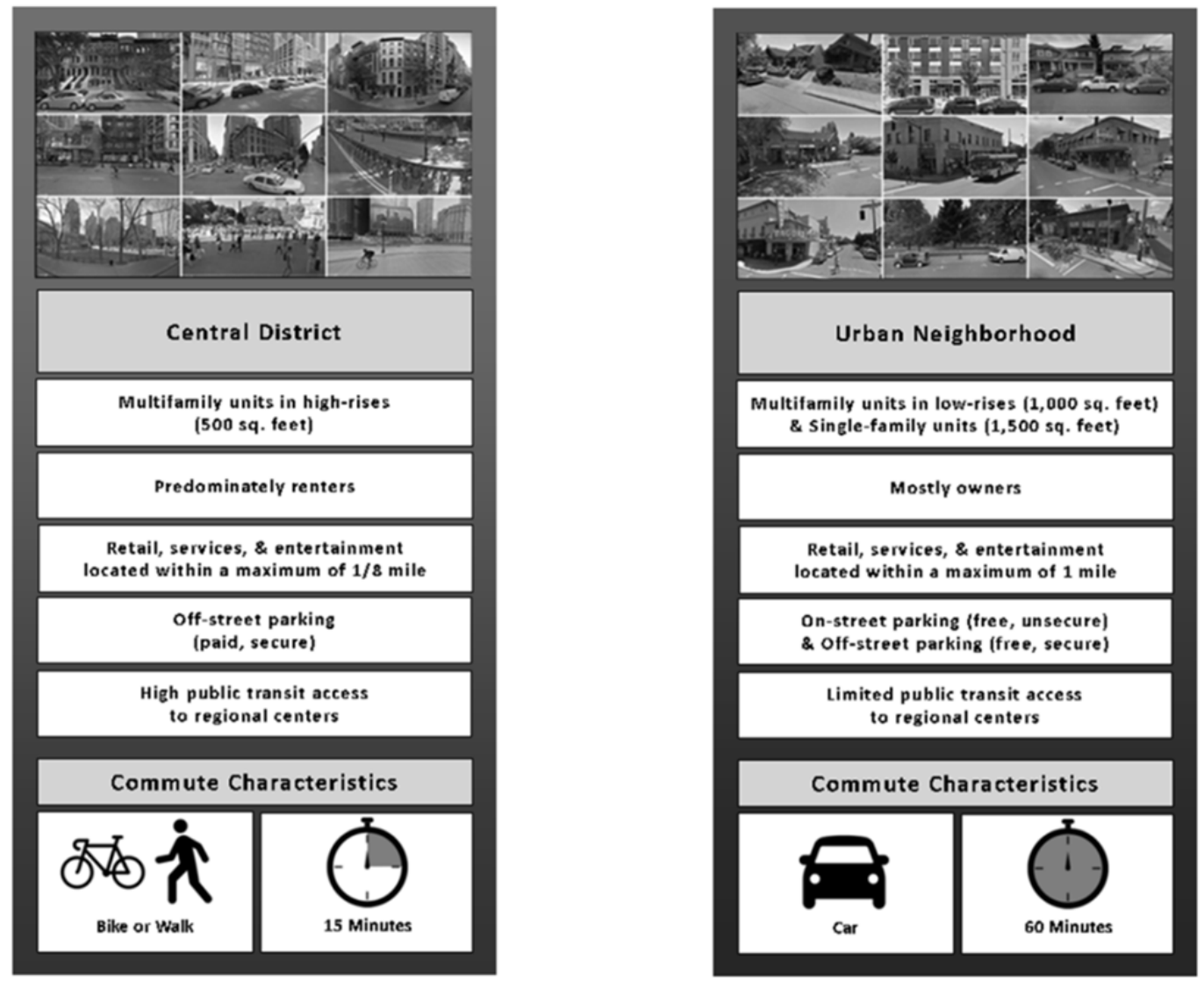

Figure 3.5: Illustration of a Potential Task in the Choice-based Conjoint Experiment

\subsubsection{Recruitment of Experimental survey Respondents}

Individuals were recruited to participate in the survey using two sampling frames. First, ReferenceUSA (Infogroup, Inc. 2014) was used to obtain home addresses for 201,444 households from among all ZIP codes in the Portland, Oregon metropolitan region. In June 2014, a recruitment postcard (Figure 3.6) with a URL link to the experimental survey website was mailed to 8,000 individuals. A second sampling frame used the 20092011 Oregon Travel and Activity Survey (Oregon Modeling Steering Committee 2013). In July 2014, recruitment postcards were mailed out to 5,249 Oregon residents who participated in this prior survey and indicated they participate in future ODOT surveys. These individuals all live outside of the Portland metropolitan region. Individuals who received a recruitment postcard were incentivized with the prospect of winning one of three gift cards in the amount of \$100 in an attempt to improve the response rate. 
Dear Current Resident,

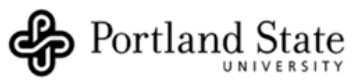

As part of the "Neighborhood Transportation Study", our research team would like to find out the housing, neighborhood, and transportation features that are most important to you.

To do so, we invite you to participate in our 15-minute online survey.

To complete our survey and also enter for a chance to win one of three $\$ 100$ gift cards to Amazon, please visit our survey website at:

www.sites.google.com/site/ntstudypdx Household ID Number: «HHID»

Your input is valuable to us and will ensure this study is a success!

Sincerely,

Kelly J. Clifton, Ph.D.

Professor, Civil \& Environmental Engineering

For more information about our study, please contact us at: Email: $x x x x x @ p d x . e d u$ Phone: $(x x x) x x x-x x x x$

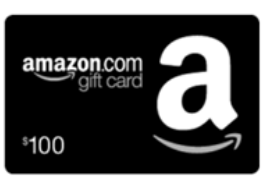

Figure 3.6: Recruitment Postcard

The first recruitment wave yielded 489 survey responses, with 104 postcards being returned because of vacancies and another 188 postcards for miscellaneous reasons (e.g., incomplete address, refused delivery). The overall response rate for the Portland-based recruitment wave was $6.3 \%$. In turn, the second recruitment wave produced 546 survey responses, with 87 postcards being returned due to vacancies and another 112 postcards returned due to miscellaneous reasons. The response rate for the second recruitment wave was $10.8 \%$. When aggregating the survey responses for the two recruitment waves, the total number of responses was 1,035 . Accordingly, the overall response rate was $8.1 \%$. The median completion time for the experimental survey was 10 minutes for the total sample of 1,011 participants. The choice experiment portion of the survey (5 tasks)which was only administered to part- or full-time workers or students - took, on average, 2 minutes.

\subsubsection{Summary Statistics of Experimental Survey Respondents}

Survey respondents indicated an average household income of approximately $\$ 82,700$ per year, with 2.0 vehicles per household (6\% reported zero vehicle households). Of those respondents who provided information on gender and age, approximately $51 \%$ were female and the average respondent age was 54 years. The average household size of a survey respondent was 2.5, which was nearly identical to the average Oregon household, which has 2.5 members. In general, the survey respondents were older, more likely to reside in a zero vehicle household (3\% of Oregon households), and earned a higher 
median income than the average Oregon resident ${ }^{3}$, who is 38 years old (median) and has an annual household income of $\$ 50,036$ (median). In terms of tenure, a greater percentage of experimental survey respondents owned their home (83\%) than the statewide average (62\%).

Table 3.5: Distribution of Sampled Oregon Residents by Neighborhood Concept and Work Status

\begin{tabular}{|c|c|c|c|c|c|c|c|c|c|c|}
\hline \multirow{3}{*}{$\begin{array}{l}\text { Neighborhood } \\
\text { Concept } \\
\text { Urban } \\
\text { Residential } \\
\text { District } \\
\end{array}$} & \multicolumn{8}{|c|}{ Work Status } & \multirow{2}{*}{\multicolumn{2}{|c|}{ Total }} \\
\hline & \multicolumn{2}{|c|}{$\begin{array}{c}\text { Full- or Part-time } \\
\text { Worker }\end{array}$} & \multicolumn{2}{|c|}{$\begin{array}{l}\text { Full- or Part- } \\
\text { time Student }\end{array}$} & \multicolumn{2}{|c|}{ Retired } & \multicolumn{2}{|c|}{ Other } & & \\
\hline & 2 & $0 \%$ & 0 & $0 \%$ & 2 & $1 \%$ & 0 & $0 \%$ & 4 & $<1 \%$ \\
\hline $\begin{array}{l}\text { Urban } \\
\text { Neighborhood }\end{array}$ & 193 & $33 \%$ & 8 & $30 \%$ & 89 & $25 \%$ & 15 & $31 \%$ & 305 & $30 \%$ \\
\hline $\begin{array}{l}\text { Suburban } \\
\text { Neighborhood }\end{array}$ & 390 & $67 \%$ & 19 & $70 \%$ & 259 & $74 \%$ & 34 & $69 \%$ & 702 & $69 \%$ \\
\hline Total & 585 & $58 \%$ & 27 & $3 \%$ & 350 & $35 \%$ & 49 & $5 \%$ & & \\
\hline
\end{tabular}

A closer examination of the observed residential location choices for the accumulated sample from the two recruitment waves revealed a set of trends across certain predefined lifecycle segments. In example, Table 3.5 provides a breakdown of the number of sampled Oregon residents per neighborhood concept classified by their indicated work status. Regardless of work status, nearly all sampled survey respondents presently resided in either a suburban (EF: 69\%) or urban neighborhood (C: 30\%). A higher percent of retired survey respondents lived in the suburban neighborhood concept (EF: 37\%) than the urban neighborhood concept (D: 29\%). Subsequently, a higher percent of survey respondents in the urban neighborhood indicated that they were either part- or full-time workers (63\%) than residents residing within a suburban neighborhood (56\%). The experimental survey yielded a limited number of respondents who were in school, which was an artifact of the survey being directed only toward adult household members. Approximately 2\% of respondents in either the urban or suburban neighborhood indicated they were primarily full- or part-time students. Urban residential districts (C) represent the least represented of the three neighborhood concepts found in Oregon.

Table 3.6 offers an examination of how the work status of survey respondents differed based on dwelling type. Most experimental survey respondents currently lived in a single-family detached (SFD) dwelling unit (81\%), while $11 \%$ of the aggregated sample presently lived in an apartment unit. Of those residents living in an apartment unit, about one quarter (25\%) of these individuals indicated they were in retirement. This share was considerably less than the percent of sampled residents living in a SFD unit who are retired (37\%). Less than one-fifth (19\%) of the residents living in a single-family attached (SFA) dwelling type were retired, while two-thirds of SFA residents were presently

\footnotetext{
${ }^{3}$ Regional sociodemographic characteristics for households and persons; mean and median were collected from the 2010 United States Census and 2008-2012 (5-year) American Community Survey for Oregon.
} 
employed. Only 57\% of residents of a SFD dwelling unit indicated that they were currently employed. Only six respondents were resided in a high-rise apartment (HRA), which is likely due to the difficulty of contacting these residents (e.g., incomplete apartment addresses, high turnover) and the small portion of residents in the urban residential districts often containing these dwelling types.

Table 3.6: Distribution of Sampled Oregon Residents by Dwelling Type and Work Status

\begin{tabular}{|c|c|c|c|c|c|c|c|c|c|}
\hline \multirow{3}{*}{$\begin{array}{l}\text { Dwelling } \\
\text { Type } \\
\text { High-Rise } \\
\text { Apartment }\end{array}$} & \multicolumn{8}{|c|}{ Work Status } & \multirow{3}{*}{$\begin{array}{r}\text { Tota } \\
6\end{array}$} \\
\hline & \multicolumn{2}{|c|}{$\begin{array}{l}\text { Full- or Part- } \\
\text { time Worker }\end{array}$} & \multicolumn{2}{|c|}{$\begin{array}{l}\text { Full- or Part- } \\
\text { time Student }\end{array}$} & \multicolumn{2}{|c|}{ Retired } & \multicolumn{2}{|c|}{ Other } & \\
\hline & 2 & $0 \%$ & 0 & $0 \%$ & 3 & $1 \%$ & 1 & $2 \%$ & \\
\hline $\begin{array}{l}\text { Mid-Rise } \\
\text { Apartment }\end{array}$ & 11 & $2 \%$ & 3 & $11 \%$ & 2 & $1 \%$ & 1 & $2 \%$ & 17 \\
\hline $\begin{array}{l}\text { Low-Rise } \\
\text { Apartment }\end{array}$ & 51 & $9 \%$ & 5 & $19 \%$ & 22 & $6 \%$ & 8 & $17 \%$ & 86 \\
\hline $\begin{array}{l}\text { Single-Family } \\
\text { Attached }\end{array}$ & 52 & $9 \%$ & 5 & $19 \%$ & 15 & $4 \%$ & 6 & $13 \%$ & 78 \\
\hline $\begin{array}{l}\text { Single-Family } \\
\text { Detached }\end{array}$ & 468 & $80 \%$ & 14 & $52 \%$ & 300 & $88 \%$ & 32 & $67 \%$ & 814 \\
\hline Total & \multicolumn{2}{|c|}{584} & \multicolumn{2}{|c|}{27} & \multicolumn{2}{|c|}{342} & \multicolumn{2}{|c|}{48} & 1,001 \\
\hline
\end{tabular}

Finally, Table 3.7 provides a breakdown of common travel mode by work status. Common travel mode was used in place of typical commute travel mode for this descriptive summary because of the large subsample of retirees. Looking at active travel, less than one quarter of sampled Oregonians who were presently employed indicated they most often travel by walking (23\%), while only $6 \%$ of employed respondents indicated they commonly travel by bicycle. As expected, fewer retired survey respondents typically travel by bicycle (4\%), while a greater share of retirees commonly traveled by walking (28\%). Concerning auto travel, $67 \%$ of employed survey respondents commonly travel with a personal vehicle, while one percent of employed residents typically travel by shared vehicle. In turn, $65 \%$ of sampled retirees use a personal vehicle as their common travel mode and about one percent of employees use a shared vehicle. Regarding transit, $14 \%$ of students indicated they use public transit as their most common travel mode, while only $2 \%$ of retirees commonly use transit. 
Table 3.7: Distributions of Sampled Oregon Residents by Common Travel Mode and Work Status

\begin{tabular}{|c|c|c|c|c|c|c|c|c|c|}
\hline \multirow{3}{*}{$\begin{array}{l}\text { Most Common } \\
\text { Travel Mode } \\
\text { Personal Vehicle }\end{array}$} & \multicolumn{8}{|c|}{ Work Status } & \multirow{3}{*}{$\begin{array}{r}\text { Total } \\
672 \\
\end{array}$} \\
\hline & \multicolumn{2}{|c|}{$\begin{array}{l}\text { Full- or Part- } \\
\text { time Worker }\end{array}$} & \multicolumn{2}{|c|}{$\begin{array}{l}\text { Full- or Part- } \\
\text { time Student }\end{array}$} & \multicolumn{2}{|c|}{ Retired } & \multicolumn{2}{|c|}{ Other } & \\
\hline & 396 & $69 \%$ & 17 & $61 \%$ & 231 & $65 \%$ & 28 & $55 \%$ & \\
\hline Shared Vehicle & 3 & $1 \%$ & 0 & $0 \%$ & 3 & $1 \%$ & 1 & $2 \%$ & 7 \\
\hline Public Transit & 20 & $3 \%$ & 4 & $14 \%$ & 7 & $2 \%$ & 2 & $4 \%$ & 33 \\
\hline Bicycle & 35 & $6 \%$ & 0 & $0 \%$ & 15 & $4 \%$ & 1 & $2 \%$ & 51 \\
\hline Walk & 135 & $23 \%$ & 7 & $25 \%$ & 99 & $28 \%$ & 19 & $37 \%$ & 260 \\
\hline Total & \multicolumn{2}{|c|}{589} & \multicolumn{2}{|c|}{28} & \multicolumn{2}{|c|}{355} & \multicolumn{2}{|c|}{51} & 1,023 \\
\hline
\end{tabular}

For workers or students, a personal vehicle was the most common commute mode (70\%), followed by bicycle and public transit (each 9\%), walking (5\%) and carpool (1\%).

Roughly $6 \%$ of respondents work or went to school at home.

\subsubsection{Summary}

This section summarized the experimental survey methodology adopted in this project, including the design of a three-component experimental survey, development of a sampling strategy, and recruitment of respondents. Initial summary statistics were also presented. The administration of the experimental survey instrument provided the data source needed to estimate the socioeconomic, residential location, and transportation characteristics associated with the housing and neighborhood preferences exhibited by individuals. Additionally, the implementation of an experimental survey with a choice-based conjoint analysis exercise has provided an invaluable data source to be incorporated in future evaluations of the tradeoffs in preferences for commute mode and travel time in relation to the neighborhood concepts.

The novel application of image collages to represent these neighborhood concepts and design of a computer-aided survey instrument provides the flexibility of conducting the choice-based experiment outside of a classroom setting and adaptability to conduct this survey in other study areas. Accordingly, the experimental survey could be targeted in future applications to increase the sample of those survey respondents who live in urban residential district neighborhoods characterized by multifamily dwelling units, commonly travel by public transit or bicycle, or are full- or part-time students. A heightened focus on these subsamples of the population would enable future efforts to answer other research questions related to the residential location decisions of certain market segments. Finally, the experimental design may be easily altered in the future to examine the value individual place on other important attributes of the residential location choice process such as varying dwelling types or housing costs.

\subsection{NEIGHBORHOOD PREFERENCE ANALYSIS}

Although the primary goal of the project was to develop and test the survey infrastructure, the administration of the experimental survey instrument provided adequate sample size to permit an analysis of the neighborhood preferences of a sample of Oregon residents. The collection of data 
on the neighborhood preferences of survey respondents as well as present socioeconomic, residential location, and transportation characteristics enabled an examination of how observable characteristics may inform the residential location preferences of individuals. In addition to these characteristics, the analysis of the survey data allowed a study of how the importance rankings of a set of 17 housing, neighborhood, and transportation items related to neighborhood preferences.

The following subsection presents the results of this examination of neighborhood preferences estimated using multinomial logit models. Discussion of this methodology offers both a description of the data used in this empirical application and an account of the employed modeling strategy. This section then continues with a depiction of the socioeconomic, residential location choice, importance ranking, and transportation characteristics associated with the neighborhood and housing preferences of sampled residents. It concludes with the presentation of future work of a conjoint analysis of the tradeoffs associated with these choices using the data obtained from the choice experiment.

\subsubsection{Analytical Approach}

\subsubsection{Data Description}

Data used to analyze neighborhood preferences originated from a sample of 1,035 Oregon residents who participated in an administration of the online experimental survey during June and July of 2014. The dataset used in this empirical application was further reduced to exclude incomplete responses, which decreased the sample size used for the final neighborhood and housing preference models to 642 respondents. Incomplete survey observations were due to unanswered questions related to the current socioeconomic, residential location, importance ranking, and transportation characteristics of survey participants as well as skip logic in the experimental survey design and a failure of respondents to select a preferred neighborhood concept.

Socioeconomic status characteristics were collected in the experimental survey and tested in both preference models. These variables pertained to features of the survey respondent's household such as size, composition, and income in addition to information about the individual's gender and employment status. Table 3.8 provides descriptive statistics for these socioeconomic characteristics. In complement to socioeconomic status variables, a set of measures related to an individual's current residential location were collected. Housing-related measures included the respondent's current dwelling type, dwelling size, and monthly housing costs as well as his/her preference in dwelling type. Similarly, information related to an individual's current and preferred neighborhood concept were collected. Table 3.9 provides descriptive statistics of these residential location decisions tested in the preference models. The outcome variable used for the neighborhood preference analysis was the categorical variable of preferred neighborhood 
concepts (AB, C, D, EF, described previously) along an urban-to-rural spectrum of image sets. For the purpose of this analysis, we will discuss the neighborhood concepts with the names presented to respondents within the survey:

(AB) Central District

(C) Urban Residential District

(D) Urban Neighborhood

(EF) Suburban Neighborhood

As for the housing preference models, the categorical measure representing one of the five unique dwelling types: single-family detached), single-family attached (SFA), highrise apartment, mid-rise apartment, and low-rise multi-family (MF) units was initially established. Low sample sizes for the three apartment dwelling types led to an aggregation of these responses in the two preference models. When examining neighborhood preference, most respondents selected Suburban Neighborhood $(n=349)$, which was followed by Urban Neighborhood $(n=234)$, Urban Residential District $(n=$ 50 ), and Central District ( $n=9)$. As for dwelling type preference, the vast majority of respondents in the final sample selected SFD $(n=569)$, while 35 and 38 survey respondents preferred a single-family attached and multi-family dwelling type, respectively.

Table 3.8: Descriptive Statistics for Socioeconomic Characteristics for Preference Dataset

\begin{tabular}{l|c|c|c|c|c|c}
\hline \multirow{2}{*}{$\begin{array}{l}\text { Chacioeconomic } \\
\text { Characteristic }\end{array}$} & \multicolumn{7}{|c}{ Descriptive Statistics } \\
\cline { 2 - 7 } Household Size & Mean & St. Dev. & Min & Max & Count & Percent \\
\hline Children & 2.61 & 1.28 & 1 & 7 & --- & --- \\
\hline Age & 0.47 & 0.90 & 1 & 5 & --- & --- \\
\hline Gender (Male) & ---- & --- & --- & --- & 317 & 0.49 \\
\hline Employee & --- & --- & --- & --- & 404 & 0.63 \\
\hline Student & --- & --- & --- & --- & 16 & 0.02 \\
\hline Retired & --- & --- & --- & --- & 193 & 0.30 \\
\hline Household Income & --- & --- & --- & --- & --- & -- \\
\hline$\$ 0-\$ 14,999$ & --- & --- & --- & --- & 18 & 0.03 \\
\hline$\$ 15,000-\$ 24,999$ & --- & --- & --- & --- & 30 & 0.05 \\
\hline$\$ 25,000-\$ 34,999$ & --- & --- & --- & --- & 50 & 0.08 \\
\hline$\$ 35,000-\$ 49,999$ & --- & --- & --- & --- & 80 & 0.12 \\
\hline$\$ 50,000-\$ 74,999$ & --- & --- & --- & --- & 153 & 0.23 \\
\hline$\$ 75,000-\$ 99,999$ & --- & --- & --- & --- & 109 & 0.17 \\
\hline$\$ 100,000-\$ 149,999$ & --- & --- & --- & --- & 123 & 0.19 \\
\hline$\$ 150,000-\$ 199,999$ & --- & --- & --- & --- & 50 & 0.08 \\
\hline$\$ 200,000-\$ 249,999$ & --- & --- & --- & --- & 15 & 0.02 \\
\hline$>=\$ 250,000$ & --- & --- & --- & --- & 14 & 0.02 \\
\hline
\end{tabular}


Table 3.9: Descriptive Statistics for Residential Location Characteristics for Preference Dataset

\begin{tabular}{|c|c|c|c|c|c|}
\hline \multirow{2}{*}{$\begin{array}{l}\text { Current Residential } \\
\text { Location Characteristic }\end{array}$} & \multicolumn{2}{|c|}{ Descriptive Statistics } & \multirow{2}{*}{$\begin{array}{l}\text { Current Residential } \\
\text { Location Characteristic } \\
\end{array}$} & \multicolumn{2}{|c|}{ Descriptive Statistics } \\
\hline & Count & Percent & & Count & Percent \\
\hline Tenure (Own) & 538 & 0.84 & \begin{tabular}{|c|} 
Current Dwelling \\
Type
\end{tabular} & --- & --- \\
\hline $\begin{array}{c}\text { Monthly Housing } \\
\text { Costs } \\
\end{array}$ & --- & --- & Apartment/Condo & 52 & 0.08 \\
\hline$\$ 0-\$ 250$ & 123 & 0.19 & High-Rise & 0 & 0.00 \\
\hline$\$ 250-\$ 499$ & 32 & 0.05 & Mid-Rise & 6 & 0.01 \\
\hline$\$ 500-\$ 749$ & 70 & 0.11 & Low-Rise & 46 & 0.07 \\
\hline$\$ 750-\$ 999$ & 100 & 0.16 & Single-family attached & 51 & 0.08 \\
\hline$\$ 1,000-\$ 1,499$ & 168 & 0.26 & Single-family detached & 539 & 0.84 \\
\hline$\$ 1,500-\$ 1,999$ & 82 & 0.13 & \begin{tabular}{|c|} 
Preferred Dwelling \\
Type
\end{tabular} & --- & --- \\
\hline$\$ 2,000-\$ 2,499$ & 41 & 0.06 & Apartment/Condo & 38 & 0.06 \\
\hline$\$ 2,500-\$ 2,999$ & 10 & 0.02 & High-Rise & 3 & 0.00 \\
\hline$\$ 3,000-\$ 3,499$ & 8 & 0.01 & Mid-Rise & 11 & 0.02 \\
\hline$>=\$ 3,500$ & 8 & 0.01 & Low-Rise & 24 & 0.04 \\
\hline $\begin{array}{c}\text { Current } \\
\text { Neighborhood }\end{array}$ & --- & --- & Single-family attached & 35 & 0.05 \\
\hline Central District & 0 & 0.00 & Single-family detached & 569 & 0.89 \\
\hline $\begin{array}{l}\text { Urban Residential } \\
\text { District }\end{array}$ & 0 & 0.00 & $\begin{array}{l}\text { Dwelling Size } \\
\end{array}$ & --- & --- \\
\hline Urban Neighborhood & 203 & 0.32 & $0-750$ sq. feet & 25 & 0.04 \\
\hline $\begin{array}{l}\text { Suburban } \\
\text { Neighborhood }\end{array}$ & 439 & 0.68 & $750-1,499$ sq. feet & 205 & 0.32 \\
\hline $\begin{array}{c}\text { Preferred } \\
\text { Neighborhood } \\
\end{array}$ & --- & --- & $1,500-2,499$ sq. feet & 296 & 0.47 \\
\hline Central District & 9 & 0.01 & 2,500-4,999 sq. feet & 106 & 0.17 \\
\hline $\begin{array}{l}\text { Urban Residential } \\
\text { District }\end{array}$ & 50 & 0.08 & $>=5,000$ sq. feet & 3 & 0.00 \\
\hline Urban Neighborhood & 234 & 0.36 & --- & --- & --- \\
\hline $\begin{array}{l}\text { Suburban } \\
\text { Neighborhood }\end{array}$ & 349 & 0.54 & --- & --- & --- \\
\hline
\end{tabular}

A set of transportation-related characteristics associated with the number of household vehicles and bikes as well as personal access to various travel modes (driver's license, transit pass, and car share membership) were collected. Information on the commute and other travel modes of survey respondents were also collected in the survey and used to examine an individual's neighborhood and housing preferences. Table 3.10 provides sample statistics for these transportation characteristics. Furthermore, the importance rankings described in a previous section were also converted to a set of dummy variables distinguishing whether or not one of the housing, transportation, or accessibility items 
were considered to be very, somewhat, or not at all important in a survey respondent's residential location decision-making process. Table 3.11 summarizes the count and percent of responses for each importance ranking item.

Table 3.10: Descriptive Statistics for Transportation Characteristics for Preference Dataset

\begin{tabular}{|c|c|c|c|c|c|c|}
\hline \multirow{2}{*}{$\begin{array}{l}\text { Transportation } \\
\text { Characteristic }\end{array}$} & \multicolumn{6}{|c|}{ Descriptive Statistics } \\
\hline & Mean & St. Dev. & Min & Max & Count & Percent \\
\hline Household Vehicles & 2.05 & 1.22 & 0 & 12 & --- & --- \\
\hline Household Bikes & 1.67 & 1.58 & 0 & 11 & --- & --- \\
\hline Driver's License & --- & --- & --- & --- & 628 & 0.98 \\
\hline Car share Membership & --- & --- & --- & --- & 34 & 0.05 \\
\hline Transit Pass & --- & --- & --- & --- & 94 & 0.15 \\
\hline $\begin{array}{c}\text { Commute Travel } \\
\text { Mode }\end{array}$ & -- & --- & --- & --- & --- & --- \\
\hline Vehicle & --- & --- & --- & --- & 312 & 0.48 \\
\hline Transit & --- & --- & --- & --- & 35 & 0.05 \\
\hline Bike & --- & --- & --- & --- & 42 & 0.07 \\
\hline$\overline{\text { Walk }}$ & --- & --- & --- & --- & 17 & 0.03 \\
\hline (None) & -- & --- & --- & --- & 236 & 0.37 \\
\hline Other Travel Mode & --- & --- & --- & --- & --- & --- \\
\hline Vehicle & --- & --- & --- & --- & 439 & 0.69 \\
\hline Transit & --- & --- & --- & --- & 18 & 0.03 \\
\hline Bike & -- & --- & --- & --- & 33 & 0.05 \\
\hline Walk & --- & --- & --- & --- & 152 & 0.24 \\
\hline
\end{tabular}


Table 3.11: Importance Ranking of Residential Location Choice Items for Preference Dataset

\begin{tabular}{l|c|c|c|c|c|c}
\hline \multirow{2}{*}{$\begin{array}{l}\text { Residential Location } \\
\text { Choice Item }\end{array}$} & \multicolumn{6}{|c}{ Stated Level of Importance Ranking } \\
\cline { 2 - 7 } & Not at All Important & Somewhat Important & \multicolumn{2}{c}{ Very Important } \\
\cline { 2 - 7 } Own House & Count & Percent & Count & Percent & Count & Percent \\
\hline Large Dwelling Size & 42 & 0.07 & 127 & 0.20 & 473 & 0.74 \\
\hline Single-family Detached & 61 & 0.10 & 173 & 0.27 & 408 & 0.64 \\
\hline Private Yard & 41 & 0.06 & 159 & 0.25 & 442 & 0.69 \\
\hline $\begin{array}{l}\text { Privacy from } \\
\text { Neighbors }\end{array}$ & 22 & 0.03 & 234 & 0.36 & 386 & 0.60 \\
\hline Center of it All & 413 & 0.64 & 197 & 0.31 & 32 & 0.05 \\
\hline High-Quality Schools & 304 & 0.47 & 152 & 0.24 & 186 & 0.29 \\
\hline $\begin{array}{l}\text { Near Established } \\
\text { Houses }\end{array}$ & 287 & 0.45 & 251 & 0.39 & 104 & 0.16 \\
\hline Highway Access & 161 & 0.25 & 349 & 0.54 & 132 & 0.21 \\
\hline $\begin{array}{l}\text { Variety of } \\
\text { Transportation Options }\end{array}$ & 111 & 0.17 & 314 & 0.49 & 217 & 0.34 \\
\hline $\begin{array}{l}\text { Commute <= 25 } \\
\text { minutes }\end{array}$ & 116 & 0.18 & 165 & 0.26 & 361 & 0.56 \\
\hline Walk to Transit & 171 & 0.27 & 280 & 0.44 & 191 & 0.30 \\
\hline Off-street Parking & 179 & 0.28 & 319 & 0.50 & 144 & 0.22 \\
\hline Dedicated Parking & 34 & 0.05 & 125 & 0.19 & 483 & 0.75 \\
\hline $\begin{array}{l}\text { Access to Recreation } \\
\text { Area }\end{array}$ & 38 & 0.06 & 245 & 0.38 & 359 & 0.56 \\
\hline Walk to Nearby Places & 69 & 0.11 & 259 & 0.40 & 314 & 0.49 \\
\hline Bike to Nearby Places & 219 & 0.34 & 245 & 0.38 & 178 & 0.28 \\
\hline
\end{tabular}

\subsubsection{Preference Model Specification and Estimation}

The measures listed in Table 3.8 to Table 3.11 were included as independent variables in the final neighborhood. The decision to include these measures was based upon theoretical considerations as well as empirical testing in a stepwise model building processes. Each of the preference outcomes were examined by performing a backward elimination stepwise process using the measures of the socioeconomic, current residential location, transportation, and importance ranking characteristics outlined above. The backward elimination process was iterative and stopped once all of the explanatory variables included in either preference model were statistically significant according to a p-value $<0.10$. After establishing the MNL neighborhood preference model, an explanatory variable reflecting the preference for the neighborhood concept or dwelling type modeled in the other preference model was tested. For example, an individual's preference for one of the three dwelling types was added as an explanatory variable in the neighborhood preference model. Table 3.12 and Table 3.13 provide the final model 
estimation results for the neighborhood preference models which are discussed in greater detail in the following subsections.

Table 3.12: Neighborhood Concept Preference Model Estimation (Base $=$ Suburban Neighborhood/EF)

\begin{tabular}{|c|c|c|c|c|c|c|}
\hline \multicolumn{7}{|c|}{ Model Statistics } \\
\hline \multicolumn{7}{|c|}{ Log-likelihood (Beta)-320 } \\
\hline \multicolumn{7}{|c|}{ Log-likelihood (Null)-615 } \\
\hline \multicolumn{7}{|c|}{ McFadden $\mathrm{R}^{2} 0.48$} \\
\hline \multicolumn{7}{|c|}{ Sample Size (N)642 } \\
\hline & Estimate & SE & t-value & $\operatorname{Pr}(>|t|)$ & & R2 \pm \\
\hline \multicolumn{7}{|l|}{ Intercept } \\
\hline C: Urban Residential District & -18.77 & $4,670.50$ & 0.00 & 1.00 & & \\
\hline D: Urban Neighborhood & -0.56 & 1.30 & -0.43 & 0.67 & & \\
\hline \multicolumn{7}{|l|}{ Socioeconomic Characteristics } \\
\hline \multicolumn{7}{|l|}{ Annual Household Income } \\
\hline C: $\$ 100,000-\$ 149,999$ & 1.05 & 0.62 & 1.70 & 0.09 & & $0.4 \%$ \\
\hline \multicolumn{7}{|l|}{ Respondent Age } \\
\hline D: 30 - 34 years old & 1.37 & 0.48 & 2.87 & 0.00 & $* *$ & $0.9 \%$ \\
\hline D: 35 - 39 years old & 1.27 & 0.47 & 2.69 & 0.01 & ** & $0.7 \%$ \\
\hline D: 40 - 44 years old & 1.29 & 0.44 & 2.91 & 0.00 & ** & $0.8 \%$ \\
\hline \multicolumn{7}{|c|}{ Current Residential Location Characteristics } \\
\hline \multicolumn{7}{|l|}{ Dwelling Size } \\
\hline D: 0 - 749 square feet & 1.57 & 0.67 & 2.34 & 0.02 & * & $1.1 \%$ \\
\hline \multicolumn{7}{|l|}{ Monthly Housing Cost } \\
\hline C: $\$ 0-\$ 250$ & 1.45 & 0.60 & 2.41 & 0.02 & * & $0.8 \%$ \\
\hline \multicolumn{7}{|l|}{ Dwelling Type Preference } \\
\hline $\begin{array}{l}\text { C: Multifamily Apartment or } \\
\text { Condominium }\end{array}$ & 1.71 & 0.82 & 2.08 & 0.04 & * & $0.9 \%$ \\
\hline \multicolumn{7}{|c|}{ Current Transportation Characteristics } \\
\hline C: Household Bikes & 0.26 & 0.09 & 2.97 & 0.00 & ** & $0.8 \%$ \\
\hline \multicolumn{7}{|l|}{ Mode for Other Travel } \\
\hline C: Walk & 1.15 & 0.50 & 2.32 & 0.02 & * & $10 \%$ \\
\hline D: Walk & 0.69 & 0.30 & 2.29 & 0.02 & * & 1.07 \\
\hline
\end{tabular}




\subsubsection{Neighborhood Preference Model Estimation Results}

\subsubsection{Variables Most Associated with Neighborhood Preference}

Estimation results from the neighborhood preference model (see Table 3.12) have suggested that an individual's importance ranking of residential location items related to a set of neighborhood, housing, and transportation characteristics most strongly explained his/her neighborhood preference. In general, individual- and household-level socioeconomic characteristics (e.g., household size, estimated annual income) had a minor and/or statistically non-significant effect on determining an individual's preference for a neighborhood concept. While a handful of characteristics related to an individual's transportation and residential location characteristics had some significant explanatory power in the final neighborhood preference model, the importance ranking characteristics appeared to be the major drivers of whether a survey respondent preferred a more urban or suburban neighborhood.

The residential location items ranked in terms of importance by individuals with the largest effect on neighborhood preference may be divided into either 'pro-urban' or 'prosuburban' categories. For the former 'pro-urban' category, importance ranking characteristics for items like "being in the 'center of it all"” and "walking to bus and/or rail stops” were consistently strong predictors of a preference for a more urban neighborhood concept. As for the latter category, "Living in a detached single-family home”, "having a private yard" and "having privacy from my neighbors" mattered most for survey respondents who preferred a more suburban neighborhood concept. Consequently, preferences for "living near access to highways/freeways”, "having a commute that takes 25 minutes or less", and "having off-street parking at local destinations” were not identified as being significant predictors in estimating neighborhood preference. These results have suggested that respondents focus on tradingoff between accessibility of their neighborhood location and having a more private living space and dwelling type.

A simple distinction of survey respondents using the "pro-urban" or "pro-suburban" preference categories does not provide a complete picture since some participants did not necessarily fall entirely into either category. As described in more detail on page 46, 90\% of respondents identified "living in a single-family detached home" as being either somewhat or very important; however, of these survey respondents, only 33\% identified "being in the 'center of it all'” as important. A greater discussion of this trade-off is provided elsewhere (see pages 46 and 48). Neighborhood preference model results have suggested Urban Residential Neighborhood (D) as being preferred by those survey respondents who wish to have the space and privacy offered by the single-family detached dwelling units found in the Suburban Neighborhood (EF) as well as the local accessibility to many activity opportunities offered in the Central District (AB) and Urban Residential District (C).

Respondents between 30 and 44 years of age largely preferred Neighborhood D to the more suburban concept (EF). A closer examination of this demographic revealed $15 \%$ of the respondents within this cohort who presently live in the Suburban Neighborhood (EF) 
preferred a more urban (AB, C, or D) neighborhood, and that $9 \%$ of these survey respondents would prefer to live in the Central District (AB) and Urban Residential District (C) (see Table 3.14). Survey respondents between 25 and 29 years of age exhibited a similar, but non-significant, preference for more urban neighborhood concepts. Taken together, a potential demand for urban living may exist among younger survey respondents, which would seem to echo national trends expressing a desire for younger generations to live in activity-rich, urban neighborhoods..

Regardless of age, approximately $27 \%$ of all survey respondents preferred a neighborhood more urban than their current neighborhood, whereas $12 \%$ of those surveyed preferred a neighborhood more suburban than their present residential location. The remaining survey participants, more than half of the sample, preferred to reside in a neighborhood concept matching their present circumstance. About one-quarter of those individuals currently living in the most suburban concept, the Suburban Neighborhood (EF), stated that they would prefer a more urban neighborhood. Meanwhile, only $2 \%$ of respondents currently living in Urban Neighborhood (D) stated a preference for living in one of the two more urban neighborhood concepts, while 12\% of Urban Neighborhood (D) respondents would prefer something less urban (see Table 3.14).

Table 3.14: Comparison of Current and Stated Neighborhood Preference

\begin{tabular}{|c|c|c|c|c|c|c|c|c|c|}
\hline \multirow{3}{*}{$\begin{array}{l}\text { Current } \\
\text { Neighborhood } \\
\text { Concept }\end{array}$} & \multicolumn{8}{|c|}{ Stated Neighborhood Preference } & \multirow{3}{*}{$\begin{array}{l}\text { Total } \\
\text { Count }\end{array}$} \\
\hline & \multicolumn{2}{|c|}{$\begin{array}{c}\mathrm{AB} \\
\text { Central District }\end{array}$} & \multicolumn{2}{|c|}{\begin{tabular}{c|}
$\mathrm{C}$ \\
Urban Residential \\
District
\end{tabular}} & \multicolumn{2}{|c|}{$\begin{array}{c}\text { D } \\
\text { Urban } \\
\text { Neighborhood }\end{array}$} & \multicolumn{2}{|c|}{$\begin{array}{c}\text { EF } \\
\text { Suburban } \\
\text { Neighborhood }\end{array}$} & \\
\hline & Count & Percent & Count & Percent & Count & Percent & Count & Percent & \\
\hline $\mathrm{AB}$ & 0 & 0.00 & 0 & 0.00 & 0 & 0.00 & 0 & 0.00 & 0 \\
\hline $\mathrm{C}$ & 0 & 0.00 & 0 & 0.00 & 0 & 0.00 & 0 & 00 & 0 \\
\hline $\mathrm{D}$ & 0 & 0.00 & 16 & 0.02 & 109 & 0.17 & 78 & 0.12 & 203 \\
\hline $\mathrm{EF}$ & 9 & 0.01 & 34 & 0.05 & 125 & 0.19 & 271 & 0.42 & 439 \\
\hline Total & 9 & 0.01 & 50 & 0.08 & 234 & 0.36 & 349 & 0.54 & 642 \\
\hline
\end{tabular}

Estimated annual household income was not found to be significant in explaining neighborhood preference. Only one of the ten income brackets (\$150-200,000 per year) was statistically significant when differentiating preference between Urban Neighborhood (D) and Suburban Neighborhood (EF). Figure 3.7 shows the observed distribution of neighborhood preferences across the household income categories collected in the experimental survey sample. This finding may also indicate an equal desire for surveyed respondents to reside in similar neighborhoods regardless of annual household income, which in-turn may emphasize a need to provide a greater variety of dwelling types and housing costs within each neighborhood concept. The present sample used for the preference models has an under-representation of respondents who reside in the Urban Residential District (C). Of the 642 survey responses included in the final estimation dataset, none of the surveyed individuals currently resided in the most urban neighborhood found within Oregon. Provided a representative sample of surveyed 
households, greater variation in the distribution of household incomes and preferred neighborhoods may be exacted.
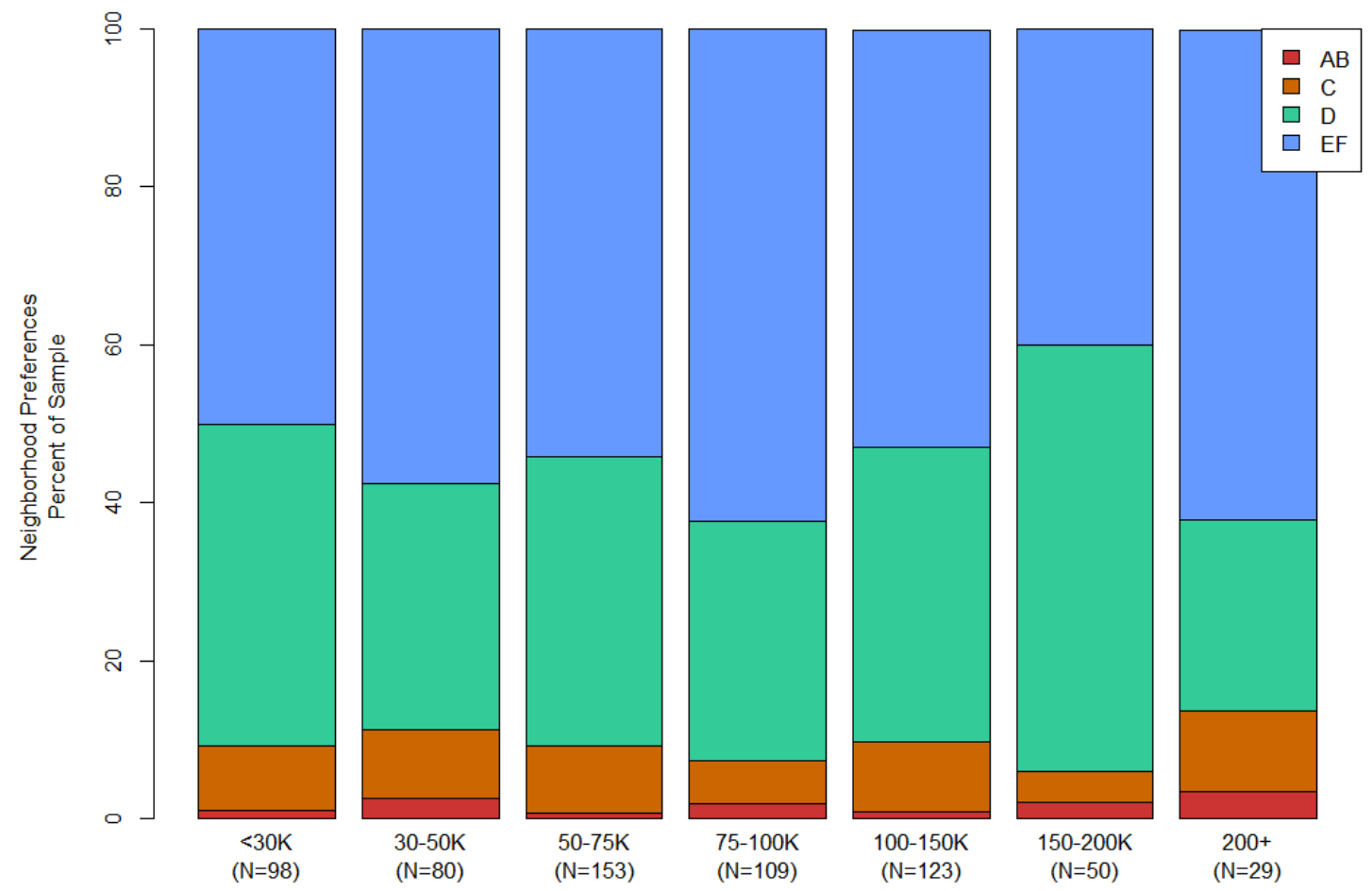

Annual Household Income

Figure 3.7: Observed Distribution of Stated Neighborhood Preferences by Annual Household Income

\subsubsection{Summary of Model Performance}

The neighborhood preference model had McFadden's $\mathrm{R}^{2}$ value of 0.48 , which may be translated to mean that $48 \%$ of the variation in neighborhood preferences may be explained by the socioeconomic status, current residential location, transportation, and importance ranking characteristics specified in the final model. In terms of model prediction accuracy, the estimated neighborhood preference model predicted the preferred neighborhood with a user accuracy of $81 \%$. User accuracy of the neighborhood model, displayed in Table 3.15, increased as the predicted neighborhood preference became less urban along the spectrum. This increased user accuracy was likely an artifact of an increased sample size in the overall individual preference for those neighborhood concepts located in more suburban contexts. 
Table 3.15: Neighborhood Preference Model Accuracy—Predicted versus Stated Preferences

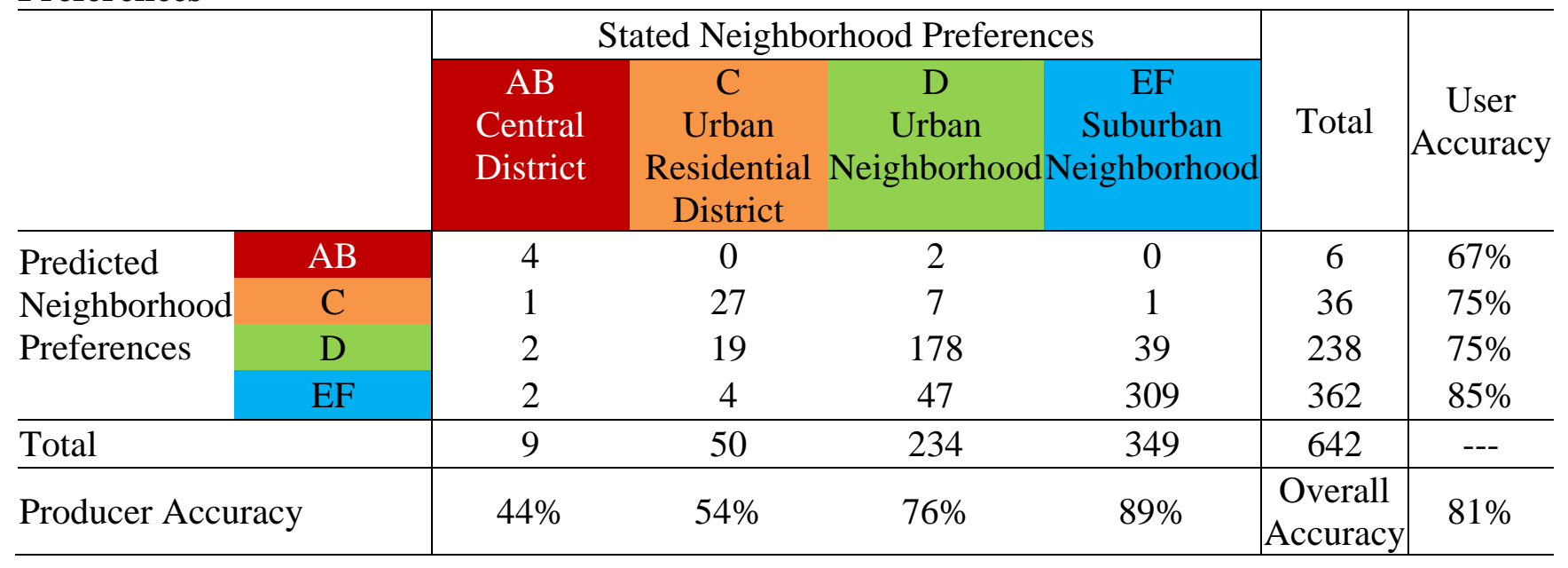

Coefficients for these explanatory variables of the model specification represent the relationship between the relative utility of each neighborhood concept alternative (AB, C, D) against the base case alternative (the Suburban Neighborhood (EF)). For each significant variable entered into the final model, a separate coefficient was derived to reflect each alternative against the base reference. If a coefficient for any of the explanatory variables was found to be both positive and statistically significant, then the characteristic was interpreted as having a positive relationship between the given variable and relative utility for that alternative ( $\mathrm{AB}, \mathrm{C}$, or $\mathrm{D})$, compared against the base case (Suburban Neighborhood/EF). When the magnitude or effects size of one parameter was larger than a second parameter, the first parameter was identified to have a larger effect on that alternative's utility than the second alternative. Due to the limited sample of survey respondents, who either prefer or reside in most urban neighborhood concepts, caution should be taken when interpreting coefficients related to Neighborhoods $C$ in this model. In fact, parameters estimated for the Central District (AB) alternative, which comprised less than $1 \%$ of the overall sample, were removed from the model results to reduce the interpretation of a potentially spurious finding.

In order to examine the contribution of each independent variable in explaining the variation in the probability of neighborhood preferences, the impact of each coefficient on the change in probability that each neighborhood would be preferred was calculated; assuming, that all other variables are at the mean value observed. To do so, an equation assigning the probability for each neighborhood given the average value of the other included variables was estimated (see Equation 3.1 for Neighborhood AB example). For each estimated probability, additional control variables were taken at either their mean value for continuous variables or observed distribution for dummy variables. 
Equation 3.1 Calculating the Probability that Central District (AB) is Preferred (MNL model)

Where,

$$
P_{A B}=\frac{\exp \left(V_{A B}\right)}{\exp \left(V_{A B}\right)+\exp \left(V_{C}\right)+\exp \left(V_{D}\right)+\exp \left(V_{E F}\right)}
$$

\section{(3.1)}

$V_{\text {nhood }}=\boldsymbol{\beta} * \boldsymbol{X}+\varepsilon$, nhood $\in\{A B, C, D, E F\}$

$\boldsymbol{\beta}$ : Signficiant estimated coefficients

$\boldsymbol{X}$ : Mean values for each variable used in the model specification

To determine the effect of each coefficient on the probability of preferring a neighborhood ( $\mathrm{AB}, \mathrm{C}, \mathrm{D}$, and $\mathrm{EF}$ ), the probability of selecting a neighborhood concept was calculated twice with separate mean values. First, the probabilities were calculated by setting $\boldsymbol{X}=0$, while leaving all other variables equal to their average value. Likewise, the probabilities were then calculated for $\boldsymbol{X}=1$. As shown in Equation 3.2, the difference between the two estimates was next calculated in order to determine the contribution of each variable if it was to be excluded from the final preference model.

Equation 3.2 Calculating the Impact of Variable $\mathrm{X}$ on $\mathrm{P}_{\text {nhood }}$

$$
P_{\text {nhood }}(X=1)-P_{\text {nhood }}(X=0)=\text { Impact of } X \text { to } P_{\text {nhood }}, \text { nhood } \in\{A B, C, D, E F\}
$$

A result of this process was an ability to define the contribution of each socioeconomic status, residential location, transportation, and importance ranking variable to the change in the probability of preferring a neighborhood. The impact of each statistically significant explanatory variable specified in the preference model has been provided in Figure 3.8 and Figure 3.9, representing substantial individual-level variables and ranking preferences, respectively. This graphic may be used to examine the effect size of each variable in changing neighborhood preference probability when all other variables are at an average value. In other words, this graphic depicts the impact of each explanatory variable with respect to the change in neighborhood preference probabilities. 


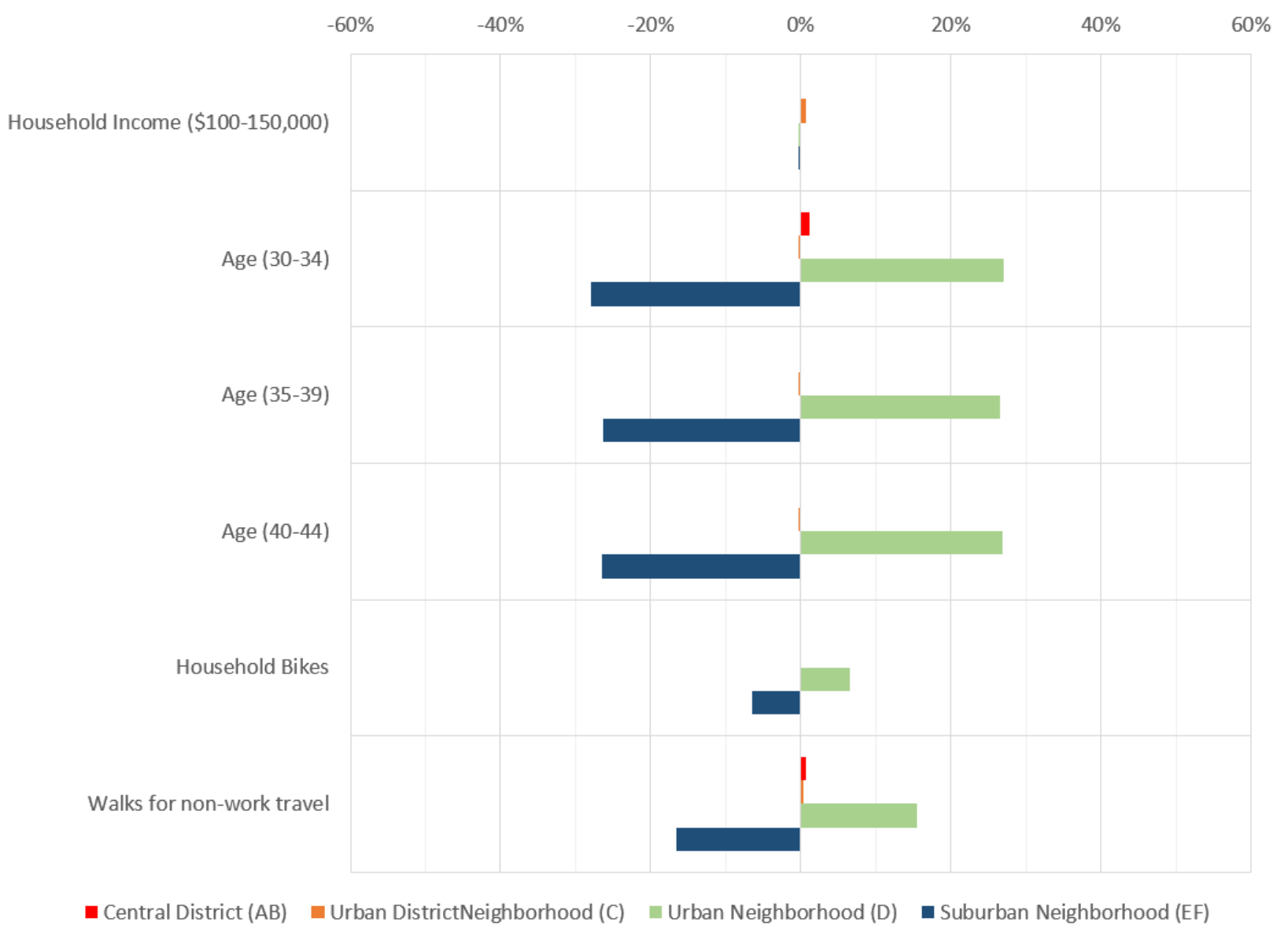

Figure 3.8: Individual-Level Variables- Contribution to the Change in Probability of Neighborhood Preference, all other variables at their mean value 


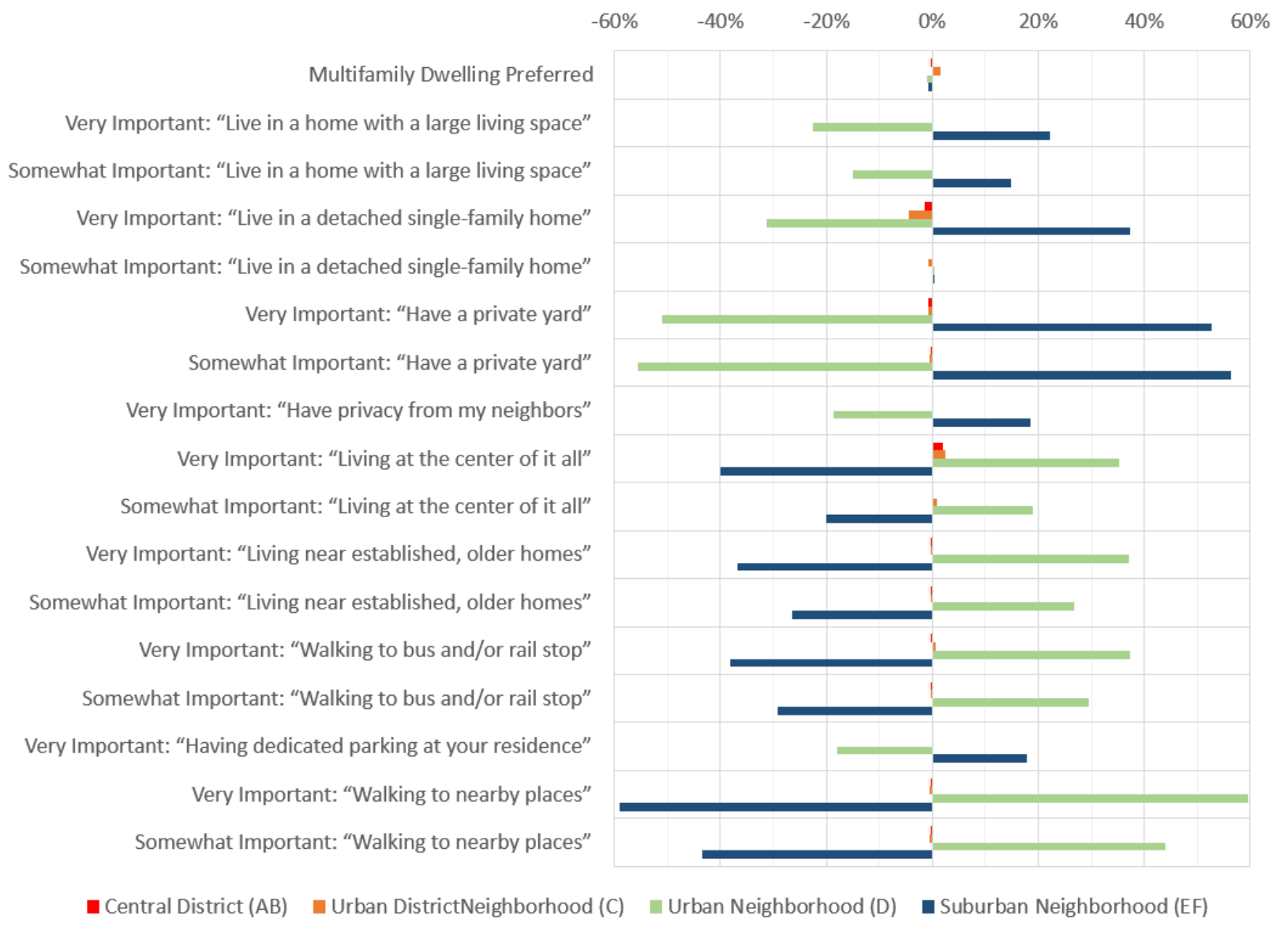

Figure 3.9: Importance Ranking Preferences - Variable Contribution to the Change in Probability of Neighborhood Preference, all other variables at their mean value

While Figure 3.8 and Figure 3.9 illustrates the impact of a variable on neighborhood preference probabilities, the figure may also be useful in detailing the contribution of each parameter in explaining neighborhood preference variation. Although, there is a potential for the coefficient with the largest effect size to have the smallest contribution in explaining this variation. In all, the variables specified in the final preference model have explained approximately $48 \%$ of the overall variation in the neighborhood preference of surveyed Oregonians. Looking at the different sets of explanatory variables, the socioeconomic status- and transportation-related variables explained $1.9 \%$ of the overall variance, respectively. As for the residential location characteristics, an individual's preference in dwelling type explained about $1.8 \%$ of the variance. An individual's importance ranking of neighborhood, housing, and transportation characteristics proved to have the most substantial contribution to the variance explained; having accounted for 
$23 \%$ of the $48 \%$ total variance explained (McFadden's $\mathrm{R}^{2}$ ). The specific residential location items whose ranking of importance provided the highest explanation of variance included:

- Living near established, older homes ${ }^{4}(4.4 \%)$;

- Living in a detached single-family home (3.8\%);

- $\quad$ Living at the "center of it all" (3.6\%);

- Having a private yard (3.3\%);

- Walking to bus and/or rail stops (3.0\%); and

- Walking to nearby places (2.5\%).

\subsubsection{When do People Prefer Neighborhood C: Urban Residential Districts}

Individuals who preferred Urban Neighborhoods (C) instead of Urban Residential Neighborhoods (D) or Suburban Neighborhoods (EF) tended to feel that "living in a single-family detached house" and "having a private yard" were less important than the other items. In fact, the more important a single-family detached dwelling or a private yard was to a respondent, the less likely he or she was to prefer an urban neighborhood when compared to a more suburban concept $\left(\beta_{\text {SFDvery }}=-4.98 ; \beta_{\text {SFDsomewhat }}=\right.$ $\left.-2.47 ; \beta_{\text {YARDvery }}=-3.40 ; \beta_{\text {YARDsomewhat }}=-2.72 ; p<0.01\right)$. In total, these four preferences explained $7 \%$ of the overall variance in neighborhood preference, more than many of the other modeled explanatory variables. Unsurprisingly, respondents who sought to "live at the center of it all" were far more likely to prefer Urban Neighborhoods (C) $\left(\beta_{\text {veryimp }}=4.16, p<0.001 ; \beta_{\text {somewhat }}=2.10, p<0.001\right)$. A desire to reside in a neighborhood with high local accessibility explained nearly $4 \%$ of the overall variance, representing the second most influential importance ranking item in the neighborhood preference model.

Accordingly, survey participants appeared to be recognizing activity level differences between the different neighborhood concepts. Naturally, a small portion of surveyed respondents who preferred a Suburban Neighborhood (EF) also desired to reside somewhere at the "center of it all." Approximately 90\% of respondents identified "living in a single-family detached house" to be either very or somewhat important to them. Of those respondents, $4 \%$ of them identified "living at the 'center of it all'" to be a "very important" residential location characteristics, while $29 \%$ ranked this item as being "somewhat important" to them.

\footnotetext{
4 The interpretation of "living near established, older homes” was intended to identify an architectural preference for historic homes. Caution should be taken when interpreting the effect of this variable as respondents may be interpreting this characteristics as "living near established households"; a potential indicator of a preference to live near or farther away from apartment dwelling types.
} 
By using the neighborhood preference model estimates, the change in probability for preferring each neighborhood was estimated based on whether an individual ranked "being at the "center of it all"” and "living in a single-family detached home" as an important item, after all other variables were taken at their average observed value. The results of this analysis, shown in Figure 3.10, indicate the sensitivity between the preferences for "living in a single-family detached home" and also "being at the "center of it all"”. Only when "living in a single-family detached home" is "not important" and "being at the 'center of it all'” is very or somewhat important do individuals begin to prefer a more urban neighborhood.

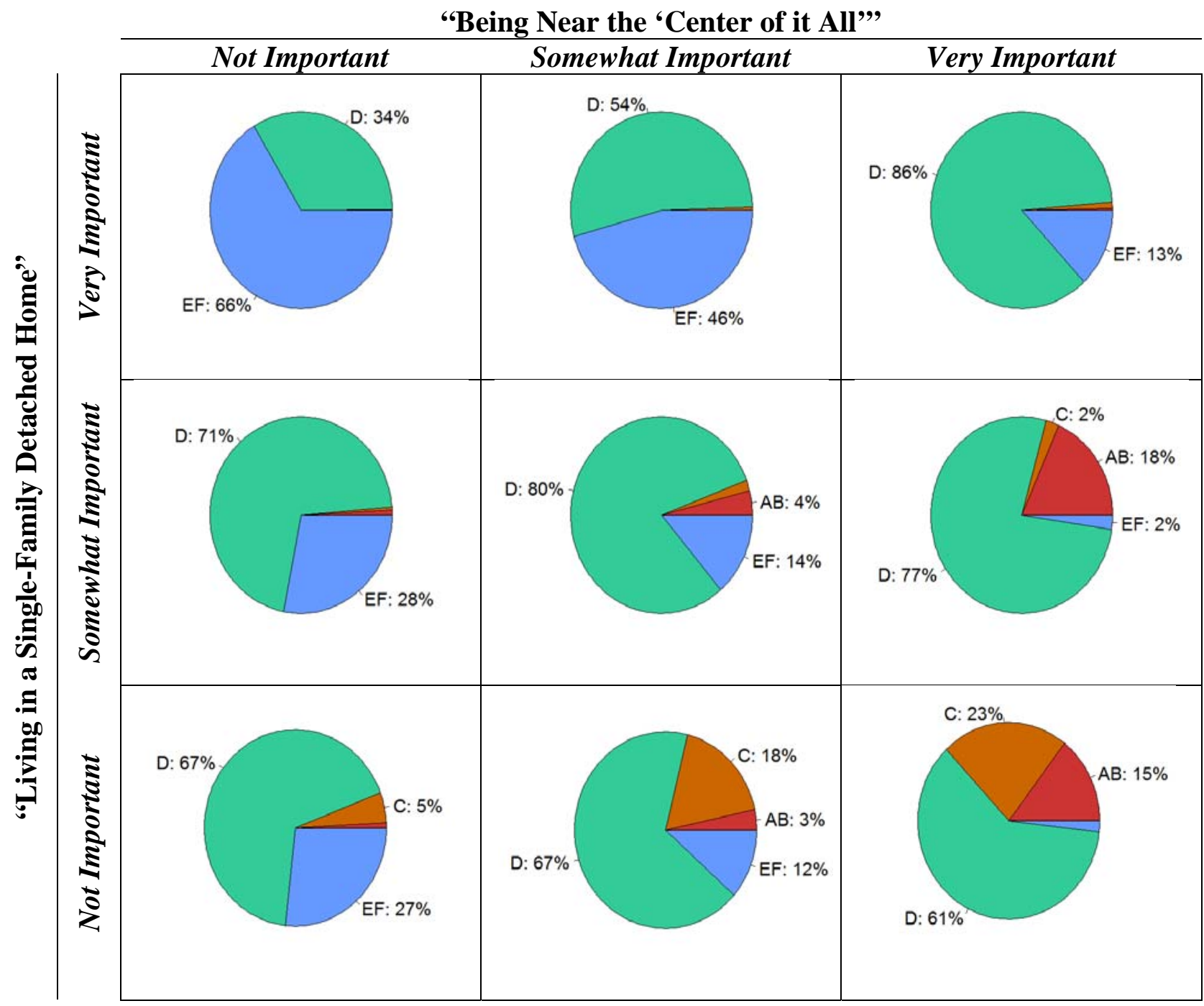

Figure 3.10: Fitted Probabilities for Neighborhood Preference, All Other Variables at the Mean Values

Respondents who preferred the Central Residential District (C) also showed an affinity for walking. In particular, survey respondents who stated they walk for non-work travel (i.e., trips to a restaurant, grocery store, or theater) also generally preferred the Central Residential District (C) more than Neighborhoods D or EF $(\beta=1.15, p<0.05)$. Moreover, respondents who preferred Neighborhood $C$ also typically felt that an ability 
to walk to transit stops was a very important residential location characteristic ( $\beta=$ $2.48, p<0.01)$.

As mentioned previously, little evidence was found to suggest an individual's annual household income, age, or housing costs played an influential or significant role in his or her preference for one of the four neighborhood concepts. However, some variation was observed to exist within these variables. Individuals who preferred the Central Residential District (C) tended to have higher household incomes. Respondents with an estimated annual household income between $\$ 100-150,000$ were more likely to select the Central Residential District (C) rather than the Urban Residential Neighborhood (D) or $\mathrm{EF}(\beta=1.05, p<0.1)$. Respondents with a preference for apartments in comparison to single-family detached or attached dwelling types also preferred the Central Residential District (C) more than the Urban Residential Neighborhood (D) or EF $(\beta=1.71, p<$ 0.05 ). This result has highlighted an intuitive understanding that households who prefer or are looking for apartments or condominiums are more likely look into the neighborhoods that would contain a greater supply.

On the other hand, survey respondents who stated they have a monthly housing cost (rent or mortgage) below $\$ 250$ tended to prefer the Central Residential District (C) instead of the suburban neighborhoods $(\beta=1.45, p<0.05)$. While this result does not explain whether a respondent or household with a very low monthly cost may be able to afford the housing costs likely associated with living in Neighborhood C, there does appear to be a trend suggesting that these individuals have a stated preference if there were more reasonable financial opportunities.

\subsubsection{When do People Prefer Neighborhood D: Urban Neighborhoods}

In comparison to the factors explaining a preference for the Central Residential District (C), many more significant predictors informing an individual's desire to live in the Urban Residential Neighborhood (D) were found to be significant. Having a larger sample size of respondents with these stated neighborhood preference likely factored heavily into this finding. In general, a strong relationship was found to exist between a preference to live in the Urban Residential Neighborhood (D) rather than EF and those survey respondents between 30 and 45 years of age $\left(\beta_{A G E 30-34}=1.37 ; \beta_{A G E 35-39}=\right.$ $1.27 ; \beta_{A G E 40-44}=1.29, p<0.01$ ). Although there was not enough statistical power to compare the preferences of this age cohort to live in the Urban Residential Neighborhood (D) versus the more urban alternatives (Central District (AB) or Urban Residential Neighborhood (C)), the coefficient effect size suggested this cohort had the strongest preference for the Urban Residential Neighborhood (D). Observationally, younger respondents were found to have a tendency to prefer the Urban Residential Neighborhood (D) (see Figure 3.11 and Figure 3.7). A respondent between the ages of 30 and 34 years was approximately $27 \%$ more likely to prefer the Urban Residential Neighborhood (D) and 27\% less likely to prefer the Suburban Neighborhood (EF). 


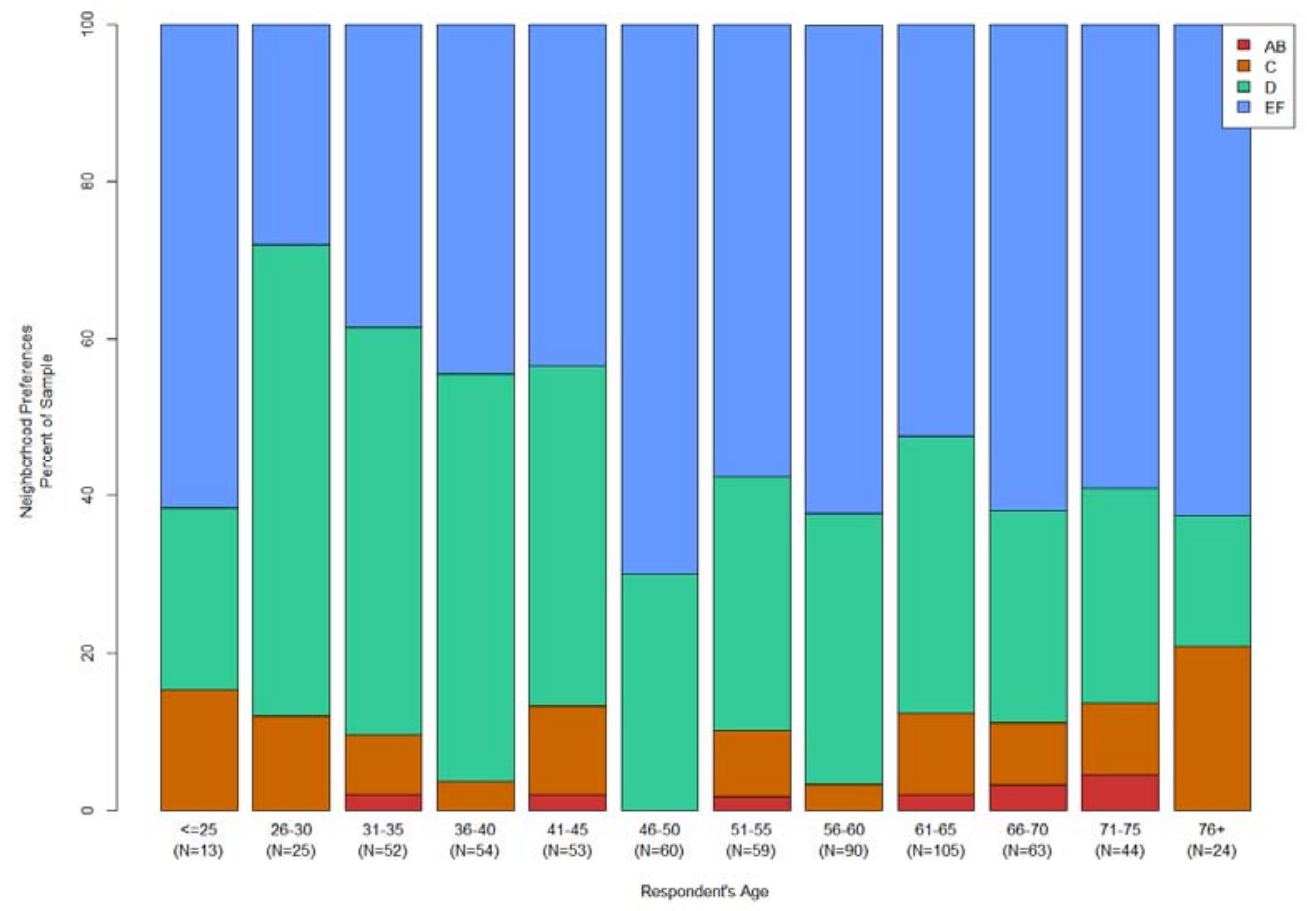

Figure 3.11: Observed Distribution of Stated Neighborhood Preferences by Respondent Age

Similar to the the Central Residential District (C) preferences, individuals who preferred the Urban Residential Neighborhood (D) tended to experience a set of urban-suburban trade-offs. For the suburban trade-offs, individuals who preferred to live in larger, singlefamily detached house and stated that having a private yard or privacy from their neighbors was important were more likely to select the Suburban Neighborhood (EF) than the Urban Residential Neighborhood (D). When respondents noted a large dwelling size was a very or somewhat important residential location item, they were significantly less likely to prefer the more urban the Urban Neighborhood (D) than the Suburban Neighborhood (EF). Alternatively, those respondents who valued living in a neighborhood with greater access to activities (living at the "center of it all”), owned more household bikes, and currently walked or wanted to walk to nearby places or transit stations exhibited a higher likelihood for preferring the Urban Residential Neighborhood (D) compared with the Suburban Neighborhood (EF). These urban preferences explained $12 \%$ of the overall variation in the model, and therefore accounted for approximately one quarter of the variance in neighborhood preference explained by all the modeled parameters

In turn, suburban preferences explained about $9 \%$ of the overall variation explained by the final model specification. These so-called suburban preferences were expressed as an individual's importance ranking for having a large dwelling size, detached single-family house, private yard, or off-street parking availability. An individual was less likely to reside in the Urban Residential Neighborhood (D) if he or she ranked having a large dwelling size an important locational factor $\left(\beta_{\text {very }}=-0.92, p<0.01 ; \beta_{\text {somewhat }}=\right.$ 
$-0.61, p<0.05)$. When respondents displayed a strong preference for a detached singlefamily dwelling unit or private yard, they were significantly less likely to prefer the Urban Residential Neighborhood (D) versus EF

$\left(\beta_{\text {YARDvery }}=-2.67, p<0.01 ; \beta_{\text {YARDsomewhat }}=-2.62, p<0.01 ; \beta_{\text {SFDvery }}=\right.$ $-1.60, p<0.05)$, although they were still more likely to prefer $\mathrm{D}$ over the Central Residential District (C). Respondents who valued privacy from their neighbors as a very important characteristic also tended to prefer the Suburban Neighborhood (EF) over the Urban Residential Neighborhood (D) $\left(\beta_{\text {very }}=-0.78, p<0.01\right)$. Finally, when survey respondents preferred to have dedicated off-street parking at their residence, they were significantly less likely to select the Urban Residential Neighborhood (D) when compared to $\operatorname{EF}\left(\beta_{\text {very }}=-0.77, p<0.01\right)$.

Still, those individuals who have a revealed urban preference find that the Urban Residential Neighborhood (D) offered them the ability to be near a variety of activity locations, as represented by the "living at the 'center of it all'” residential location item $\left(\beta_{\text {very }}=2.56, p<0.001 ; \beta_{\text {somewhat }}=0.84, p<0.01\right)$. An ability to walk to nearby places such as markets, restaurants, and retail establishments was significantly important for those respondents who also preferred the Urban Residential Neighborhood (D) $\left(\beta_{\text {very }}=2.81, p<0.01 ; \beta_{\text {somewhat }}=1.99, p<0.05\right)$. Survey respondents who preferred to be within a walking distance of transit stations favored the Urban Residential Neighborhood (D) compared with the Suburban Neighborhood (EF) $\left(\beta_{\text {very }}=1.77, p<\right.$ $0.001 ; \beta_{\text {somewhat }}=1.26, p<0.001$ ). If a respondent currently walked for non-work travel, then they also tended to prefer living in the Urban Residential Neighborhood (D) ( $\beta=0.69, p<0.05)$, although they exhibited a stronger preference for more urban neighborhoods $(\beta=1.15, p<0.05$ ). Also, households who owned more bikes preferred the Urban Residential Neighborhood (D) compared with the more urban and rural neighborhood concepts $(\beta=0.26, p<0.01)$.

Finally, respondents who noted being located near "older, established homes" as an important factor in their residential location decision were more likely to prefer the Urban Residential Neighborhood (D) over the Suburban Neighborhood (EF) $\left(\beta_{\text {very }}=1.88, p<\right.$ $\left.0.001 ; \beta_{\text {somewhat }}=1.14, p<0.001\right)$. While this variable accounted for $4.4 \%$ of the overall variance observed in the neighborhood model, the described finding may be unsettled due to the vague nature of the associated statement, which may be interpreted as either an individual's preference to be located near historic homes or established households. If the intention of this statement, which was to understand the importance of residing in a neighborhood characterized by older housing structures, was accepted, then individuals who valued this characteristic when selecting a neighborhood concept had a strong preference for the more urban the Urban Residential Neighborhood (D).

\subsubsection{Future Work: Methodology for Stated-Choice Experiment Analysis}

This section describes a proposed method and approach to be used to analyze the data resulting from the stated-choice experiment portion of the study survey. This section provides an overview of the method proposed to test the trade-offs using a stated choice experiment, expanding on the experimental analysis provided in the previous section. This portion of the report-in 
combination with the preference analysis from the previous section-supports Task \#9 in the SPR 745 Workplan (9/11/2013). We do not intend to provide a full documentation of all the tests and methods required to develop this proposed model, for that we recommend a few basic technical texts (Ben-Akiva and Lerman 1985; Hensher et al. 2005; Koppelman and Bhat 2006). Instead, this section acts as a recommended direction for how this study-and the corresponding survey instrument developed — could be estimated and used in the future to benefit or supplement existing Oregon Department of Transportation and other analytical tools in use in Oregon and elsewhere. In the test application of this survey infrastructure, we explored the trade-offs in the respondent's preferences for commute mode and travel time and the bundle of characteristic associated with each neighborhood concept. To do this, we will administer a choice-based conjoint survey (CBC) - this falls in the family of stated-preference methods and has been referred to as a discrete choice experiment.
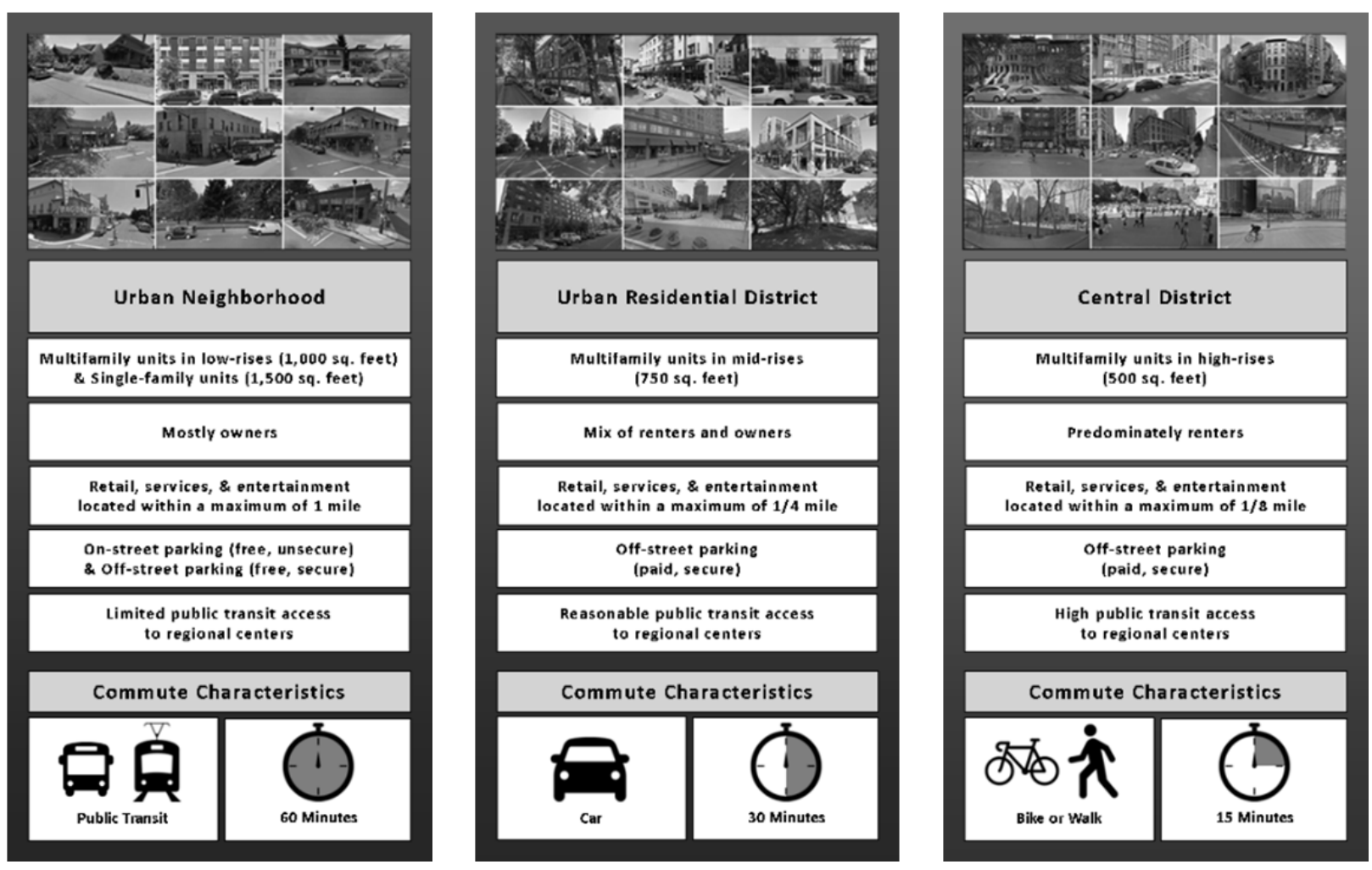

Figure 3.12: hree cards: each with one of the three alternatives for neighborhood, commute mode and commute travel time

In this portion of the survey, described in detail in Section 3.2, we defined collectively exhaustive and mutually exclusive categories_called "levels" —of three attributes: neighborhood concepts, commute time and commute mode. We defined the various alternatives of these attributes (Neighborhoods: AB, C, D; Mode: car, bike/walk, transit; Time: 15, 30, and 60 minutes) that will vary in the experiment. Then, we combined every possible combination of these three attributes and their levels to make 27 different potential choice sets or "cards". The 
respondent was prompted with five choice tasks, each task comparing a random sample of two cards, asking the respondent to pick their preferred card for each task. We can then use this information collected from the choice experiment - the five tasks and the respondent's corresponding preferred cards - to examine the trade-offs these respondents make when deciding what neighborhood concept to live in and how to commute. Figure 3.7 provides an example of a choice sets a respondent might have seen in our survey.

In this analysis, we employed a full-factorial, orthogonal survey design. Here we generated all possible combinations of neighborhoods and commute times. For example, with three attributes (neighborhood concept, commute time, and commute mode) and three levels for each attribute (3 for each attribute), we have 27 unique "cards” to consider. When administered, the survey infrastructure drew card sets to compare at random (without replacement) from the total choice set of cards, presenting two cards at a time to the respondent, asking them to decide which they would prefer. All possible combinations of cards were considered in this survey (351 tasks or paired-card combinations total), but respondents was only be prompted with a few combinations or comparisons to reduce respondent burden.

To examine the trade-offs that individuals make when deciding where to live and how to commute, we propose a type of discrete choice model called the nested logit (NL) model. In general, discrete choice models evaluate the decisions people make when choosing a discrete alternative from a set of finite alternatives based on observed and unobserved attributes of each alternative and the decision maker. In these models, parameters are estimated which reflect the relationship between a unit of each alternative attribute (such as travel time or cost) or individual characteristics (such as income) and the relative utility that attribute or characteristics provides for the respondent.

The probability that a certain alternative neighborhood concept/commute mode choice will be selected can be calculated, and the corresponding elasticity that define relationships between neighborhood and individual characteristics and the probability to make a certain choice can be computed and evaluated. These elasticities derived from this study could be incorporated into existing ODOT models, providing a means to weight the distribution of synthetic households across the region based on their propensity in selecting neighborhood concepts and commute modes based on the household's socio-demographic and economic characteristics. Similarly, the SDEC of the survey respondent and their household were collected in a way comparable to the Oregon Household Activity Survey (Oregon Modeling Steering Committee 2013), such that models developed and coefficients estimated based on this research project might have parity with existing ODOT models.

The following section in this report describes the proposed nested logit method to analyze the choice experiment data administered within this survey. Moreover, the data collected from the stated choice experiment contains multiple observations, or repeated measures, for each survey respondent. To handle this panel data, we propose two different methods used in the literature. This is discussed at the end of the follow section. 


\subsubsection{Nested Logit Models and Trade-offs Between Neighborhood and Commute Mode}

Discrete choice models evaluate the revealed or stated decisions people when choosing from a set of available alternatives. For a multidimensional choice analysis, the propose a nested logit (NL) model_compared with a more traditional and widely applied joint multinomial logit (MNL) model — is in the theory of the choice structure. In a joint MNL model (Figure 3.13), we assume that ever "card" or choice set is independent of each other, but we know that some of the cards are related to each other simply because they share a common element. A NL model specification (Figure 3.14) controls for these similarities, both in the parameter estimates and the error terms, and allows the analyst to determine which choices might be more or less related (i.e., develop the nesting structure) and provides a means to test these assumptions.

Joint Mode/

Neighborhood Choice

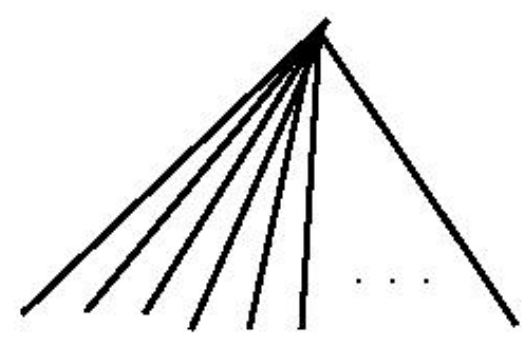

兵 兵

Figure 3.13: Joint multinomial logit structure. 


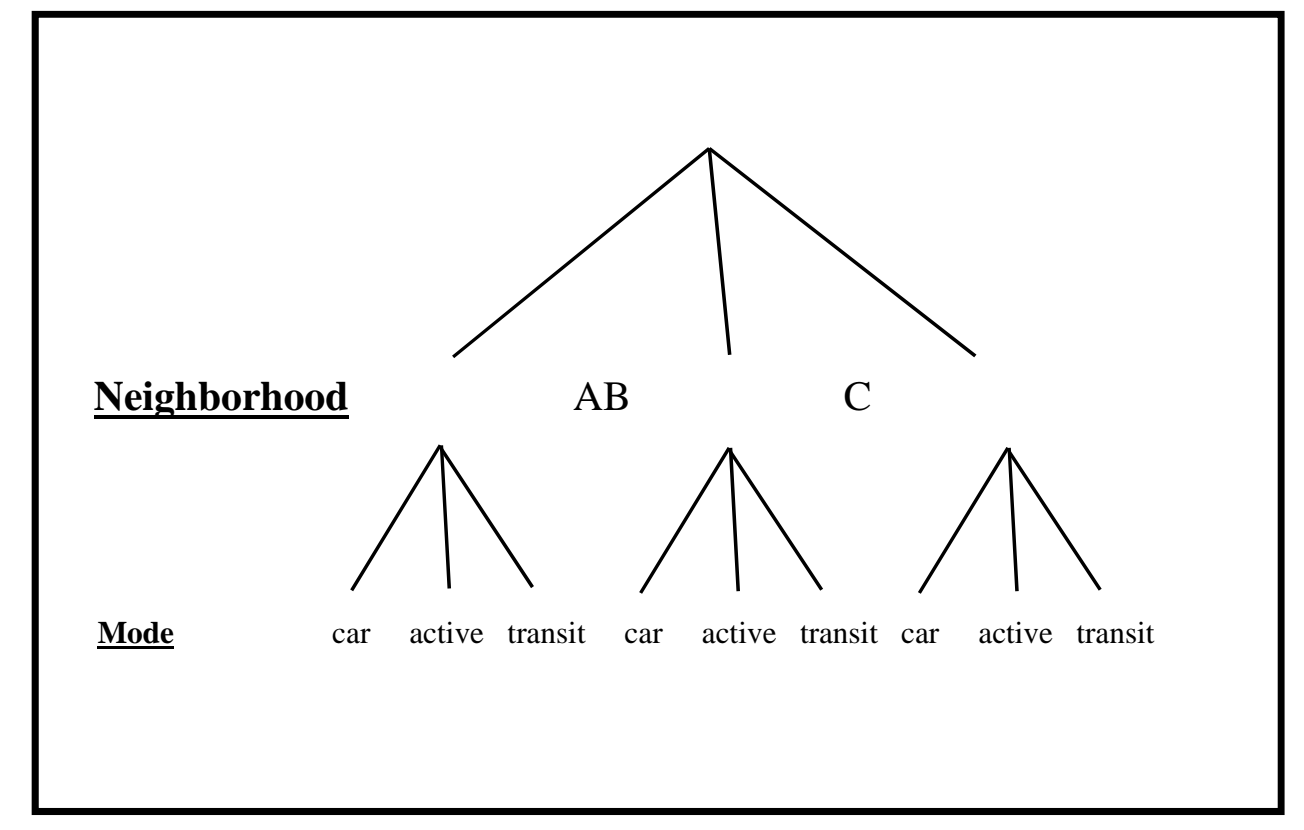

Figure 3.14: Proposed nested logit structure.

To examine the results from our stated choice experiment, we recommend using a nested logit (NL) model, which estimates the relationships between alternatives, attributes, and characteristics of the individual for the joint decision of residential location neighborhood and commute mode. We recommend using commute travel time, the third alternative attribute varied within our card choice set, as a continuous attribute of the joint alternatives for commute mode and neighborhood concept. As we will elaborate on in the following section, this proposed specification will also the analyst to examine a more compact group of parameter estimates — one for each of night neighborhood and commute mode alternatives - for each variable added to the model, compared with a triple tiered nested design (neighborhood > mode $>$ travel time) which would derive 27 alternative-specific parameters and coefficients for every variable the enters into the model. During initial iterations of nested logit models "commute travel time" would be estimated as an alternative-specific parameter for each combination of alternatives, mode and neighborhood. While commute travel time can be included in a nested logit model under a third nest, this expands the number of potential parameters estimated for each variable exponentially, reducing the overall degrees of freedom. "Time" is also not commonly used in the literature as a "discrete choice" and, therefore, has been included in this proposed method as a continuous variable, which may result in alternative-specific or generic parameters.

\subsubsection{Formulating the Model}

A nested logit model comprises of a set of alternative-specific systematic components, each with their own set of parameters and error terms, contributing to the overall utility function. The probability or likelihood that a given alternative will be selected from a set of available alternatives is defined by the exponent of the sum of the chosen alternative's utility, divided by the exponent of the sum of all available alternative utility. For nested 
logit models, this probability is actual the product of the conditional probability of a mode choice, given a choice of neighborhood, and the marginal probability of that mode-but we'll get to calculating the probabilities in the following section. We modify and specify the model in this report based on equations from the Ben-Akiva and Lerman (Ben-Akiva and Lerman 1985).

\subsubsection{Maximizing the Likelihood and Calculating Probabilities}

A NL model is estimated by maximizing the formulated likelihood function, which is defined by the product of the probabilities of each mode $(m)$ and neighborhood $(n)$ alternative choice for all observations, $i$, shown here:

Equation 3.3: Likelihood Function for Nested Logit Model

$$
L^{*}=\log \left(\prod_{i=1}^{I} \prod_{(m, n)}\left[P_{n}(m, n)\right]^{y_{m, n, i}}\right)
$$

Where $\mathrm{y}_{\mathrm{m}, \mathrm{n}, \mathrm{i}}$ is the "chosen" vector indicating which choice was selected for each task, or card comparison, shown to participants. We define $m$ as the mode-alternative within the full set of modal alternatives, $\boldsymbol{M}=$ \{car, active,transit $\}$; $n$ is defined as the neighborhood-alternative within the full set of neighborhood alternatives, $\boldsymbol{N}=$ $\{A B, C, D\}$, and $m n$ is defined as a joint mode/neighborhood alternative from within the full set of nine alternatives, $\boldsymbol{M} \boldsymbol{N}=\{(\operatorname{car}, A B),(\operatorname{car}, C),(\operatorname{car}, D) \ldots($ transit,$D)\}$. The joint probability of $P(m, n)$ is the product of the marginal probability and conditional probability, or:

Equation 3.1 Nested Logit Probabilities

$$
P(m, n)=P(m \mid n) * P(m)
$$

The marginal probabilities, or the probability that a user will choose a specific alternative in the choice set, such as a mode choice $\boldsymbol{m}$ in the modal alternative set $\boldsymbol{M}$, can be calculated given the following equation:

Equation 3.5 Marginal Probability of Mode Choice in Figure 4.4 Specified NL Model

$$
P(m)=\frac{\exp ^{\left(V_{m}+V_{m}^{\prime}\right) \mu^{d}}}{\sum_{m^{\prime} \in M} \exp ^{\left(V_{m}+V_{m}^{\prime}\right) \mu^{m}}}
$$

Where,

$$
V_{m}^{\prime}=\frac{1}{\mu^{m}} \ln \sum_{m \in M} \exp ^{\left(V_{m}+V_{n}\right) \mu^{m}}
$$

and $\mu^{m}$ is an estimated scale parameter for the nesting " $m$ " or "mode" (in this example). Correspondingly, the marginal probability of a neighborhood choice $\boldsymbol{n}$ was selected from the alternative set $\boldsymbol{N}$ can be calculated using the same equation, but substituting the 
subscripts $\boldsymbol{n}$ and $\boldsymbol{m}$. Alternatively, we may be interested in the conditional probability of an alternative, or the probability that a one choice will be made, conditional that another choice has already been made. For example, if we are interested in examining the mode choice of $\boldsymbol{m}$ from the choice set $\boldsymbol{M}$, conditional that the choice of neighborhood alternative $\boldsymbol{n}$ has already been selected from the choice set $\boldsymbol{N}$, we would calculate the conditional probability:

Equation 3.6 Conditional Probability of Mode Choice, given Neighborhood Choice.

$$
P(m \mid n)=\frac{\exp ^{\left(V_{m n}+V_{m}\right) \mu}{ }^{m}}{\sum_{m n \in M N} \exp ^{\left(V_{m n}+V_{m}\right) \mu^{m}}}
$$

Correspondingly, the conditional probability of selecting neighborhood $\boldsymbol{n}$ provided a commute mode, $\boldsymbol{m}$, has already been selected can be calculated using the same equation, but substituting the subscripts $\boldsymbol{m}$ and $\boldsymbol{n}$. These probabilities, calculated from the estimated model parameters and scale factors, can then be compared to the probabilities derived from the observed choices of specific alternatives. This comparison will evaluate both the accuracy of the model.

\subsubsection{Systematic Components and Utilities}

To construct and maximize the likelihood function of a NL model, we first specify the utility functions, including the systematic components which determine which parameters the model estimation will provide. The utility function or the utility for a given mode/neighborhood choice, $U_{m n}$, is comprised of the sum of the systematic components for a given mode, $\mathrm{V}_{\mathrm{m}}$; neighborhood, $\mathrm{V}_{\mathrm{n}}$, and; mode/neighborhood joint choice, $\mathrm{V}_{\mathrm{mn}}$, based on the observed attributes of each choice and the individual characteristics. These parameters may be estimated as alternative-specific — which provides a separately estimated parameter for each alternative — or they may be estimated as generic — which constrains the parameters to be the same across all alternatives, or some subset of alternatives.

Equation 3.7 Utility and Systematic Component Functions

$$
\begin{gathered}
U_{m n}=\boldsymbol{V}_{\boldsymbol{m}}+\boldsymbol{V}_{\boldsymbol{n}}+\boldsymbol{V}_{\boldsymbol{m} \boldsymbol{n}}+\boldsymbol{\varepsilon}_{\boldsymbol{m}}+\boldsymbol{\varepsilon}_{\boldsymbol{n}}+\boldsymbol{\varepsilon}_{\boldsymbol{m} \boldsymbol{n}} \\
V_{m}=\boldsymbol{\beta}_{\boldsymbol{m}} * \boldsymbol{X}_{\boldsymbol{m}}+\boldsymbol{\beta}_{\text {indiv, } \boldsymbol{m}} * \boldsymbol{X}_{\text {indiv }} \\
V_{n}=\boldsymbol{\beta}_{\boldsymbol{n}} * \boldsymbol{X}_{\boldsymbol{n}}+\boldsymbol{\beta}_{\text {indiv }, \boldsymbol{n}} * \boldsymbol{X}_{\text {indiv }} \\
\boldsymbol{V}_{\boldsymbol{m} \boldsymbol{n}}=\boldsymbol{\beta}_{\boldsymbol{m} \boldsymbol{n}} * \boldsymbol{X}_{\boldsymbol{m} \boldsymbol{n}}+\boldsymbol{\beta}_{\text {indiv, } \boldsymbol{m} \boldsymbol{n}} * \boldsymbol{X}_{\text {indiv }}
\end{gathered}
$$

Alternative-specific or generic characteristics of the alternatives are specified in the parameters and variables $\boldsymbol{\beta}_{\boldsymbol{j} \boldsymbol{i}}$ and $\boldsymbol{X}_{\boldsymbol{j} \boldsymbol{i}}$, which includes the alternative-specific constants, $\boldsymbol{\beta}_{\mathbf{0}, j}$. Each alternative, $j$, in the set of alternatives $(m, n, m n)$ may include the same attributes or variables, $i$, or attributes specific only to that alternative. 
One major limitation of a large nested choice model is that alternative-specific parameters estimated for each variable decrease the degrees of freedom for each number of alternatives in the sets, $\boldsymbol{M}, \boldsymbol{N}$, and $\boldsymbol{M} \boldsymbol{N}$. For example, with three modes, three neighborhoods, and nine joint mode-neighborhood choices, an alternative-specific parameter estimated for "commute travel time” would result in 15 parameters estimated, each one identifying the contribution of a unit of commute travel time toward the systematic component of utility for that alternative.

Individual-specific characteristics, $\mathrm{k}$, are also incorporated within the model, $\boldsymbol{\beta}_{\text {indiv, } \boldsymbol{k}}$ and $\boldsymbol{X}_{\text {indiv, } \boldsymbol{k}}$, represent the relationship between the characteristics and its contribution to the systematic component of the utility for that alternative. These characteristics may include those variables incorporated in the Section 3.2.2 (e.g., income, household size, preferences). Additional models may be specified with a reduced set of variables to make the model more readily applicable within existing ODOT models. Similar to alternativespecific variables, these models estimate $\boldsymbol{\beta}_{\text {indiv, } \boldsymbol{k}}$ and $\boldsymbol{X}_{\boldsymbol{i n d i v}, \boldsymbol{k}}$, the set of estimated individual-specific parameters and corresponding variables, $\mathrm{k}$.

To make the model specification more parsimonious - and to increase the efficiency of the degrees of freedom available-we constrain certain alternative-specific parameters or constants to either be equal to each other or to zero, thus reducing the total number of parameters estimated. This process is iterative, and requires several models to be estimated and different parameter specifications tested for the (a) ability to improve the overall model fit, and (b) the ability to represent the relationship between variables and utility in the most efficient way without losing explanatory power.

For the purpose of this analysis, we presented survey participants with a card that includes one alternative from $\boldsymbol{M}$ and one alternative from $\boldsymbol{N}$, prompting them with a joint choice. It may be relevant to examine the case in which all parameters for the systematic components of the individual alternatives within $\boldsymbol{M}$ and $\boldsymbol{N}\left(V_{m}\right.$ and $\left.V_{n}\right)$ are constrained to zero, thus reducing the complexity of the model specification based on the survey design. Each alternative-specific parameter or constant would then represent the average contribution to the systematic components of the utility for each alternative $\boldsymbol{M N}$ set.

\subsubsection{Interpreting NL Models}

The purpose of utility-based or choice models it to estimate the probability that a choice will be chosen when the full set of alternatives are known-while controlling for alternative-specific, generic, or individual-specific characteristics. For stated choice experiments such as these, each "task" is an observation made up of two alternative cards - one of them "chosen" and one of them "not chosen". For each observation or "task", all other alternatives not presented to the participant are set to zero. The estimated parameters are therefore representative of the utility-variable relationship according to the respondents who viewed those alternatives.

The estimated constants ( $\boldsymbol{\beta}_{\mathbf{0}, \boldsymbol{j}}$ for each systematic component or alternative, $\boldsymbol{j}$ ) represent the average role of all the unobserved sources of utility for that systematic component for that alternative. The estimated parameters $\left(\boldsymbol{\beta}_{j i}\right.$ for each systematic component or 
alternative, $\boldsymbol{j}$, and each variable, $\boldsymbol{i}$ ) represent the average role of an observed unit of the corresponding variable to the systematic component for that alternative. It is difficult to interpret the estimated parameters and derive information about attributing how characteristics relate to utility. To derive more information from the model estimates, we then consider the marginal or conditional probabilities for each alternative and the corresponding parameters estimated and interpret the elasticity with respect to the different variables specified.

By specifying a nested logit model, we assume that certain alternative parameters and error terms correlate with each other. For example, the alternative $\boldsymbol{M N}$ sets (car, AB) and (bike, $\mathrm{AB}$ ) both have the same choice alternative for neighborhood, $N$. We would assume, therefore, that the parameters or constants-along with their corresponding error terms - estimated for each alternative set (car, AB) and (bike, AB) are dependent and would therefore co-vary. While this assumption adds complexity to the model specification and the overall estimation process, we also control for the relationships between alternative sets which may otherwise have led to spurious or inefficient (not statistically significant) results. This assumption also adds complexity to calculating the marginal or conditional probabilities once the estimation process is complete, compared with MNL joint estimation models (Ben-Akiva and Lerman 1985).

\subsubsection{Evaluating Trade-offs in Neighborhood, Commute Mode and Travel Time}

From these probabilities, we can also estimate the elasticities of each alternative as it impacts the likelihood that the individual will select a given neighborhood or commute mode choice. Elasticities can be described as the relationship between the percent changes in the variables (e.g., $10 \%$ increase in income or a $20 \%$ decrease in travel time) with a percent change in the marginal or conditional probability that an alternative or set of alternatives will be chosen. Hensher et al. (Hensher et al. 2005) defined the elasticity of a MNL model to be:

Equation 3.8 Deriving Elasticities from Probability Functions of an Estimated Discrete Choice Model

$$
E_{X_{j i q}}^{P_{j q}}=\frac{\partial P_{j q}}{\partial X_{j i q}} * \frac{X_{j i q}}{P_{j q}},
$$

which can be interpreted as the elasticity of the probability of the alternative, $j$, for the decision maker, $q$, with respect to the marginal change in the variable, $i$.

Moreover, because we specify commute travel time as an attribute of the alternatives in the choice set $\boldsymbol{M N}$, we are also able to evaluate cross-elasticities of the neighborhood or commute mode alternative choices with commute travel time - thus deriving a rate of trade-off between neighborhood choice (and the corresponding bundle of characteristics) and/or commute mode choice with commute travel time. These elasticities or trade-off rates may be implemented in existing models during the allocation of synthetic household to travel analysis zones (thereby classified into neighborhood concepts) as a propensity for certain households to locate in given neighborhoods. 
We do not formulate the elasticities of the proposed model specification in this report because of the complexity of the calculations and the derivatives required. However, some discrete choice software are more adept at estimating these point, arc, and cross elasticities to help interpret and apply the specified and estimated model. For example, the program $N \operatorname{logit}{ }^{5}$, a product related to limdep, provides functions to estimate a variety of elasticities, integrating when necessary. The statistical programing languages like $\mathrm{R}$ also have discrete choice analysis packages such as mlogit that estimate nested logit models, but elasticities must be calculated by hand.

\subsubsection{Controlling for Repeated Measures}

The natural of a stated choice experiment requires collecting multiple observations or choices from each survey respondent. In our study, we prompted respondents with five "tasks", each time asking them to select one of the two choices that best meets their preferences. There are several ways this repeated-measure data can be handled to control for the multiple observations taken within the survey. In trip-based analyses, analysts often weight each individual's observations based on the number of trips they have contributed to the total number of trips in the model. However, this type of controlalthough easier to estimate and interpret-does not apply easily to a stated choice experiment in which each respondent was prompted and observed for the same number of choice scenarios (five tasks).

Since mid-2000, mixed logit (ML) models have become more accessible to analysts, with a growing literature describing and testing the application and interpretation of ML models. Specifying a mixed nested logit model in off-the-shelf software, however, still lacks in transparency. Ideally, the analyst should be able to write a program to perform the proper theoretically-specified model. Moreover, there is little evidence that suggests that a ML model would improve the accuracy of the parameters estimated. Because of this, we describe (in the following subsections) two methods to test or control for the impact of the repeated measures in the model specification: running specified models on a subset of task-observations, and specifying a panel mixed-logit model.

\subsubsection{Running specified Models on a Subset of Task-observations}

Without knowing how much of an impact the repeated observations have on the model, we propose a method to test how much of an impact the repeated measures have on the parameter estimates. In this method, we formulate our nested choice model using the full set of observations, without controlling for the set of five observations recorded from each respondent. In this formulation, we perform the necessary model development tasks described in the previous section on the NL model, including testing for improvements to the overall model structure (-2LL tests) and tests that constrain parameters to be equal to each other or zero (reducing the overall burden on the total number of degrees of freedom.

\footnotetext{
${ }^{5}$ http://www.limdep.com/features/capabilities/nlogit/index.php
} 
Once the desired specification has been reached, a series of additional model runs will be

completed based on a sub-set of the data in which all observations are independent. In this series of model runs, the analyst selects one observation for each respondent at random to include in the data for that model run. After a series of runs (5-10) the parameters and errors from each of these model runs, and the original model run on the full data set, to compare the differences changes in the estimated parameters, the changes or variation in the probabilities and elasticities, and the error terms.

We would assume the greatest impact will be related to the parameters for the travel time attributes, which vary across the tasks presented to each respondent, and therefore the choices each individual make regarding that variable would be correlated. If there is little variation in these estimates, there may not be justification to incorporate a more complex, and robust, model such as a panel mixed logit model. If there is a large amount of variation between the full-dataset model and the subset-dataset runs, there may be evidence to recommend a more intricate model.

\subsubsection{Panel Mixed Logit (ML) Models}

A second, more complex and robust, type of model structure can be used to control for the repeated measures collected in stated preference experiments. These methods have been employed for other repeated-measure choice experiments, both revealed and stated preference, and due to recent advances in technology, the have become more accessible to the common researcher.

To estimate a ML model, the analyst determines which variables have fixed effects, and which variables might have random effects. A fixed effect is similar to a regular parameter or coefficient. It provides an estimate of the average contribution of that variable toward the overall utility. If the fixed effect is an average, the random effect provides a standard deviation of that relationship. By specifying a fixed and a random effect of a given parameter in the systematic components, the model specification will provide the distribution of effects on utility (and corresponding probabilities and elasticities) that variable has within the sample population. In short, these parameters control for the repeated measures taken from the respondent (the set of five task comparisons) and the model specification provide an estimation of preference heterogeneity for a given variable.

The estimation for this type of method is more complex than the maximization the utility function as described for Equation 3.3, discussed further in (Louviere et al. 2000).

Equation 3.9 Likelihood Function for Mixed Logit Model

$$
L^{*}=\log \left(\prod_{i=1}^{I} \prod_{t \in T} \prod_{(m, n)}\left[P_{n}(m, n)\right]^{y_{m, n, i}}\right.
$$

Where $t$ is task that respondent, $\mathrm{i}$, completed in the set of five tasks $T$. In this configuration of the likelihood function for a panel mixed logit model, we control for the multiple observations recorded for each participant, and estimate the distributional properties of the parameters (defined by the analyst). 
Furthermore, application or documentation of a hybrid mode, such as a panel mixed logit methods with a nested logit specification, may be limited in off-the-shelf software packages (mlogit in [R], nlogit in SPSS, nlogit, or limdep). Once a preferred model is specified in theory, and existing packages are examined, the analyst should consider the current discrete choice literature on implementing systems of models based on the theory of the research question as described in (Ben-Akiva et al. 2002). As with many hybrid models, what is described in software packaging is not always what is provided in the code, and custom code may be required to estimate the correct parameters. 


\subsection{CONCLUSIONS}

This project advanced the understanding of residential location decisions and the ability to capture residential and transportation preferences using the stated choice survey infrastructure developed here. The project offered several lessons learned for the design and administration residential and transportation state choice surveys, identified where the survey infrastructure and findings from the pilot data may be implemented within the current planning tools in Oregon, and outlines possibilities for future work.

\subsection{ASSESSMENT OF SURVEY INFRASTRUCTURE AND ADMINISTRATION}

The main objective of this phase of this project was to gain experience with the design and administration of state preference surveys online. The development of the stated preference survey infrastructure made a positive contribution and introduced innovation into the design. The pilot of this instrument provided valuable insight and lessons learned that can be introduced into future surveys.

The recruitment strategy of a mail-out postcard with a link to the online survey worked well considering: (1) the respondent had to type website URL, (2) no follow-up reminder, and (3) basic postcard design (e.g., black and white, paper stock). The additional incentive of entering participants into a drawing for a gift card and addressing postcards sent to single-family dwellings as "name or current resident" contributed to an improved response rate over our "pilot of pilot" ( $\sim 5 \%)$. The pilot yielded a greater overall sample size than we expected and we were able to conduct preliminary analyses on these data collected. This exceeded our expectation.

Future applications should consider alternative sources of sampling frames, including purchasing them from private vendors. This would likely expedite survey administration and allow for stratified sampling, but would probably increase administration costs.

A few respondents expressed concerns with hosting survey on Google site and offering Amazon incentives due to their personal objections with these firms. In addition, we received a small portion of the survey participants wrote to inform us that the website was "unavailable". These issues were traced back to the occasional unavailability of the Google site's servers-where the introduction and link to the survey instrument, but not the instrument itself, was hosted. In the future, we recommend a project-specific website (with a very simple URL) be developed for future surveys on a tested server to prevent this unnecessary delay in the respondent's time.

Future applications may need to oversample more urban neighborhoods, where we observed a lower response rate. This was likely due to reliability problems associated with multifamily addresses (more common in urban areas). Also, the choice of doing an overall random sample of Portland naturally resulted in an under sampled urban area, since few people in the region live in this neighborhoods. The resulting sample derived from the OHAS respondents resulted in a large 
number of from retirees ( $50 \%)$. In sum, a more targeted sampling strategy in future applications could provide more info for market segments of interest.

The survey instrument that the team developed was interactive, engaging, and grounded participants in the richness of the neighborhood characteristics that they were considering. The use of visual imagery was beneficial in this regard and represented an important innovation in stated choice survey design. In addition to the imagery, the variety of techniques used to gather background and other information appeared to be beneficial in reducing item nonresponse. Asking respondents if they would be willing to complete an additional set of tasks proved to be a nice test of respondent burden that could be added to other stated preference design. We found that $83 \%$ of respondents agreed to continue with the survey, indicating that they were still engaged with the experiment. We also recommend putting the choice experiments at the end of the survey to ensure all the background information has been collected before the respondent leaves the survey.

We found that exposing respondents to the set of alternatives via pictures and text and asking questions about their unconstrained preferences prior to the choice experiment prepared respondents and contributed to a shorter survey duration. Given that the neighborhood concepts are a complex bundle of attributes, the combination of text descriptions of the neighborhood concepts with the visual imagery emphasized the transportation and built environment attributes of neighborhoods that we wanted to convey.

In terms of things to consider for future designs, we believe that asking respondents to rank their unconstrained preference for neighborhood concepts would provide more information than merely to choose the alternative that they prefer the most. Similarly, ranking their preferences for housing, neighborhood and transport attributes that they consider in making location choices would give more insight to the tradeoffs made later in the choice experiment.

The neighborhood concepts could have better fleshed out an exurban/rural alternative. Given our constraints on the number of choices we could test, we combined this with a more suburban alternative and labeled it as "Suburban", which was misleading for some respondents. However, because our experience implementing the survey and the willingness for respondents to take on more tasks, future work can likely relax the constraints on the number of alternatives and the levels tested in the choice experiment.

In general the online administration of the survey using Qualtrics software worked well. However, the more "efficient" the survey design, the more likely that customized software is required. An "efficient” design reduces the total set of card comparisons (in our study case, we had 351 total possible tasks or comparisons), by creating sets of tasks which help to estimate the model specified with the most efficient sample size. Qualtrics software limits the ability for the analyst to administer experimentally designed or computer-optimized choice sets to test on the user. Here, the analyst is limited to a random draw of cards for each task, and while the user may constrain the random draw to an equal distribution of card-presentations across all survey respondents for each task, there is not (yet) a function that easily allows the analyst to: (a) predefine sets of choice (e.g., orthogonal designs) for participants, (b) restrict cards according to the respondents previous answers (e.g., dynamically eliminating cards that are not feasible to the participant), (c) optimize the tasks shown based on previous answer to optimize the ability to 
estimate main and interacted effects, or (d) present tasks according to predesigned "blocks" of task sets. All of these methods may provide more robust data to estimate main/interacted effects more efficiently. If this survey were to be expanded and repeated, with additional alternatives or alternative-specific characteristics, the administration methods may be required to be able to estimate main effects.

There were some internet browser version control issues on the respondent end. Administering surveys online-especially to households in rural or small town areas - requires a certain amount of attention to software, websites, and version control issues. Qualtrics and other JavaScriptbased survey tools run on the latest version of the HTML5 standards, which means that special survey question buttons or sliders may not be supported by older versions of the survey respondent browsers. Chrome and Firefox tend to reflect the most recent HTML5 standards, while Internet Explorer and Safari tend to lag behind in their updates. Pilot surveys tested in house on a variety of browsers will help ensure that survey questions will appear in a way-or allow respondents to respond in a way_consistent with the research design.

\subsection{OPPORTUNITIES FOR IMPLEMENTATION AND FUTURE WORK}

Based upon feedback from the technical advisory committee, a number of areas have been identified where the application of the survey infrastructure could help to refine analytical tools and inform current and future policy concerns. The current modeling tools are not sensitive to existing or changing tastes for housing, transportation and neighborhoods and instead rely on socio-demographic characteristics to estimate future residential location. Yet, preliminary analysis of the pilot data revealed that socio-demographics are a poor predictor relative to preferences. Thus, survey tools such as the one developed here can help to collect information to help address the deficiency in these models.

In order to better address policy, there are several modifications to the survey that would be beneficial. The survey needs to add sensitivity to housing costs and the size of dwelling unit as it currently asks minimal questions about cost and the stated choice experiment does not include willingness to pay, although the unconstrained preference questions do. The choice experiment could be modified to look at other attributes as well, including tradeoffs between tenure, housing size and structure type.

Given that the pilot survey yielded sufficient data for preliminary analysis, there are several analyses that will be conducted in the future, including:

- Conduct Stated-Choice Experimental Analysis

- More detailed exploration of the stated household income, monthly housing costs (rent/mortgage), and the willingness to pay more for a "home or a location that better suits your preferences”

- Exploration of the characteristics of individuals who stated they preferred to live in a neighborhood more urban (or less urban) than the one they currently own.

- Identify factors influencing housing (dwelling type) preference 
- Identify market segments based upon preferences, rather than solely socio-economic factors

- Finally, the opportunity to link the state preference data with the revealed preference data exists. Supplementing stated preference data with revealed preference data can provide a means to ground or scale the preferences estimated in models. 


\subsection{REFERENCES}

Bagley, M.N., and P.L. Mokhtarian. The Impact of Residential Neighborhood Type on Travel Behavior: A Structural Equations Modeling Approach. The Annals of Regional Science, Vol. 36, No. 2, 2002, pp. 279-297.

Bagley, M.N., P.L. Mokhtarian, and R. Kitamura. A Methodology for the Disaggregate Multidimensional Measurement of Residential Neighbourhood Type. Urban Studies, Vol. 39, No. 4, 2002, pp. 689-704.

Ben-Akiva, M., D. McFadden, K. Train, J. Walker, C. Bhat, M. Bierlaire, D. Bolduc, A. Boersch-Supan, D. Brownstone, D. S. Bunch, A. Daly, A. de Palma, D. Gopinath, A. Karlstrom, and M. A. Munizaga. Hybrid Choice Models: Progress and Challenges. Marketing Letters, Vol. 13, No. 3, 2002, pp. 163-175.

Ben-Akiva, M., and S.R. Lerman, Discrete Choice Analysis: Theory and Applicaiton to Travel Demand. Cambridge, Massachusetts: The MIT Press, 1985.

Borgers, A., and H. Timmermans. Transport Facilities and Residential Choice Behavior: A Model of Multi-Person Choice Process. Papers in Regional Science, Vol. 72, No. 1, 1993, pp. 45-61.

Borgers, A., D. Snellen, J. Poelman, and H. Timmermans. Preferences for Car-Restrained Residential Areas. Journal of Urban Design, Vol. 13, No. 2, 2008, pp. 257-267.

Brower, S. The Sectors of the Transect. Journal of Urban Design, Vol. 7, No. 3, 2002, pp. 313320.

Cervero, R., and C. Radisch. Travel Choices in Pedestrian Versus Automobile Oriented Neighborhoods. Transport Policy, Vol. 3, No. 3, 1996, pp. 127-141.

Cervero, R., and K. Kockelman. Travel Demand and the 3Ds: Density, Diversity, and Design. Transportation Research Part D, Vol. 2, No. 3, 1997, pp. 199-219.

Chaskin, R.J. Perspectives on Neighborhood and Community: A Review of the Literature. The Social Services Review, 1997, pp. 521-547.

Chen, R.B., S.R. Gehrke, J.H. Liu, Y. Jang, and K.J. Clifton. Exploring Engagement in Household Activities and Decisions on Residential Tenure and Household Type. Transportation Research Record: Journal of the Transportation Research Board, Vol. 2344, Transportation Research Board of the National Academies, Washington, D.C., 2013, pp. 68-78. 
Coulton, C.J., J. Korbin, T. Chan, and M. Su. Mapping Residents' Perceptions of Neighborhood Boundaries: A Methodological Note. American Journal of Community Psychology, Vol. 29, No. 2, 2001, pp. 371-383.

Cox, M.K., and C.H. Key. Post Hoc Pair-Wise Comparisons for the Chi-Square Test of Homogeneity of Proportions. Educational and Psychological Measurement, Vol. 53, No. 4, 1993, pp. 951-962.

Cutchin, M.P., K. Eschbach, C.A. Mair, H. Ju and J.S. Goodwin. The Socio-Spatial Neighborhood Estimation Mehod: An Approach to Operationalizing the Neighborhood Concept. Health \& Place, Vol. 17, No. 5, 2011, pp. 1113-1121.

Diez Roux, V. Investigating Neighborhood and Area Effects on Health. American Journal of Public Health, Vol. 91, No. 11, 2001, pp. 1783-1789.

Duany, A., and E. Talen. Transect Planning. Journal of the American Planning Association, Vol. 68, No. 3, 2002, pp. 245-266.

Ewing, R., and S. Handy. Measuring the Unmeasureable: Urban Design Qualtities Related to Walkability. Journal of Urban Design, Vol. 14, No. 1, 2009, pp. 65-84.

Fisher, W.D. On Grouping for Maximum Homogeneity. Journal of the American Statistical Association, Vol. 53, No. 284, 1958, pp. 789-798.

Galster, G. On the Nature of Neighbourhood. Urban Studies, Vol. 38, No. 12, 2001, pp. 21112124.

Gauvin, L., E. Robitaille, M. Riva, L. McLaren, C. Dassa, and L. Potvin. Conceptualizing and Operationalizing Neighbourhoods: The Conundrum of Identifying Territorial Units. Canadian Journal of Public Health/Revue Canadienne de Sante'e Publique, 2007, pp. S18-S26.

Grannis, R. The Importance of Trivial Streets: Residential Streets and Residential Segregation. American Journal of Sociology, Vol. 103, No. 6, 1998, pp. 1530-1564.

Guo J.Y., and C.R. Bhat. Operationalizing the Concept of Neighborhood: Application to Residential Location Choice Analysis. Journal of Transport Geography, Vol. 15, No. 1, 2007, pp. 31-45.

Handy, S.L. Urban Form and Pedestrian Choices: Study of Austin Neighborhoods. Transportation Research Record: Journal of the Transportation Research Board, Vol. 1552, No. 1, Transportation Research Board of the National Academies, Washington, D.C. 1996, pp. 135144.

Hensher, D., J. Louviere, and J. Swait. Combining Sources of Preference Data. Journal of Econometrics, Vol. 89, 1999, pp. 197-221. 
Hensher, D.A., J.M. Rose, and W.H. Greene. Applied Choice Analysis: A Primer. Cambridge, UK: Cambridge University Press, 2005.

Hoshino, T. Estimation of the Preference Heterogeneity within Stated Choice Data using Semiparametric Varying-Coefficient Methods. Empirical Economics, Vol. 45, No. 3, 2013, pp. 1129-1148.

Hunt, J.D. Stated Preference Analysis of Sensitivities to Elements of Transportation and Urban Form. Transportation Research Record: Journal of the Transportation Research Board, Vol. 1780, No. 1, Transportation Research Board of the National Academies, Washington, D.C., 2001, pp. 76-86.

Infogroup, Inc. Reference USA. 2014. http://referenceusa.com/. Accessed October 02, 2014.

Jacques, C., and A. El-Geneidy. Does Travel Behavior Matter in Defining Urban Form? A Quantitative Analysis Characterizing Distinct Areas within a Region. Journal of Transport and Land Use, Vol. 7, No. 1, 2014, pp. 1-14.

Jansen, S., H. Boumeester, H. Coolen, R. Goetgeluk, and E. Molin. The Impact of Including Images in a Conjoint Measurement Task: Evidence from Two Small-Scale Studies. Journal of Housing and the Built Environment, Vol. 24, No. 3, 2009, pp. 271-297.

Katoshevski, R., and H. Timmermans. Using Conjoint Anlaysis to Formulate User-Centered Guidelines for Urban Design: The Example of New Residential Development in Israel. Journal of Urban Design, Vol. 6, No. 1, 2001, pp. 37-53.

Koppelman, F., and C. Bhat. A Self-Instructing Course in Mode Choice Modeling: Multinomial and Nested Logit Models. U.S. Department of Transportation Federal Transit Administration, Washington, D.C., 2006.

Krizek, K.J. Operationalizing Neighborhood Accessibility for Land Use-Travel Behavior Research and Regional Modeling. Journal of Planning Education and Research, Vol. 22, No. 3, 2003, pp. 270-287.

Lawton, K.T. The Urban Structure and Personal Travel: An Analysis of Portland, Oregon Data and Some National and International Data. Presented in Supplementary Materials: Papers and Analyses for the E-Vision 2000 Conference, Vol. 14, 2001.

Liao, F.H., S. Farber, and R. Ewing. Compact Development and Preference Heterogeneity in Residential Location Choice Behavior: A Latent Class Anlaysis. Urban Studies, 2014, pp. 1-24.

Lin, J., and L. Long. What Neighborhood are You In? Empirical Findings of Relationships Between Household Travel and Neighborhood Characteristics Transportation, Vol. 35, No. 6, 2008, pp. 739-758. 
Louviere, J.J., D.A. Hensher, and J.D. Swait. Stated Choice Methods: Analysis and Application. Cambridge, UK: The University of Cambridge Press, 2000.

Louviere, J.J., and H. Timmermans. Using Hierarchical Information Integration to Model Consumer Responses to Possible Planning Actions: Recreation Destination Choice Illustration. Environment \& Planning A, Vol. 22, 1990, pp. 291-308.

Lund, H. Reasons for Living in a Transit-Oriented Development, and Associated Transit Use. Journal of the American Planning Association, Vol. 72, No. 3, 2006, pp. 357-366.

McFadden, D. The Measurement of Urban Travel Demand. Journal of Public Economics, Vol. 3, No. 4, 1974, pp. 303-328.

Meegan, R., and A. Mitchell. 'It's Not Community Round Here, It's Neighbourhood:

Neighbourhood Change and Cohesion in Urban Regeneration Policies. Urban Studies, Vol. 38, No. 12, 2001, pp. 2167-2194.

Molin, E., H. Oppewal, and H. Timmermans. Group-Based versus Individual-Based Conjoint Preference Models of Residential Preferences: A Comparative Test. Environment and Planning A, Vol. 31, No. 11, 1999, pp. 1935-1947.

Molin, E., and H. Timmermans. Accessibility Considerations in Residential Choice Decisions: Accumulated Evidence from the Benelux. Presented in Transportation Research Board Annual Meeting, Washington, D.C., 2003.

Morrow-Jones, H.A., E.G. Irwin, and B. Roe. Consumer Preference for Neotraditional Neighborhood Characteristics. Housing Policy Debate, Vol. 15, No. 1, 2004, pp. 171-202.

Nelson, M.C., P. Gordon-Larsen, Y. Song, and B.M. Popkin. Built and Social Environments: Associations with Adolescent Overweight and Activity. American Journal of Preventative Medicine, Vol. 31, No. 2, 2006, pp. 109-117.

O'Campo, P. Invited Commentary: Advancing Theory and Methods for Multilevel Models of Residential Neighborhoods and Health. American Journal of Epidemiology, Vol. 157, No. 1, 2003, pp. 9-13.

Olaru, D., B. Smith, and J.H. Taplin. Residential Location and Transit-Oriented Development in a New Rail Corridor. Transportation Research Part A: Policy and Practice, Vol. 45, No. 3, 2011, pp. 219-237.

Oregon Modeling Steering Committee. 2009-2011 Oregon Travel and Activity Survey. Salem, Oregon, 2013.

Orzechowski, M., T. Arentze, A. Borgers, and H. Timmermans. The Effects of Pre-Experimental Training on the Validity and Reliability of Conjoint Anlaysis: The Case of Housing Preference. Journal of Land Use Science, Vol. 8, No. 2, 2013, pp. 224-233. 
Rodriguez, D.A., A.J. Khattak, and K.R. Evenson. Can New Urbanism Encourage Physical Activity?: Comparing a New Urbanist Neighorhood with Conventional Suburbs. Journal of the American Planning Association, Vol. 72, No. 1, 2006, pp. 43-54.

Schirmer, P.M., M.A.B. van Eggermon, and K.A. Axhausen. The Role of Location in Residential Location Choice Models: A Review of Literature. Journal of Transport and Land Use, Vol. 7, No. 2, 2014, pp. 3-21.

Schwanen, T., and P. Mokhtarian. Attitudes Toward Travel and Land Use and Choice of Residential Neighborhood Type: Evidence from the San Francisco Bay Area. Housing Policy Debate, Vol. 18, No. 1, 2007, pp. 171-207.

Senior, M.L., C.J. Webster and N.E. Blank. Residential Relocation and Sustainable Urban form: Statistical Analyses of Owner-Occupiers' Preferences. International Planning Studies, Vol. 11, No. 1, 2006, pp. 41-57.

Shay, E., and A.J. Khattak. Automobiles, Trips, and Neighborhood Type: Comparing Environmental Measures. Transportation Research Record: Journal of the Transportation Research Board, Vol. 2010, no. 1, Transportation Research Board of the National Academies, Washington, D.C., 2007, pp. 73-82.

Smith, B., and D. Olaru. Lifecycle Stages and Residential Location Choice in the Presence of Latent Preference Heterogeneity. Environment \& Planning A, Vol. 45, 2011, pp. 2495-2514.

Song, Y., and G.J. Knaap. Quantitative Classification of Neighbourhoods: The Neighbourhoods of New Single-Family Homes in the Portland Metropolitan Area. Jounral of Urban Design, Vol. 12, No. 1, 2007, pp. 1-24.

Southworth, M., and P.M. Owens. The Evolving Metropolis: Studies of Community, Neighborhood, and Street Form at the Urban Edge. Journal of the American Planning Association, Vol. 59, No. 3, 1993, pp. 271-287.

U.S. EPA. Smart Location Database. 2014. http://www.epa.gov/smartgrowth/smartlocationdatabase.html. Accessed February 5, 2014.

Walker, J., and J. Li. Latent Lifestyle Preferences and Household Location Decisions. Journal of Geographic Systems, Vol. 9, 2007, pp. 77-101.

Wang, D., and S.M. Li. Housing Preferences in a Transitional Housing System: The Case of Beijing, China. Environment and Planning A, Vol. 36, No. 1, 2004, pp. 69-88.

Weisbrod, G., S.R. Lerman, and M. Ben-Akiva. Tradeoffs in Residential Location Decisions: Transportation versus Other Factors. Transport Policy and Decision Making, Vol. 1, No. 1, 1980, pp. 13-26. 
Wheeler, S.M. The Evolution of Urban Form in Portland and Toronto: Implications for Sustainability Planning. Local Environment, Vol. 8, No. 3, 2003, pp. 317-336.

Zondag, B., and M. Pieters. Influence of Accessibility on Residential Location Choices. Transportation Research Record: Journal of the Transportation Research Board, Vol. 1902, Transportation Research Board of the National Academies, Washington, D.C., 2005, pp. 63-70. 


\section{APPENDIX A}



Image Sets Visually Representing Five Neighborhood Concepts (Validation)
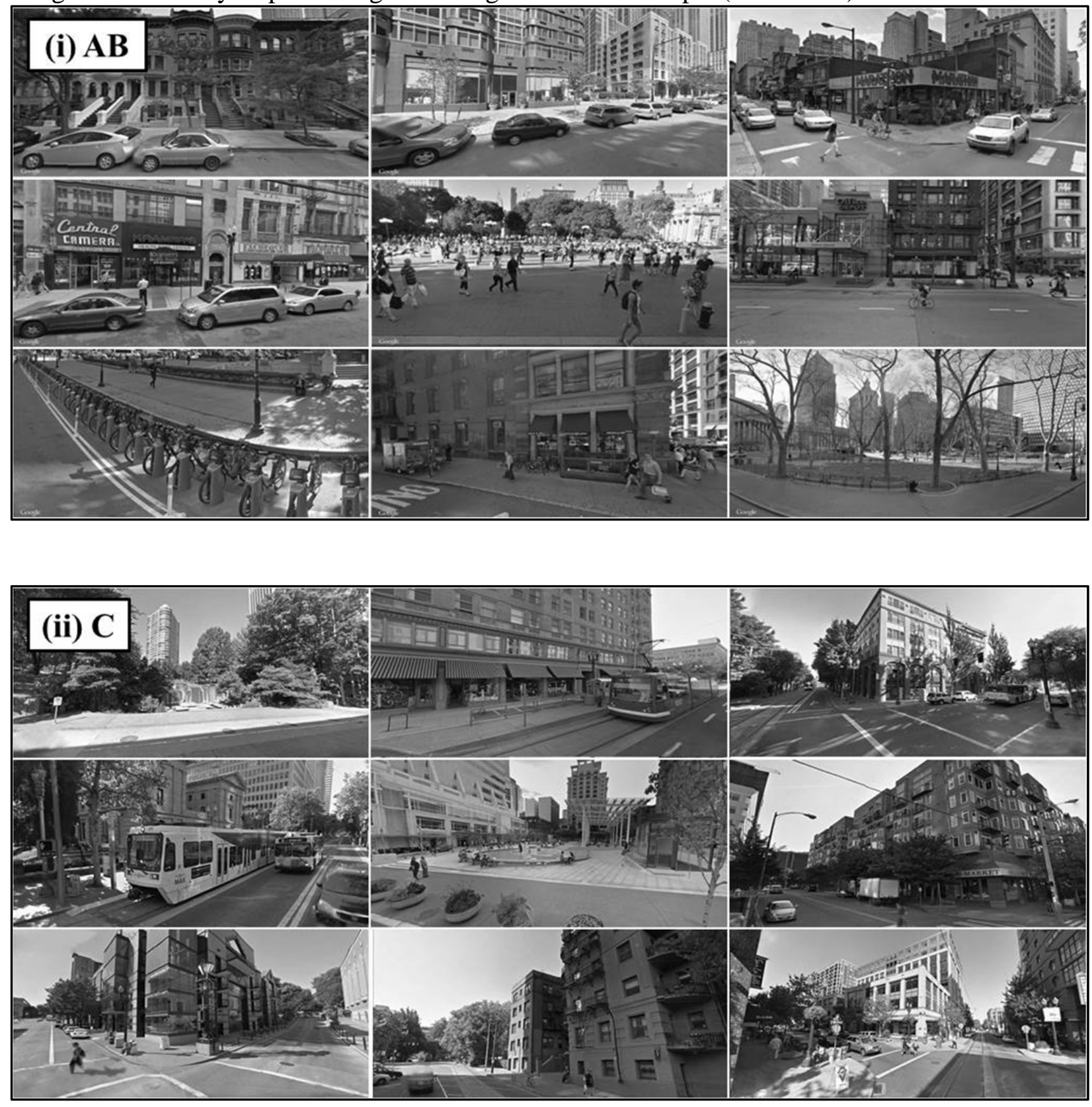

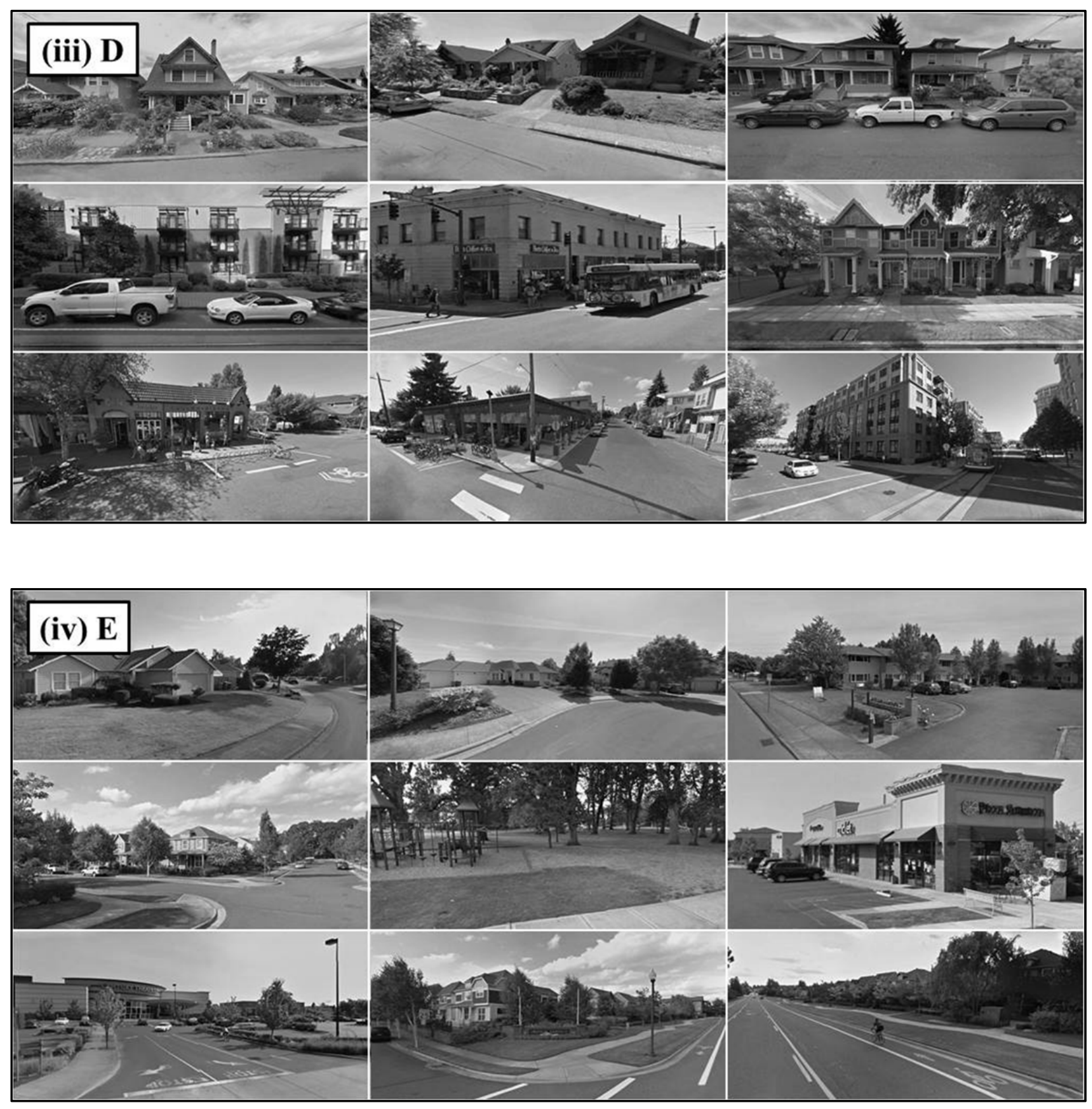


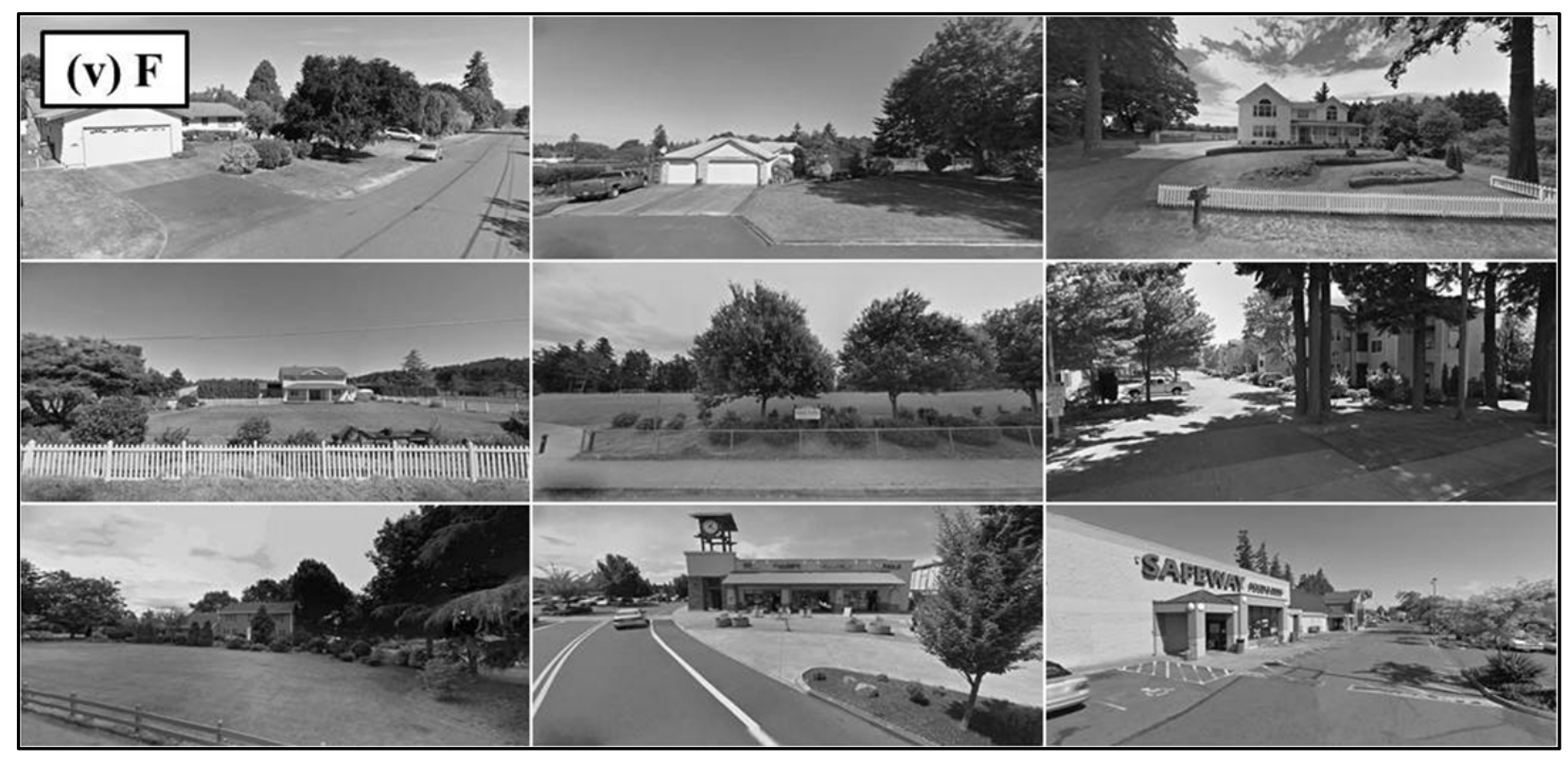


Validation Survey Instrument

Please begin this survey by entering the HOUSEHOLD ID NUMBER provided on the postcard we sent you:

Thank you in advance for taking our survey!

We would like to begin by asking you some questions about your current home, neighborhood, and transportation preferences.

1. Do you OWN or RENT your current home?
a) Own
b) Rent
c) Other

2. Which TYPE OF DWELLING best describes your current home?
a) Single-family structure
b) Duplex or townhouse
c) Apartments or condominiums unit in a building less than 4 stories tall
d) Apartments or condominiums unit in a building between 4 and 15 stories tall
e) Apartments or condominiums unit in a building more than 15 stories tall
f) Mobile home
g) Farm
h) Other

3. What is the approximate SIZE of the RESIDENTIAL LIVING SPACE of your current home?
a) Less than 850 square feet
b) Between 850 and 1,500 square feet
c) Between 1,500 and 2,500 square feet
d) Between 2,500 and 5,000 square feet
e) More than 5,000 square feet
f) Don't Know

4. In general, how do you travel to and from work or school?
a) Personal automobile
b) Car share (e.g., car2go, Zipcar, Getaround)
c) Carpool/Vanpool
d) Public Transit (Bus, Light Rail, Streetcar)
e) Bicycle
f) Walk
g) I work or go to school at home
h) Not applicable
i) Other

5. Overall, I am SATISFIED with my current...

[Choices: Strongly Disagree, Disagree, Neither Agree nor Disagree, Agree, Strongly Agree] 
a) Neighborhood

b) Size of the living space in my home

c) Type of dwelling (single-family structure, apartment building, duplex, etc.)

d) Transportation choices for my commute to work or school

e) Transportation choices for other travel (shopping, eating out, recreation, etc.)

Great! We would now like to ask you about the items that are currently IMPORTANT to you when deciding where to live.

6. Please consider each item on the left of the screen and place it either into the "VERY IMPORTANT”, “SOMEWHAT IMPORTANT”, or “NOT IMPORTANT” box on the right of the screen.

To select an item, click on the item in the left column and drag it over into one of the three boxes on the right. At any time, you may move an item between the three boxes.
a) Own my house/condo
b) Live in a home with a large living space
c) Have a private yard
d) Have privacy from my neighbors
e) Living at the "center of it all"
f) Being near high-quality public schools
g) Living near established, older homes
h) Living around people at all stages of life
i) Living near a variety in housing structures
j) Living around people of various income levels
k) Access to highways/freeways
l) Having a commute that takes 25 minutes or less
m) Walking to bus and/or rail stop
n) Access to trails
o) Walking to nearby places
p) Biking to nearby places

Great! You have completed the first of three sections in this survey.

In this next section, we will be showing you two short videos that characterize two neighborhoods. After viewing the videos, we will then ask you questions based on your overall IMPRESSION of the housing, amenities, and transportation characteristics of each neighborhood.

Please view the following videos of Neighborhood A and Neighborhood B one at a time and respond to the following questions. You may view the videos as many times as you like.

Remember, we are most interested in your OVERALL IMPRESSION of the housing, amenities, and transportation characteristics portrayed in these neighborhood videos. 
Make the videos larger by pressing the button on the bottom right of the video ( ) and the ESC key to return to the normal screen.

$$
\text { Neighborhood A Video Neighborhood B Video }
$$

7. Based on your general impressions of these neighborhoods, please indicate the neighborhood you think is more likely to have:

[Choices: Neighborhood A, No Difference/Cannot Distinguish, or Neighborhood B]

a) larger private years

b) a greater variety in types of dwelling (single-family structure, apartment building, duplex, etc.)

c) larger housing sizes

d) better accommodations for car ownership

e) closer proximity to local shopping and/or retail establishments

f) better access to regional shopping centers and/or big box stores

g) greater population density

h) better access to parks and/or outdoor recreational facilities

i) a greater ease for finding parking spaces

j) better public transportation service

k) better walking environments

l) better streets to ride a bicycle for transportation

m) a greater variety of transportation options

Now we will show you two more videos and ask similar questions. After viewing the videos, we will then ask you questions based on your overall IMPRESSION of the housing, amenities, and transportation characteristics of each neighborhood.

Please view the following videos of Neighborhood A and Neighborhood B one at a time and respond to the following questions. You may view the videos as many times as you like.

Remember, we are most interested in your OVERALL IMPRESSION of the housing, amenities, and transportation characteristics portrayed in these neighborhood videos.

Make the videos larger by pressing the button on the bottom right of the video ( ) and the ESC key to return to the normal screen.

$$
\text { Neighborhood A Video Neighborhood B Video }
$$

8. Based on your general impressions of these neighborhoods, please indicate the neighborhood you think is more likely to have:

[Choices: Neighborhood A, No Difference/Cannot Distinguish, or Neighborhood B]

a) larger private years

b) a greater variety in housing types 
c) larger housing sizes

d) better accommodates car ownership

e) closer proximity to local shopping and/or retail establishments

f) better access to regional shopping centers and/or big box stores

g) greater population density

h) better access to parks and/or outdoor recreational facilities

i) easier to find a parking space

j) better served by public transportation

k) a better place to walk

l) better streets to ride a bicycle for transportation

m) a greater variety of transportation options

Wonderful! You have completed the second section of this survey. In this last section, we ask you for some information related to you and the other members of your household.

This information will be used for research purposes to characterize your household. We will not disclose or share this information with others.

9. For your household, how many PEOPLE (INCLUDING YOURSELF) fall within each of these categories.

Number of ADULTS (ages 18 or older)

Number of CHILDREN (younger than 18)

Number of FULL OR PART-TIME WORKERS

Number of LICENSED DRIVERS

10. Indicate HOW MANY of each of the following items your household OWNS AND USES on a regular basis?

Number of AUTOMOBILES (e.g., vehicles, motorcycles)

Number of ADULT BICYCLES

Number of TRANSIT PASSES

Number of CAR SHARING MEMBERSHIPS (e.g., car2go, Zipcar, Getaround)

11. What is your AGE?

years old

12. Which GENDER do you most identify with?

Male

Female

Prefer not to say

13. For your HOME, please provide the nearest INTERSECTION or CROSS-STREETS as well as your ZIP CODE.

(e.g., SE 10th and Nehalem Street, 97202) 
14. Please approximate the TOTAL INCOME of your HOUSEHOLD in 2013.
a) $\quad \$ 0$ to $\$ 14,999$
b) $\$ 15,000$ to $\$ 24,999$
c) $\$ 25,000$ to $\$ 34,999$
d) $\$ 35,000$ to $\$ 49,999$
e) $\$ 50,000$ to $\$ 74,999$
f) $\$ 75,000$ to $\$ 99,999$
g) $\$ 100,000$ to $\$ 149,999$
h) $\$ 150,000$ or more 
Experimental Survey Instrument

Front Page of Website (https://sites.google.com/site/ntstudypdx)

About our Survey

This online survey should only take you about 15 minutes to complete. Your involvement in this study is completely voluntary, and you may choose not to participate or stop your participation at any point without consequence.

The survey consists of a series of questions asking about:

1. your satisfaction with your current housing location and neighborhood;

2. your preferences about the housing, neighborhood, and transportation features most important to you; and

3. the characteristics of your current household.

We will protect the confidentiality of your individual responses. The information you provide will only be used for the purposes of this study. All information collected from this online survey will be kept by the research team for one year and then destroyed. The findings from this study are intended to help inform decision tools and policy needs. If published, the results will be presented in summary form only.

By clicking the link below and completing this online survey, you acknowledge that you are at least 18 years of age and that you will be agreeing to participate in the Neighborhood Transportation Study. Upon your request, you will be provided with a copy of this informed consent statement.

\section{$\underline{\text { Neighborhood Transportation Study Survey }}$}

After the survey, you will be invited to enter your name into a drawing for a chance to win a $\$ 100$ gift card to Amazon. The contact information you provide will not be linked to your survey responses.

If you have any concerns or problems about your participation in our Neighborhood Transportation Study or your rights as a research subject, please contact the Human Subjects Research Review Committee, Office of Research and Strategic Partnerships, Post Office Box 751, Portland State University, (877) 480-4400. If you have any questions about the Neighborhood Transportation Study, please feel free to call us at (xxx) xxx-xxxx or email us at xxxxx@pdx.edu.

Thank you,

Dr. Kelly J. Clifton_and the Neighborhood Transportation Study Research Team Department of Civil and Environmental Engineering Portland State University 
A-10 
Please begin this survey by entering the HOUSEHOLD ID NUMBER provided on the postcard we sent you:

4. First, we are interested in your work status. Please select the option below that best describes your work status. (Select one.)

5. Full-time or part-time worker

6. Full-time or part-time student

7. $\quad$ Retired

8. Other

Thank you in advance for taking our survey! We would like to begin by asking you some questions about your current home, neighborhood, and transportation preferences.

2. Do you OWN or RENT your current home? (Select one.)

9. Own

10. Rent

11. Other (please specify)

3. Which TYPE OF DWELLING best describes your CURRENT HOME? (Select one.)

To have a closer look at the types of dwellings, click on the photograph to make the pictures larger, and then click "close" to return to the question.

12. Single-family detached structure

13. Duplex or townhouse

14. Low-rise apartment or condominium (a building less than 4 stories tall)

15. Mid-rise apartment or condominium (a building between 4 and 15 stories tall)

16. High-rise apartment or condominium (a building more than 15 stories tall)

17. Other (please specify)

4. Which TYPE OF DWELLING best describes you would PREFER? (Select one.) 
To have a closer look at the types of dwellings, click on the photograph to make the pictures larger, and then click "close" to return to the question.

18. Single-family detached structure

19. Duplex or townhouse

20. Low-rise apartment or condominium (a building less than 4 stories tall)

21. Mid-rise apartment or condominium (a building between 4 and 15 stories tall)

22. High-rise apartment or condominium (a building more than 15 stories tall)

23. $\quad$ Other (please specify)

5. What is the approximate SIZE of the RESIDENTIAL LIVING SPACE of your current home? (Select one.)

24. Less than 750 square feet

25. Between 750 and 1,500 square feet

26. Between 1,500 and 2,500 square feet

27. Between 2,500 and 5,000 square feet

28. More than 5,000 square feet

29. Don’t Know

6. How do you most often travel? (Select all that apply.)

30. Personal automobile

31. Car share (e.g. car2go, Zipcar, Getaround)

32. Carpool/Vanpool/Rideshare

33. Public transit (e.g. bus, light rail, streetcar)

34. Bicycle

35. Walk

36. Not applicable

37. Other (please specify) 
7. How do you most often travel TO AND FROM WORK OR SCHOOL? (Select one.)

38. Personal automobile

39. Car share (e.g. car2go, Zipcar, Getaround)

40. Carpool/Vanpool/Rideshare

41. Public transit (e.g. bus, light rail, streetcar)

42. Bicycle

43. Walk

44. Not applicable

45. Other (please specify)

8. How SATISFIED are you with your current:

(Very Dissatisfied, Dissatisfied, Neutral, Satisfied, Very Satisfied)

46. Neighborhood

47. Size of the living space in my home

48. Type of dwelling (single-family structure, apartment building, duplex, etc.)

49. Transportation choices for my commute to work or school

50. Transportation choices for other travel (shopping, eating out, recreation, etc.)

9. For your household, how many PEOPLE fall within each of these categories.

Number of OTHER ADULTS (age 18 or older)

Number of Children (younger than 18)

10. Not including yourself, how many other people in your household work or go to school partor full-time?

Number of part- or full-time workers or students (do not count yourself)

11. Indicate HOW MANY of each of the following items your household OWN?

Number of AUTOMOBILES (e.g. vehicles, motorcycles)

Number of ADULT BICYCLES

12. Are you a LICENSED DRIVER? 
51. Yes

52. No

13. Do you have a TRANSIT PASS?

53. Yes

54. No

14. Do you have a CAR SHARING MEMBERSHIP (e.g. car2go, Zipcar, Getaround)?

55. Yes

56. No

15. What is your AGE?

$$
\text { years old }
$$

16. Which GENDER do you most identify with?

57. Male

58. Female

59. Prefer not to say

17. In order to understand what your commute is like, we are asking you to provide the location for your WORK OR SCHOOL. We understand that the place of your work or school locations may vary, but we ask that you please provide the location to where you most commonly commute.

Please provide the nearest INTERSECTION or CROSS-STREETS as well as the ZIP CODE for your WORK OR SCHOOL:

First Street (ex: SE $13^{\text {th }}$ Ave)

Cross Street (ex: SE Tacoma St)

ZIP Code (ex: 97207)

18. Please approximate the TOTAL INCOME of your household in 2013.

60. $\$ 0$ to $\$ 14,999$

61. $\$ 15,000$ to $\$ 24,999$

62. $\$ 25,999$ to $\$ 34,999$

63. $\$ 35,000$ to $\$ 49,999$ 
64. $\$ 50,000$ to $\$ 74,999$

65. $\$ 75,000$ to $\$ 99,999$

66. $\$ 100,000$ to $\$ 149,999$

67. $\$ 150,000$ to $\$ 199,999$

68. $\$ 200,000$ to $\$ 249,999$

69. $\$ 250,000$ or more

19. Please approximate your household's AVERAGE MONTHLY HOUSING COSTS (rent/ mortgage).

70. Less than $\$ 249$ per month

71. Between $\$ 250$ and $\$ 499$ per month

72. Between $\$ 500$ and $\$ 749$ per month

73. Between $\$ 750$ and $\$ 999$ per month

74. Between $\$ 1,000$ and $\$ 1,499$ per month

75. Between $\$ 1,500$ and $\$ 1,999$ per month

76. Between $\$ 2,000$ and $\$ 2,499$ per month

77. Between $\$ 2,500$ and $\$ 2,999$ per month

78. Between $\$ 3,000$ and $\$ 3,499$ per month

79. \$3,500 per month or more

20. If you were able to find a home or a location that better suited your preferences, how much more would you be willing to spend on your monthly housing costs (rent/mortgage)?

80. I would not be willing to spend more per month

81. I would be willing to spend about $\$ 50$ more per month

82. I would be willing to spend about $\$ 100$ more per month

83. I would be willing to spend about $\$ 200$ more per month

84. I would be willing to spend about $\$ 300$ more per month

85. I would be willing to spend about $\$ 400$ more per month 
86. I would be willing to spend about $\$ 500$ more per month

87. I would be willing to spend about $\$ 750$ more per month

88. I would be willing to spend about $\$ 1,000$ more per month

89. I would be willing to spend about \$1,500 more per month

90. I would be willing to spend at least \$2,000 more per month

21. Listed below are three different types of neighborhoods. Based on the photographs and descriptions below, in which neighborhood would you most PREFER to live?

To have a closer look at the neighborhoods, click on the photograph to make the pictures larger, and then click "close" to return to the question.

91. Central District: An active downtown environment composed mostly of high-rise office buildings and apartment complexes with a variety of retail, services, and entertainment. Households living in the Central District predominately rent a multifamily dwelling unit and pay to park their vehicle at a secured, off-street location. This neighborhood type is the hub of a well-connected multimodal transportation network with high regional and local access to destinations located within an 1/8 mile of any residence.

\section{[picture $^{6}$}

92. Urban Residential District: An urban living environment adjacent to the Central District composed mostly of mid-rise apartment buildings with a mix of retail, services, and office settings. Households living in an Urban Residential District either rent or own a multifamily dwelling unit and pay to park their vehicles at a secured, off-street location. There is a multimodal transportation network with reasonable regional and local access to destinations within a 1/4 mile of any residence.

\section{[picture]}

93. Urban Neighborhood: A primarily residential environment composed of both singlefamily houses and low-rise multifamily residences with local access to neighborhood retail within 1 mile of any residence. Households living in this neighborhood type live either in a multifamily dwelling unit or single-family house and have free on-street or off-

\footnotetext{
${ }^{6}$ Within the next two appendices pages of the "survey" where the reference word "[picture]” appears, the relevant photos were used in Figure 5.1 in the main text of this manuscript.
} 
street parking for their vehicle. An Urban Neighborhood has limited regional access to destinations and a modest public transit network.

\section{[picture]}

94. Suburban Neighborhood: A predominately residential environment composed of primarily single-family detached houses on larger lots. Retail and service opportunities are separated from residential areas and are clustered along arterials within 2 to 3 miles of any residence. Households park their vehicles in personal driveways or garages. A Suburban Neighborhood tends to have a sparse public transit network.

\section{[picture]}

We would now like to ask you about the housing, neighborhood and transportation characteristics that you may consider when deciding where to live.

22. Please move each item from the left of the screen and place it into one of the boxes on the right of the screen: "VERY IMPORTANT", "SOMEWHAT IMPORTANT", or "NOT IMPORTANT AT ALL".

Move all of the items into the boxes to the right before moving on.

To select an item, click on the item in the left column and drag it over into the IMPORTANT box on the right.

95. Own my house/condo

96. Live in a home with a large living space

97. Live in a detached single-family home

98. Have a private yard

99. Have privacy from my neighbors

100. Living at the "center of it all”

101. Being near high-quality public schools

102. Living near established, older homes

103. Access to highways/freeways

104. Having a variety of transportation options

105. Having a commute that takes 25 minutes or less 
106. Walking to bus and/or rail stop

107. Having off-street parking at local destinations

108. Having dedicated parking at your residence

109. Access to parks and recreational areas

110. Walking to nearby places

111. Biking to nearby places

In this next section, we will be asking you to choose between two different options. Each option includes a type of neighborhood and a type of commute. Of the two options presented, please select the most appealing to you.

To have a closer look at the neighborhoods, click on the photograph to make the pictures larger, and then click "close" to return to the question."

23. Select the card you prefer most:

To have a closer look at the neighborhoods, click on the photograph to make the pictures larger, and then click "close" to return to the question.

\section{Neighborhood Card $1 \quad$ Neighborhood Card 2}

24. Select the card you prefer most:

To have a closer look at the neighborhoods, click on the photograph to make the pictures larger, and then click "close" to return to the question.

\section{Neighborhood Card $1 \quad$ Neighborhood Card 2}

25. Select the card you prefer most:

To have a closer look at the neighborhoods, click on the photograph to make the pictures larger, and then click "close" to return to the question.

\section{Neighborhood Card $1 \quad$ Neighborhood Card 2}

26. Select the card you prefer most:

\footnotetext{
${ }^{7}$ During the survey administration, the reference to "Neighborhood Card 1 or 2" included a randomly selected pair of Choice Experiment Cards, which can be examined beginning on page A-21 of this report.
} 
To have a closer look at the neighborhoods, click on the photograph to make the pictures larger, and then click "close" to return to the question.

$$
\text { Neighborhood Card } 1 \quad \text { Neighborhood Card } 2
$$

27. Select the card you prefer most:

To have a closer look at the neighborhoods, click on the photograph to make the pictures larger, and then click "close" to return to the question.

\section{Neighborhood Card $1 \quad$ Neighborhood Card 2}

Wonderful! Would you be willing to compare five more choices?

Yes

No, I have had enough.

(NOTE: Next 5 questions are optional)

28. Select the card you prefer most:

To have a closer look at the neighborhoods, click on the photograph to make the pictures larger, and then click "close" to return to the question.

$$
\text { Neighborhood Card } 1 \quad \text { Neighborhood Card } 2
$$

29. Select the card you prefer most:

To have a closer look at the neighborhoods, click on the photograph to make the pictures larger, and then click "close" to return to the question.

\section{Neighborhood Card $1 \quad$ Neighborhood Card 2}

30. Select the card you prefer most:

To have a closer look at the neighborhoods, click on the photograph to make the pictures larger, and then click "close" to return to the question.

\section{Neighborhood Card $1 \quad$ Neighborhood Card 2}

31. Select the card you prefer most:

To have a closer look at the neighborhoods, click on the photograph to make the pictures larger, and then click "close" to return to the question. 


\title{
Neighborhood Card $1 \quad$ Neighborhood Card 2
}

32. Select the card you prefer most:

To have a closer look at the neighborhoods, click on the photograph to make the pictures larger, and then click "close" to return to the question.

\author{
Neighborhood Card $1 \quad$ Neighborhood Card 2
}

Neighborhood Concepts Image Sets and Descriptions

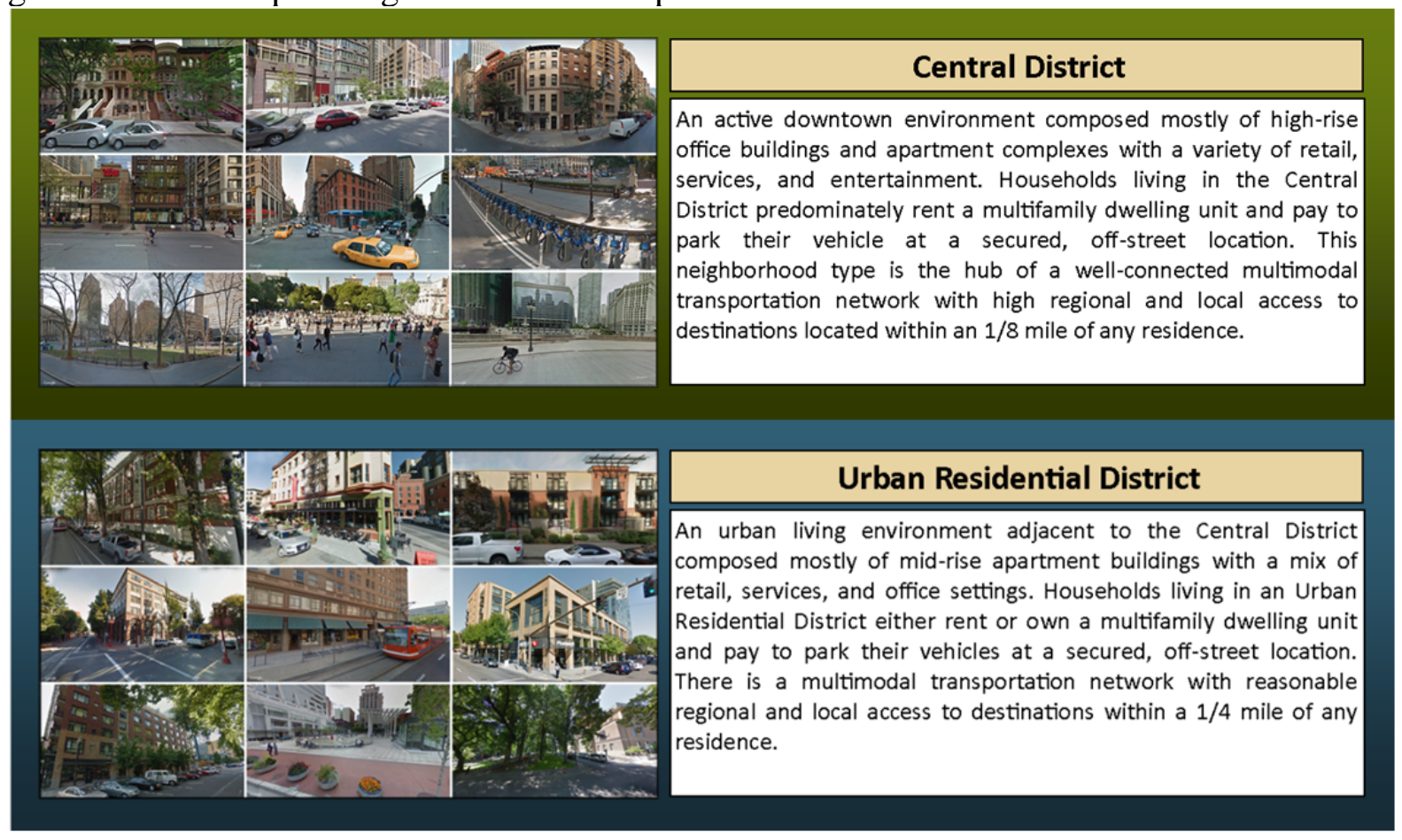




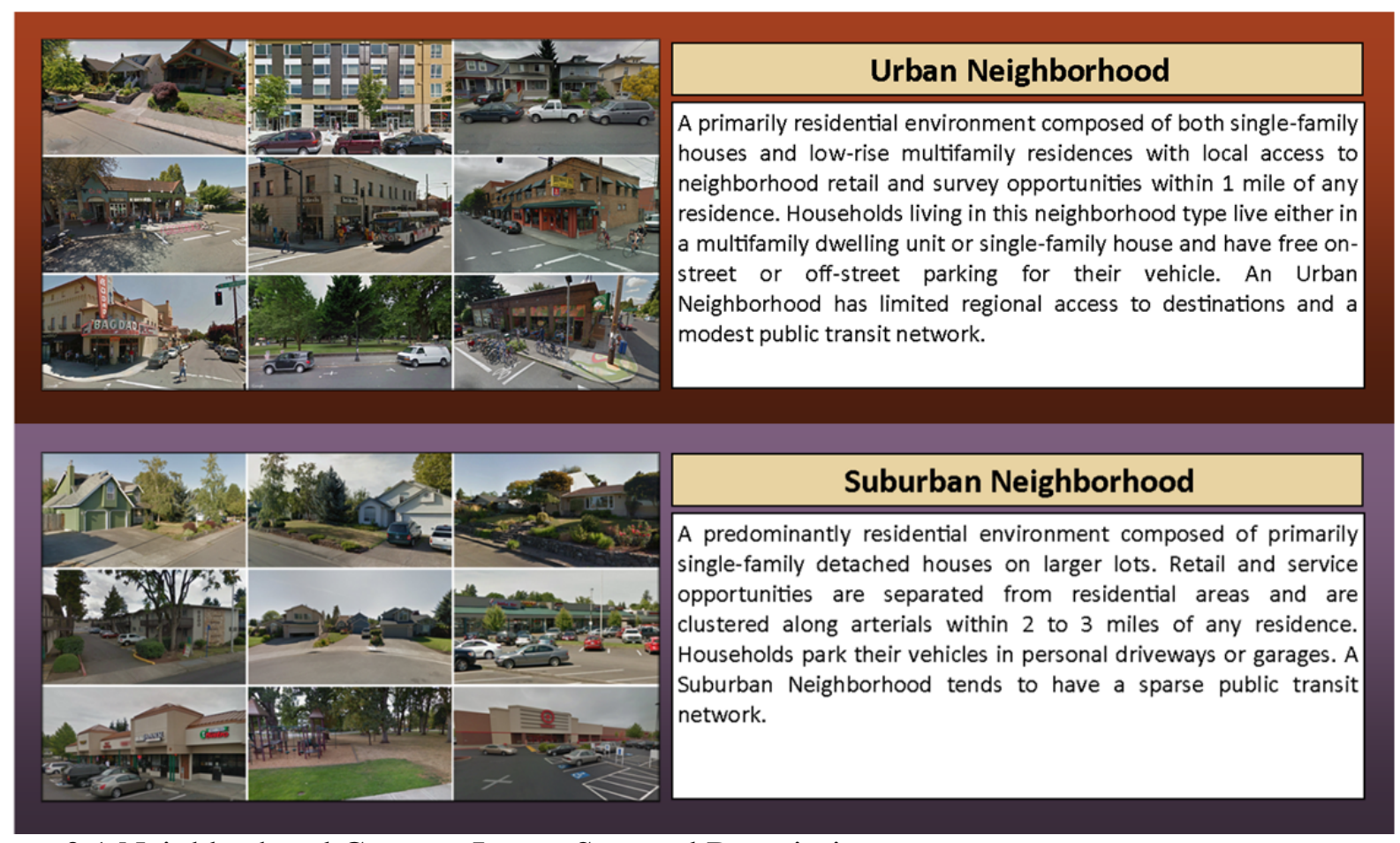

Figure 0.1 Neighborhood Concept Image Sets and Descriptions 
Choice Experiment "Cards” - Alternatives: Neighborhood, Commute Mode and Travel Time (27 cards in the set)

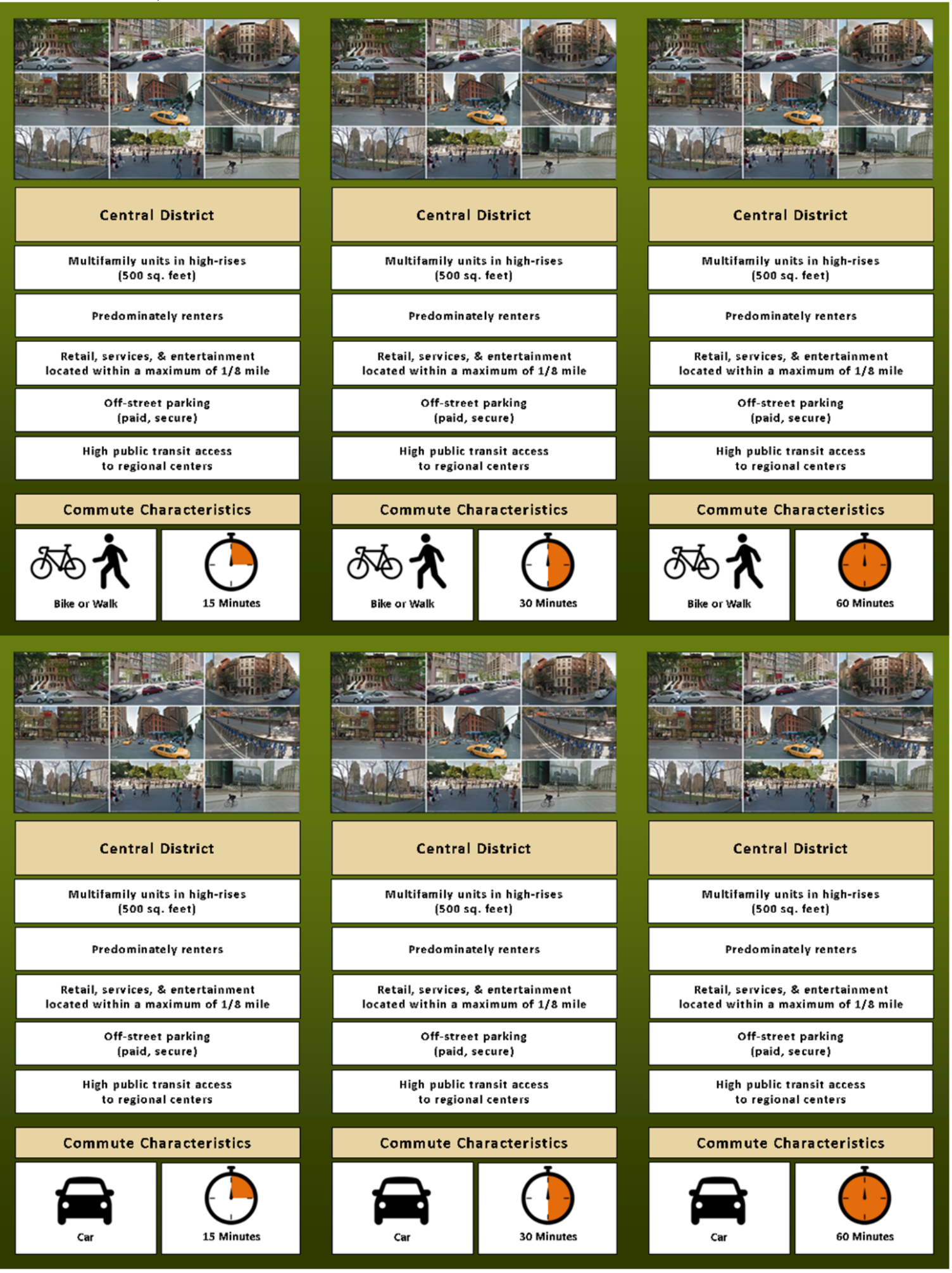




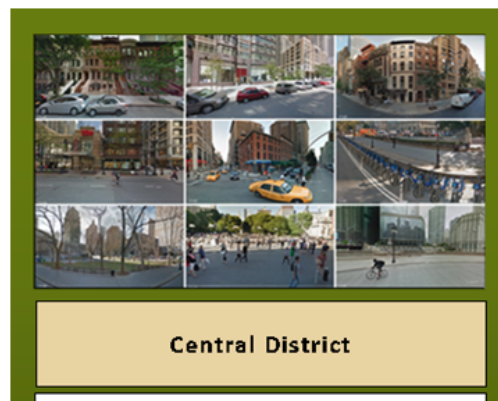

Multifamily units in high-rises

(500 sq. feet)

Predominately renters

Retail, services, \& entertainment located within a maximum of $1 / 8 \mathrm{mile}$

off-street parking (paid, secure)

High public transit access

to regional centers

Commute Characteristics

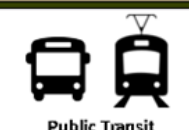

Public Transit

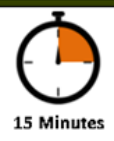

15 Minutes

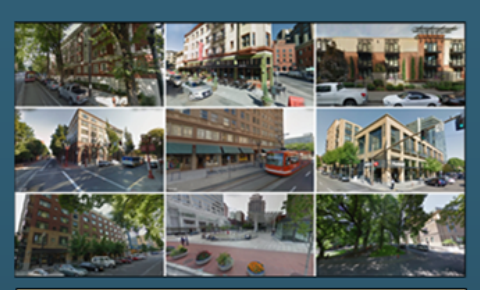

Urban Residential District

Multifamily units in mid-rises (750 sq. feet)

Mix of renters and owners

Retail, services, \& entertainmen located within a maximum of $1 / 4$ mile

Off-street parking (paid, secure)

Reasonable public transit access to regional centers

Commute Characteristics

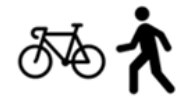

Bike or Walk

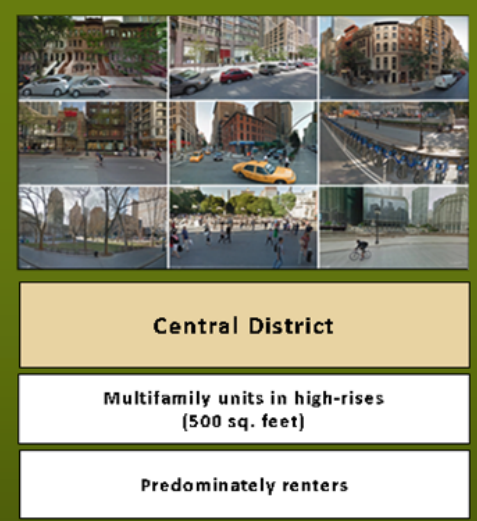

Retail, services, \& entertainment located within a maximum of $1 / 8$ mile

Off-street parking
(paid, secure)

High public transit access

to regional centers
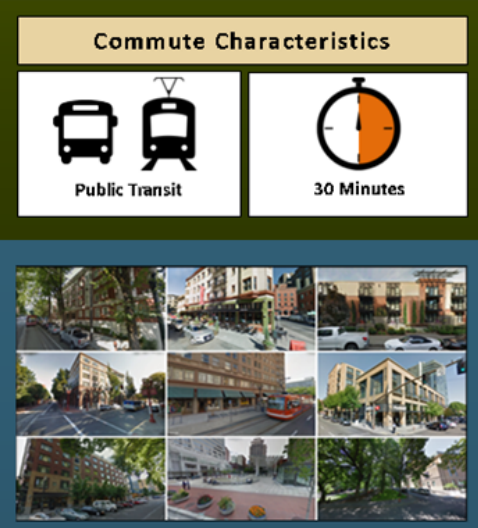

Urban Residential District

Multifamily units in mid-rises (750 sq. feet)

Mix of renters and owners

Retail, services, \& entertainment located within a maximum of $1 / 4$ mile

Off-street parking (paid, secure)

Reasonable public transit access

$$
\text { to regional centers }
$$

Commute Characteristics

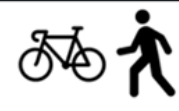

Bike or Walk

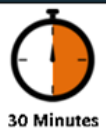

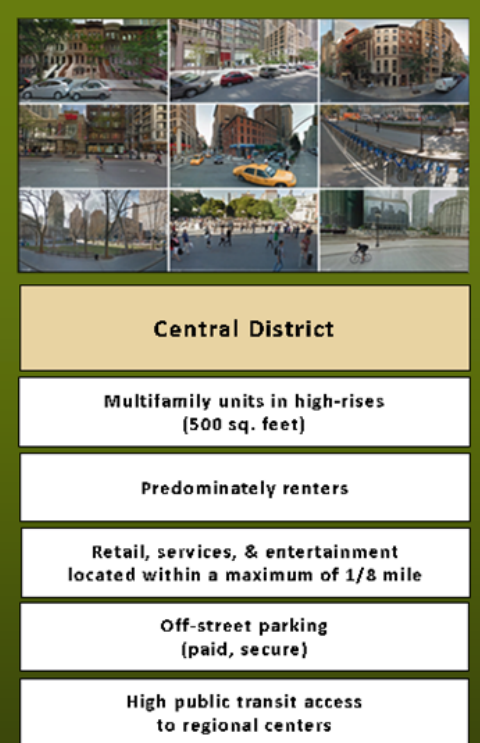

Commute Characteristics
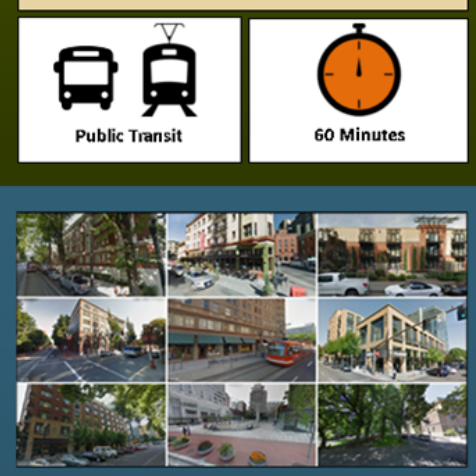

Urban Residential District

Multifamily units in mid-rises (750 sq. feet)

Mix of renters and owners

Retail, services, \& entertainment located within a maximum of $1 / 4$ mile

Off-street parking (paid, secure)

Reasonable public transit access to regional centers

Commute Characteristics

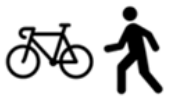

Bike or Walk

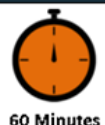




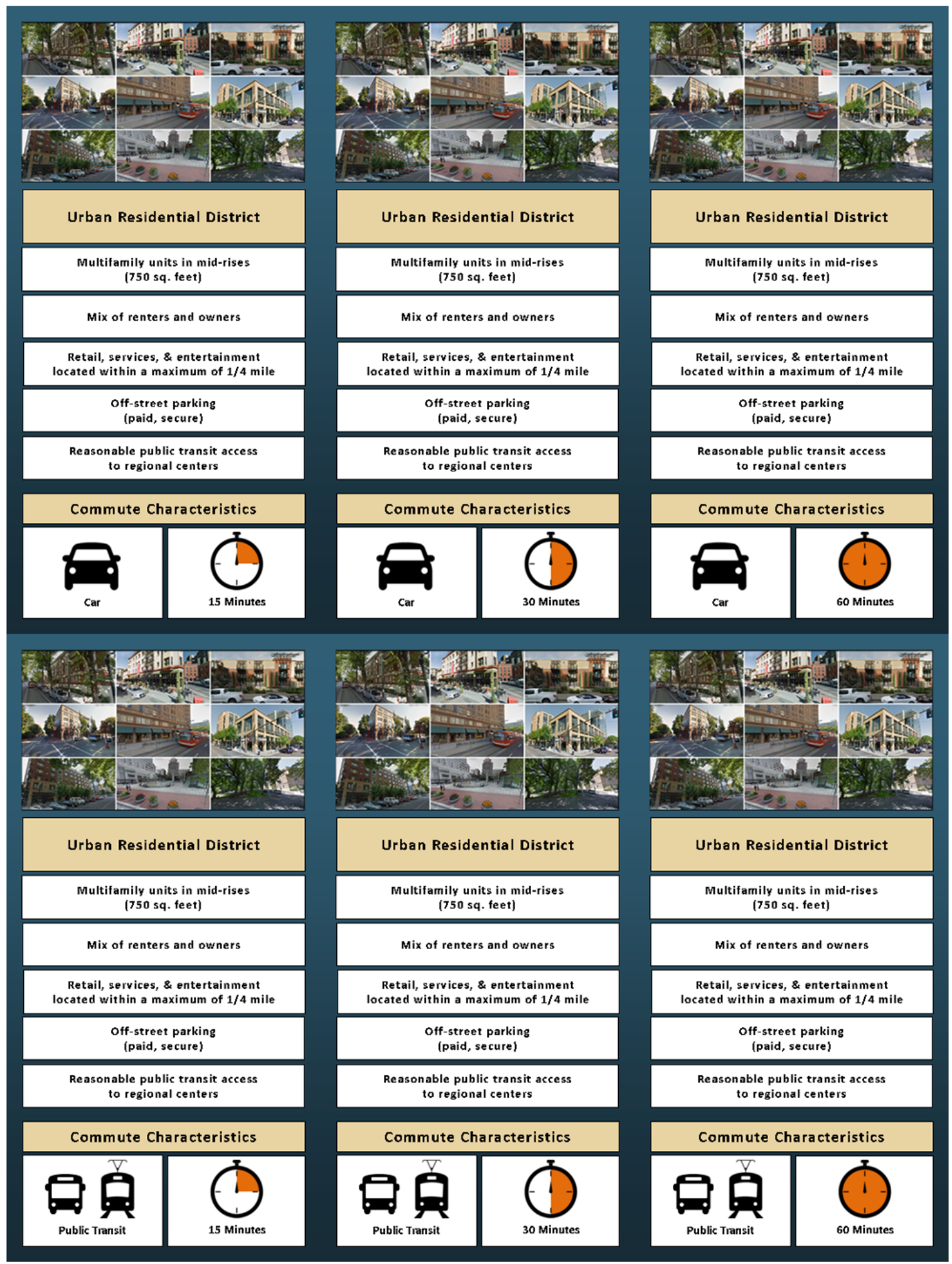




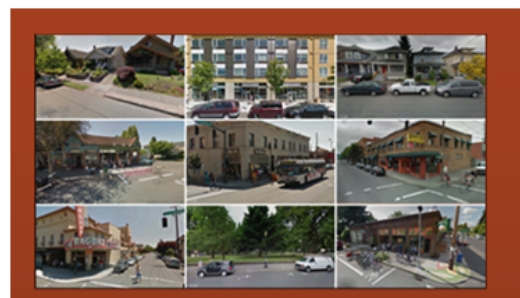

Urban Neighborhood

Multifamily units in low-rises (1,000 sq. feet) $\&$ Single-family units $(1,500 \mathrm{sq}$. feet)

Mostly owners

Retail, services, \& entertainment located within a maximum of 1 mile

On-street parking (free, unsecure) \& off-street parking (free, secure)

Limited public transit access

to regional centers

\section{Commute Characteristics}

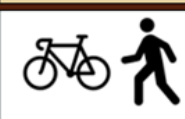

Bike or Walk

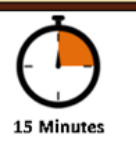

15 Minutes

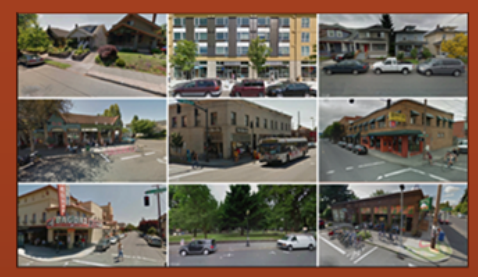

Urban Neighborhood

Multifamily units in low-rises $(1,000$ sq. feet $)$ $\&$ Single-family units $(1,500$ sq. feet $)$

Mostly owners

Retail, services, \& entertainment located within a maximum of 1 mile

On-street parking (free, unsecure) \& Off-street parking (free, secure)

Limited public transit access to regional centers

Commute Characteristics

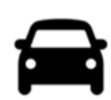

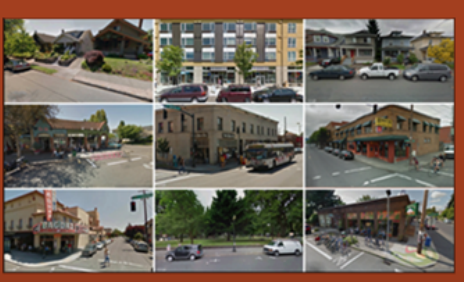

Urban Neighborhood

Multifamily units in low-rises $(1,000$ sq. feet $)$ $\&$ Single-family units $(1,500$ sq. feet $)$

Mostly owners

Retail, services, \& entertainment located within a maximum of 1 mile

On-street parking (free, unsecure) off-street parking (free, secure)

Limited public transit access

to regional centers
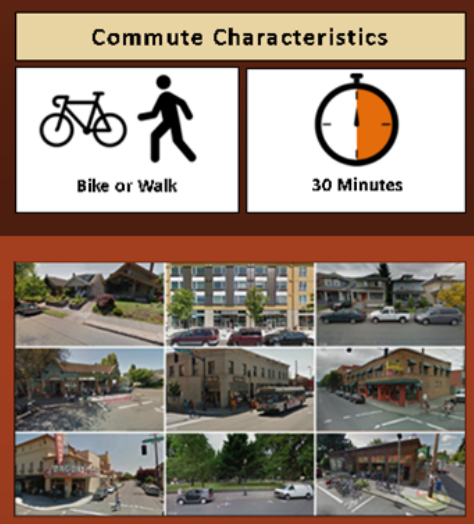

Urban Neighborhood

Multifamily units in low-rises (1,000 sq. feet) $\&$ Single-family units $(1,500$ sq. feet $)$

Mostly owners

Retail, services, \& entertainment located within a maximum of 1 mile

On-street parking (free, unsecure) $\&$ off-street parking (free, secure)

Limited public transit access

$$
\text { to regional centers }
$$

Commute Characteristics

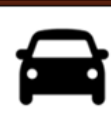

Car

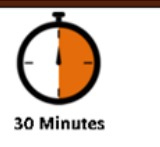

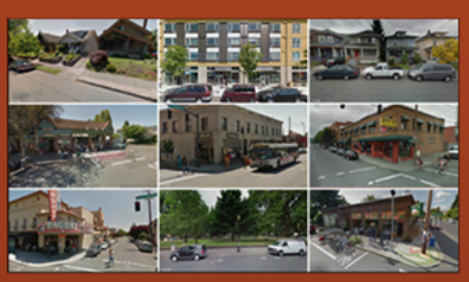

Urban Neighborhood

Multifamily units in low-rises $(1,000$ sq. feet $)$ $\&$ Single-family units $(1,500$ sq. feet $)$

Mostly owners

Retail, services, \& entertainment located within a maximum of 1 mile

On-street parking (free, unsecure) \& Off-street parking (free, secure)

Limited public transit access to regional centers

Commute Characteristics
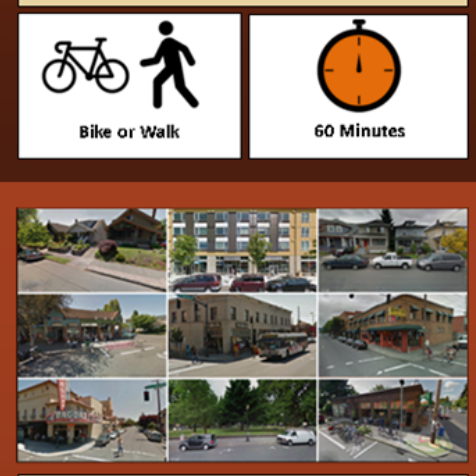

Urban Neighborhood

Multifamily units in low-rises (1,000 sq. feet) $\&$ single-family units $(1,500 \mathrm{sq}$. feet $)$

Mostly owners

Retail, services, \& entertainment located within a maximum of 1 mile

On-street parking (free, unsecure) \& off-street parking (free, secure)

Limited public transit access

$$
\text { to regional centers }
$$

Commute Characteristics

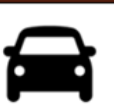

Car

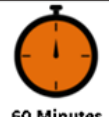

60 Minutes 


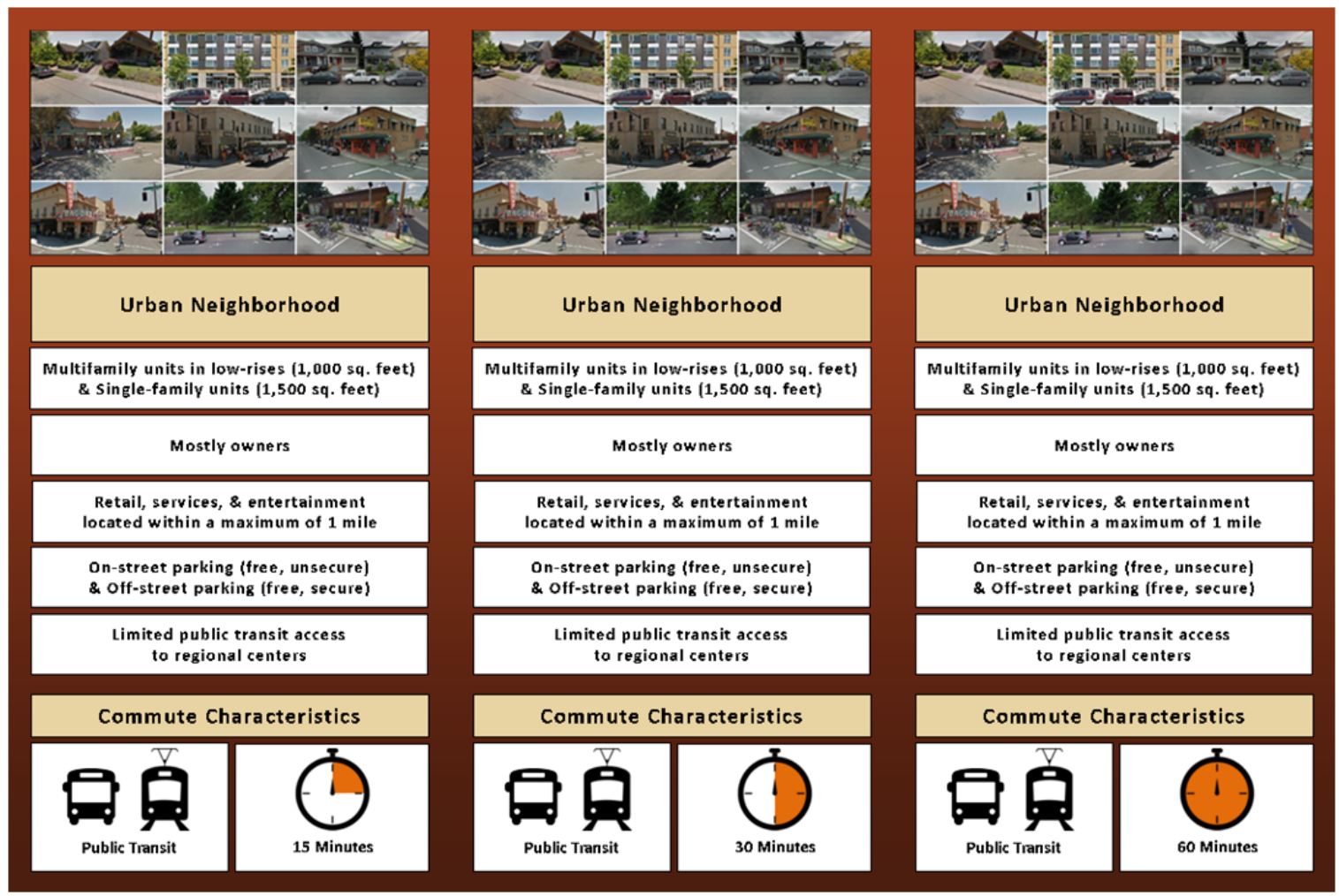


Descriptive Statistics for Experiment Survey Data

SPSS Descriptive Statistics and Frequencies for Choice Experiment Data

Notes

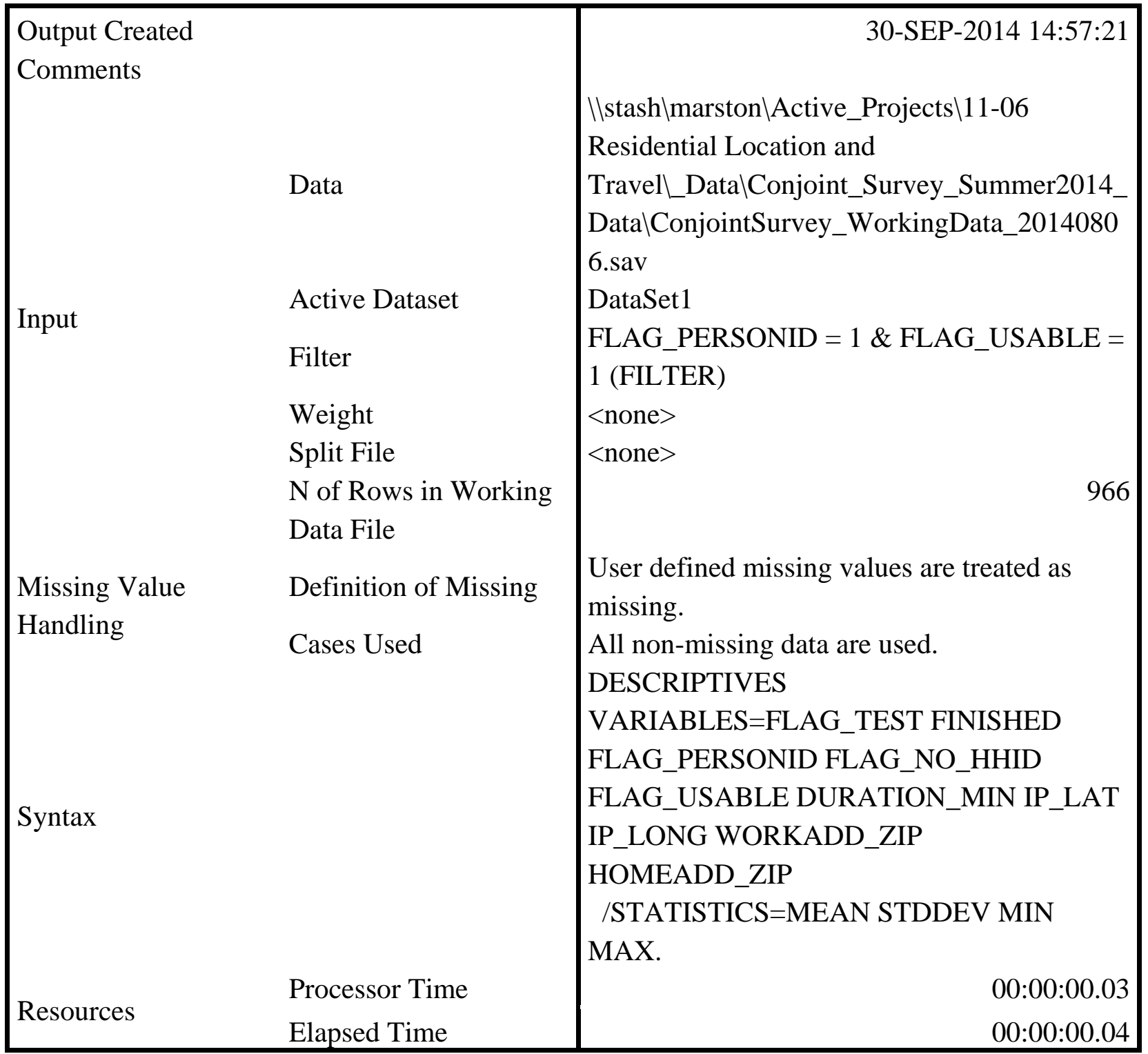


General Response Statistics

Descriptive Statistics

\begin{tabular}{|c|c|c|c|c|c|}
\hline & $\mathrm{N}$ & Minimum & Maximum & Mean & $\begin{array}{c}\text { Std. } \\
\text { Deviation }\end{array}$ \\
\hline $\begin{array}{l}\text { Surveys taken as a } \\
\text { "test" (true = do not } \\
\text { use) }\end{array}$ & 966 & 0 & 0 & .00 & .000 \\
\hline Completed Survey & 966 & 1 & 1 & 1.00 & .000 \\
\hline $\begin{array}{l}\text { Flag to identify those } \\
\text { persons that are unique, } \\
\text { such that a person level } \\
\text { (not task level) analysis } \\
\text { may be conducted }\end{array}$ & 966 & 1 & 1 & 1.00 & .000 \\
\hline $\begin{array}{l}\text { Flag for households } \\
\text { where an ID was not } \\
\text { provided }\end{array}$ & 966 & 0 & 0 & .00 & .000 \\
\hline $\begin{array}{l}\text { Flag to identify those } \\
\text { surveys that may be } \\
\text { used for analysis } \\
\text { (HHID provided, not a } \\
\text { test, Finished entire } \\
\text { survey) }\end{array}$ & 966 & 1 & 1 & 1.00 & .000 \\
\hline $\begin{array}{l}\text { Duration of survey } \\
\text { (minutes) }\end{array}$ & 966 & 3.73 & 1376.25 & 15.01 & 46.61 \\
\hline $\begin{array}{l}\text { IP Latitude (Qualtrics } \\
\text { provided) }\end{array}$ & 966 & 33.41 & 48.03 & 44.58 & 1.67 \\
\hline $\begin{array}{l}\text { IP Longitude (Qualtrics } \\
\text { provided) }\end{array}$ & 966 & -124.01 & -77.03 & -122.30 & 3.75 \\
\hline $\begin{array}{l}\text { Work-place Address - } \\
\text { Provided by respondent } \\
\text { (ZIP Code) }\end{array}$ & 528 & 37330 & 98686 & 97131.31 & 2715.99 \\
\hline $\begin{array}{l}\text { Home-place Address - } \\
\text { Provided by respondent } \\
\text { (ZIP Code) - Only for } \\
\text { SURVEY_TYPE = } \\
\text { "OHAS" } \\
\text { Valid N (listwise) }\end{array}$ & 503 & 97052 & 97914 & 97388.04 & 119.16 \\
\hline
\end{tabular}


Duration of Survey (minutes) by Survey Type (Long/Short)

Case Processing Summary

\begin{tabular}{|ll|r|r|r|r|}
\hline & Short or Full Survey (If & \multicolumn{4}{|c|}{ Cases } \\
\cline { 3 - 6 } & worker/student, full & \multicolumn{2}{|c|}{ Valid } & \multicolumn{2}{c|}{ Missing } \\
\cline { 3 - 6 } & survey was prompted) & $\mathrm{N}$ & Percent & $\mathrm{N}$ & Percent \\
\hline Duration of survey & FULL CHO & 562 & $100.0 \%$ & 0 & $0.0 \%$ \\
(minutes) & SHORT & 404 & $100.0 \%$ & 0 & $0.0 \%$ \\
\hline
\end{tabular}

\section{Descriptives}

\begin{tabular}{|c|c|c|c|c|}
\hline & Short or Full & rey (If worker/student, full sur & was prompted) & Statistic \\
\hline & & Mean & & 15.20 \\
\hline & & 95\% Confidence Interval for & Lower Bound & 13.91 \\
\hline & & Mean & Upper Bound & 16.49 \\
\hline & & 5\% Trimmed Mean & & 13.40 \\
\hline & & Median & & 12.57 \\
\hline & & Variance & & 243.25 \\
\hline & FULL CHO & Std. Deviation & & 15.59 \\
\hline & & Minimum & & 4.93 \\
\hline & & Maximum & & 242.58 \\
\hline & & Range & & 237.64 \\
\hline & & Interquartile Range & & 6.35 \\
\hline & & Skewness & & 9.52 \\
\hline Duration & & Kurtosis & & 112.70 \\
\hline $\begin{array}{l}\text { of survey } \\
\text { (minutes) }\end{array}$ & & Mean & & 14.74 \\
\hline & & 95\% Confidence Interval for & Lower Bound & 7.92 \\
\hline & & Mean & Upper Bound & 21.56 \\
\hline & & 5\% Trimmed Mean & & 9.46 \\
\hline & & Median & & 8.90 \\
\hline & & Variance & & 4864.4 \\
\hline & SHORT & Std. Deviation & & 69.74 \\
\hline & & Minimum & & 3.73 \\
\hline & & Maximum & & 1376.25 \\
\hline & & Range & & 1372.51 \\
\hline & & Interquartile Range & & 4.445 \\
\hline & & Skewness & & 18.67 \\
\hline & & Kurtosis & & 363.13 \\
\hline
\end{tabular}


Worker Status, Tenure, Dwelling Type, Nhood (Current and Preferred)

Employment/Student Status

\begin{tabular}{|l|r|r|r|r|}
\hline & $\begin{array}{r}\text { Frequenc } \\
\text { y }\end{array}$ & Percent & \multicolumn{1}{c|}{$\begin{array}{c}\text { Valid } \\
\text { Percent }\end{array}$} & \multicolumn{1}{c|}{$\begin{array}{c}\text { Cumulative } \\
\text { Percent }\end{array}$} \\
\hline Full-time or part-time & 24 & 2.5 & 2.5 & 2.5 \\
student & 538 & 55.7 & 55.7 & 58.2 \\
Full-time or part-time & & & & \\
Valid & 69 & 7.1 & 7.1 & 65.3 \\
Oorker & 335 & 34.7 & 34.7 & 100.0 \\
Other (please specify) & 966 & 100.0 & 100.0 & \\
Retired & &
\end{tabular}

Tenure - Current housing situation

\begin{tabular}{|r|r|r|r|r|}
\hline & Frequency & Percent & $\begin{array}{c}\text { Valid } \\
\text { Percent }\end{array}$ & $\begin{array}{c}\text { Cumulative } \\
\text { Percent }\end{array}$ \\
\hline -99 & 13 & 1.3 & 1.3 & 1.3 \\
Othe & 14 & 1.4 & 1.4 & 2.8 \\
Valid Own & 778 & 80.5 & 80.5 & 83.3 \\
Rent & 161 & 16.7 & 16.7 & 100.0 \\
Total & 966 & 100.0 & 100.0 & \\
\hline
\end{tabular}

Dwelling Type - Current housing situation

\begin{tabular}{|l|r|r|r|r|}
\hline & Frequency & Percent & $\begin{array}{c}\text { Valid } \\
\text { Percent }\end{array}$ & $\begin{array}{c}\text { Cumulativ } \\
\text { e Percent }\end{array}$ \\
\hline -99 & 8 & .8 & .8 & .8 \\
Duplex or townhouse & 71 & 7.3 & 7.3 & 8.2 \\
High-rise apartment or condominium & 6 & .6 & .6 & 8.8 \\
(a building more than 15 stories tal & & & & \\
Low-rise apartment or condominium & 80 & 8.3 & 8.3 & 17.1 \\
Valid (a building less than 4 stories tall) & & & & \\
Mid-rise apartment or condominium & 14 & 1.4 & 1.4 & 18.5 \\
(a building between 4 and 15 stories & & & & \\
Other (please specify) & 21 & 2.2 & 2.2 & 20.7 \\
Single-family detached structure & 766 & 79.3 & 79.3 & 100.0 \\
Total & 966 & 100.0 & 100.0 & \\
\hline
\end{tabular}


Dwelling Type - Preferred housing situation

\begin{tabular}{|l|r|r|r|r|}
\hline -99 & $\begin{array}{r}\text { Frequenc } \\
\text { y }\end{array}$ & Percent & \multicolumn{1}{|c|}{$\begin{array}{c}\text { Valid } \\
\text { Percent }\end{array}$} & $\begin{array}{c}\text { Cumulative } \\
\text { Percent }\end{array}$ \\
\hline Duplex or townhouse & 16 & 1.7 & 1.7 & 1.7 \\
High-rise apartment or & 50 & 5.2 & 5.2 & 6.8 \\
condominium (a & 10 & 1.0 & 1.0 & 7.9 \\
building more than 15 & & & & \\
stories tall) & & & & 12.5 \\
Low-rise apartment or & 45 & 4.7 & 4.7 & \\
condominium (a & & & & \\
building less than 4 & & & & \\
stories tall) & & & & \\
Mid-rise apartment or & 22 & 2.3 & 2.3 & 14.8 \\
condominium (a & & & & \\
building between 4 and & & & & \\
15 stories tall) & & & & \\
Other (please specify) & 22 & 2.3 & 2.3 & \\
Single-family detached & 801 & 82.9 & 82.9 & 100.0 \\
structure & & & & \\
Total & 966 & 100.0 & 100.0 & \\
\hline
\end{tabular}

Size of Living Space - Current housing situation

\begin{tabular}{|l|r|r|r|r|}
\hline & Frequency & Percent & \multicolumn{1}{|c|}{$\begin{array}{c}\text { Valid } \\
\text { Percent }\end{array}$} & $\begin{array}{c}\text { Cumulative } \\
\text { Percent }\end{array}$ \\
\hline -99 & 3 & .3 & .3 & .3 \\
Between 1,500 and 2,500 & 417 & 43.2 & 43.2 & 43.5 \\
square feet & 165 & 17.1 & 17.1 & 60.6 \\
Between 2,500 and 5,000 & & & & \\
square feet & 304 & 31.5 & 31.5 & 92.0 \\
Valid Between 750 and 1,500 square & & & & \\
feet & 16 & 1.7 & 1.7 & 93.7 \\
Don't Know & 58 & 6.0 & 6.0 & 99.7 \\
Less than 750 square feet & 3 & .3 & .3 & 100.0 \\
More than 5,000 square feet & 966 & 100.0 & 100.0 & \\
Total & &
\end{tabular}




\section{Current Residential Neighborhood Concept (by geocoded mailing}

address)

\begin{tabular}{|l|r|r|r|r|}
\hline & Frequency & Percent & Valid Percent & Cumulative Percent \\
\hline C & 4 & .4 & .4 & .4 \\
D & 286 & 29.6 & 29.6 & 30.0 \\
E & 382 & 39.5 & 39.5 & 69.6 \\
Valid EF & 3 & .3 & .3 & 69.9 \\
F & 272 & 28.2 & 28.2 & 98.0 \\
NA & 19 & 2.0 & 2.0 & 100.0 \\
Total & 966 & 100.0 & 100.0 & \\
\hline
\end{tabular}

Commute and "Other" Mode

Commute Mode (select one) - Current commute mode

\begin{tabular}{|l|r|r|r|r|}
\hline & Freq & Percent & $\begin{array}{c}\text { Valid } \\
\text { Percent }\end{array}$ & $\begin{array}{c}\text { Cumulative } \\
\text { Percent }\end{array}$ \\
\hline -99 & 404 & 41.8 & 41.8 & 41.8 \\
Bicycle & 3 & .3 & .3 & 42.1 \\
Carpool/Vanpool/Rideshare & 48 & 5.0 & 5.0 & 47.1 \\
I work or go to school at home & 7 & .7 & .7 & 47.8 \\
Vali Not applicable & 32 & 3.3 & 3.3 & 51.1 \\
d Other (please specify) & 2 & .2 & .2 & 51.3 \\
Personal automobile & 10 & 1.0 & 1.0 & 52.4 \\
Public Transit (e.g. Bus, Light Rail, & 383 & 39.6 & 39.6 & 92.0 \\
Streetcar) & 52 & 5.4 & 5.4 & 97.4 \\
Walk & & & & \\
Total & 25 & 2.6 & 2.6 & 100.0 \\
\hline
\end{tabular}


Nonwork Travel Modes - AUTO - "How do you most frequently travel to locations other than to your work or school (e.g. to shop, eat out, recreation destinations, etc.)? (Select all that apply.)"

\begin{tabular}{|rl|r|r|r|r|}
\hline & & Frequency & Percent & Valid Percent & Cumulative Percent \\
\hline \multirow{2}{*}{ Valid } & 0 & 102 & 10.6 & 10.6 & 10.6 \\
& 1 & 863 & 89.3 & 89.4 & 100.0 \\
\hline
\end{tabular}

Nonwork Travel Modes - CARESHARE

\begin{tabular}{|rl|r|r|r|r|}
\hline & & Frequency & Percent & Valid Percent & Cumulative Percent \\
\hline \multirow{2}{*}{ Valid } & 0 & 950 & 98.3 & 98.4 & 98.4 \\
& 1 & 15 & 1.6 & 1.6 & 100.0 \\
\hline
\end{tabular}

Nonwork Travel Modes - CARPOOL

\begin{tabular}{|rl|r|r|r|r|}
\hline & & Frequency & Percent & Valid Percent & Cumulative Percent \\
\hline \multirow{2}{*}{ Valid } & 0 & 945 & 97.8 & 97.9 & 97.9 \\
& 1 & 20 & 2.1 & 2.1 & 100.0 \\
\hline
\end{tabular}

Nonwork Travel Modes - TRANSIT

\begin{tabular}{|rl|r|r|r|r|}
\hline & & Frequency & Percent & Valid Percent & Cumulative Percent \\
\hline \multirow{2}{*}{ Valid } & 0 & 845 & 87.5 & 87.6 & 87.6 \\
& 1 & 120 & 12.4 & 12.4 & 100.0 \\
\hline
\end{tabular}

Nonwork Travel Modes - BIKE

\begin{tabular}{|rl|r|r|r|r|}
\hline & & Frequency & Percent & Valid Percent & Cumulative Percent \\
\hline \multirow{2}{*}{ Valid } & 0 & 829 & 85.8 & 85.9 & 85.9 \\
& 1 & 136 & 14.1 & 14.1 & 100.0 \\
\hline
\end{tabular}

Nonwork Travel Modes - WALK

\begin{tabular}{|rl|r|r|r|r|}
\hline & & Frequency & Percent & Valid Percent & Cumulative Percent \\
\hline \multirow{2}{*}{ Valid } & 0 & 723 & 74.8 & 74.9 & 74.9 \\
& 1 & 242 & 25.1 & 25.1 & 100.0 \\
\hline
\end{tabular}

Nonwork Travel Modes - OTHER

\begin{tabular}{|rl|r|r|r|r|}
\hline & & Frequency & Percent & Valid Percent & Cumulative Percent \\
\hline \multirow{2}{*}{ Valid } & 0 & 952 & 98.6 & 98.7 & 98.7 \\
& 1 & 13 & 1.3 & 1.3 & 100.0 \\
\hline
\end{tabular}

Nonwork Travel Modes - NOT APPLICABLE

\begin{tabular}{|rl|r|r|r|r|}
\hline & & Frequency & Percent & Valid Percent & Cumulative Percent \\
\hline \multirow{2}{*}{ Valid } & 0 & 952 & 98.6 & 98.7 & 98.7 \\
& 1 & 13 & 1.3 & 1.3 & 100.0 \\
\hline & Total & 965 & 99.9 & 100.0 & \\
\hline
\end{tabular}


Sociodemographic Statistics (Respondent and Household)

Descriptive Statistics

\begin{tabular}{|c|c|c|c|c|c|}
\hline & $\mathrm{N}$ & Minimum & Maximum & Mean & $\begin{array}{c}\text { Std. } \\
\text { Deviation }\end{array}$ \\
\hline $\begin{array}{l}\text { Other adults (count, not counting } \\
\text { participant) }\end{array}$ & 966 & 0 & 6 & 1.11 & .846 \\
\hline Total number of adults (calculated) & 966 & 1 & 7 & 2.11 & .846 \\
\hline Children (count) & 966 & 0 & 5 & .39 & .824 \\
\hline $\begin{array}{l}\text { Household Size (calculated = } \\
\text { TOTAL_ADULTS + CHILDREN) }\end{array}$ & 966 & 1 & 8 & 2.50 & 1.252 \\
\hline $\begin{array}{l}\text { Other Workers/Students (count, not } \\
\text { counting particpant) }\end{array}$ & 966 & -9 & 6 & .84 & 1.097 \\
\hline $\begin{array}{l}\text { Household Vehicles Owned (Count) } \\
\text { "How many of each of the following } \\
\text { items does your household OWN? } \\
\text { Number of AUTOMOBILES (e.g. } \\
\text { vehicles, motorcycles)" }\end{array}$ & 966 & 0 & 12 & 1.99 & 1.189 \\
\hline $\begin{array}{l}\text { Household Adult Bikes Owned (count) } \\
\text { "How many of each of the following } \\
\text { items does your household OWN? } \\
\text { Number of ADULT BICYCLES" }\end{array}$ & 966 & 0 & 11 & 1.56 & 1.570 \\
\hline $\begin{array}{l}\text { Licensed Driver (paricipant only) "Are } \\
\text { you a LICENSED DRIVER? yes/no" }\end{array}$ & 958 & 0 & 1 & .97 & 177 \\
\hline $\begin{array}{l}\text { Transit pass (paricipant only) "Do you } \\
\text { have a TRANSIT PASS? yes/no" }\end{array}$ & 959 & 0 & 1 & .15 & 359 \\
\hline $\begin{array}{l}\text { Caresharing membership (paricipant } \\
\text { only) "Do you have a CAR SHARING } \\
\text { MEMBERSHIP (e.g. car2go, Zipcar, } \\
\text { Getaround)? yes/no" } \\
\text { Valid N (listwise) }\end{array}$ & 958 & 0 & 1 & .05 & .214 \\
\hline
\end{tabular}


Household Income, Average Monthly Costs, and Willingness to Spend More

Household Income "Please approximate the TOTAL INCOME of your HOUSEHOLD in 2013."

\begin{tabular}{|l|r|r|r|r|}
\hline -99 & $\begin{array}{r}\text { Frequenc } \\
\text { y }\end{array}$ & Percent & $\begin{array}{c}\text { Valid } \\
\text { Percent }\end{array}$ & $\begin{array}{c}\text { Cumulative } \\
\text { Percent }\end{array}$ \\
\hline 0 to $\$ 14,999$ & 44 & 4.6 & 4.6 & 4.6 \\
$\$ 100,000$ to & 43 & 4.5 & 4.5 & 9.0 \\
$\$ 149,999$ & 171 & 17.7 & 17.7 & 26.7 \\
$\$ 15,000$ to $\$ 24,999$ & 49 & 5.1 & 5.1 & 31.8 \\
$\$ 150,000$ to & 65 & 6.7 & 6.7 & 38.5 \\
$\$ 199,999$ & & & & \\
Valid & 20 & 2.1 & 2.1 & 40.6 \\
$\$ 250,000$ to & & & & \\
$\$ 25,000$ to $\$ 34,999$ & 79 & 8.2 & 8.2 & 48.8 \\
$\$ 250,000$ or more & 16 & 1.7 & 1.7 & 50.4 \\
$\$ 35,000$ to $\$ 49,999$ & 115 & 11.9 & 11.9 & 62.3 \\
$\$ 50,000$ to $\$ 74,999$ & 218 & 22.6 & 22.6 & 84.9 \\
$\$ 75,000$ to $\$ 99,999$ & 146 & 15.1 & 15.1 & 100.0 \\
Total & 966 & 100.0 & 100.0 & \\
\hline
\end{tabular}

Household Costs Monthly "Please approximate your household's AVERAGE MONTHLY HOUSING COSTS (rent/mortgage)."

\begin{tabular}{|l|r|r|r|r|}
\hline & Frequency & Percent & $\begin{array}{c}\text { Valid } \\
\text { Percent }\end{array}$ & $\begin{array}{c}\text { Cumulativ } \\
\text { e Percent }\end{array}$ \\
\hline -99 & 36 & 3.7 & 3.7 & 3.7 \\
\$1,000 to 1,499 per month & 230 & 23.8 & 23.8 & 27.5 \\
\$1,500 to \$1,999 per month & 103 & 10.7 & 10.7 & 38.2 \\
\$2,000 to \$2,499 per month & 59 & 6.1 & 6.1 & 44.3 \\
\$2,500 to \$2,999 per month & 20 & 2.1 & 2.1 & 46.4 \\
\$250 to \$499 per month & 61 & 6.3 & 6.3 & 52.7 \\
Valid & 12 & 1.2 & 1.2 & 53.9 \\
\$3,500 or more per month & 14 & 1.4 & 1.4 & 55.4 \\
\$500 to \$749 per month & 92 & 9.5 & 9.5 & 64.9 \\
\$750 to \$999 per month & 136 & 14.1 & 14.1 & 79.0 \\
Less than \$249 per month & 203 & 21.0 & 21.0 & 100.0 \\
Total & 966 & 100.0 & 100.0 & \\
\hline
\end{tabular}


Add'l HH Costs Willing to Pay "If you were able to find a home or a location that better suited your preferences, how much more would you be willing to spend on your monthly housing costs (rent/mortgage)?

\begin{tabular}{|c|c|c|c|c|c|}
\hline & & Frequency & Percent & $\begin{array}{c}\text { Valid } \\
\text { Percent }\end{array}$ & $\begin{array}{c}\text { Cumulativ } \\
\text { e Percent }\end{array}$ \\
\hline & -99 & 39 & 4.0 & 4.0 & 4.0 \\
\hline & I would be willing to spend about & 31 & 3.2 & 3.2 & 7.2 \\
\hline & $\$ 1,000$ more per month. & & & & \\
\hline & I would be willing to spend about & 14 & 1.4 & 1.4 & 8.7 \\
\hline & $\$ 1,500$ more per month. & & & & \\
\hline & I would be willing to spend about $\$ 100$ & 80 & 8.3 & 8.3 & 17.0 \\
\hline & more per month. & & & & \\
\hline & I would be willing to spend about & 8 & .8 & .8 & 17.8 \\
\hline & $\$ 2,000$ more per month. & & & & \\
\hline & I would be willing to spend about $\$ 200$ & 71 & 7.3 & 7.3 & 25.2 \\
\hline & more per month. & & & & \\
\hline Volid & I would be willing to spend about $\$ 300$ & 39 & 4.0 & 4.0 & 29.2 \\
\hline andu & more per month. & & & & \\
\hline & I would be willing to spend about $\$ 400$ & 22 & 2.3 & 2.3 & 31.5 \\
\hline & more per month. & & & & \\
\hline & I would be willing to spend about $\$ 50$ & 43 & 4.5 & 4.5 & 35.9 \\
\hline & more per month. & & & & \\
\hline & I would be willing to spend about $\$ 500$ & 59 & 6.1 & 6.1 & 42.0 \\
\hline & more per month. & & & & \\
\hline & I would be willing to spend about $\$ 750$ & 22 & 2.3 & 2.3 & 44.3 \\
\hline & more per month. & & & & \\
\hline & I would not be willing to spend more & 538 & 55.7 & 55.7 & 100.0 \\
\hline & per month. & & & & \\
\hline & Total & 966 & 100.0 & 100.0 & \\
\hline
\end{tabular}

Household, Income, Age (HIA) Classification

HIA Income - Metroscope HIA classification

\begin{tabular}{|l|r|r|r|r|}
\hline & Frequency & Percent & \multicolumn{1}{|c|}{$\begin{array}{c}\text { Valid } \\
\text { Percent }\end{array}$} & $\begin{array}{c}\text { Cumulativ } \\
\text { e Percent }\end{array}$ \\
\hline High Income $(>\$ 100 \mathrm{k})$ & 272 & 28.2 & 28.2 & 28.2 \\
Valid Low Income $(<\$ 35 \mathrm{k})$ & 171 & 17.7 & 17.7 & 45.9 \\
Medium Income $(\$ 35-100 \mathrm{k})$ & 479 & 49.6 & 49.6 & 95.4
\end{tabular}




\begin{tabular}{|l|r|r|r|r|}
\hline NA & 44 & 4.6 & 4.6 & 100.0 \\
Total & 966 & 100.0 & 100.0 & \\
\hline
\end{tabular}

HIA Age - Metroscope HIA classification

\begin{tabular}{|l|r|r|r|r|}
\hline & Frequency & Percent & $\begin{array}{c}\text { Valid } \\
\text { Percent }\end{array}$ & $\begin{array}{c}\text { Cumulativ } \\
\text { e Percent }\end{array}$ \\
\hline High Age (65+ years) & 315 & 32.6 & 32.6 & 32.6 \\
Low Age (18-34 years) & 102 & 10.6 & 10.6 & 43.2 \\
Valid & 540 & 55.9 & 55.9 & 99.1 \\
Medium Age (35-64 years) & 9 & .9 & .9 & 100.0 \\
NA & 966 & 100.0 & 100.0 & \\
Total & &
\end{tabular}

HIA HHSize - Metroscope HIA classification

\begin{tabular}{|c|c|c|c|c|c|}
\hline & & Frequency & Percent & $\begin{array}{c}\text { Valid } \\
\text { Percent }\end{array}$ & $\begin{array}{c}\text { Cumulativ } \\
\text { e Percent }\end{array}$ \\
\hline \multirow{4}{*}{ Valid } & 1 Person Household & 178 & 18.4 & 18.4 & 18.4 \\
\hline & 2 Person Household & 423 & 43.8 & 43.8 & 62.2 \\
\hline & 3+ Person Household (Family) & 365 & 37.8 & 37.8 & 100.0 \\
\hline & Total & 966 & 100.0 & 100.0 & \\
\hline
\end{tabular}

HIA Tenure - Metroscope HIA classification

\begin{tabular}{|ll|r|r|r|r|}
\hline & Frequency & Percent & $\begin{array}{c}\text { Valid } \\
\text { Percent }\end{array}$ & $\begin{array}{c}\text { Cumulativ } \\
\text { e Percent }\end{array}$ \\
\hline VA & 27 & 2.8 & 2.8 & 2.8 \\
Valid Own & 778 & 80.5 & 80.5 & 83.3 \\
Rent & 161 & 16.7 & 16.7 & 100.0 \\
Total & 966 & 100.0 & 100.0 & \\
\hline
\end{tabular}

Descriptive Statistics

\begin{tabular}{|l|r|r|r|r|r|}
\hline & N & Minimum & Maximum & Mean & $\begin{array}{c}\text { Std. } \\
\text { Deviation }\end{array}$ \\
\hline $\begin{array}{l}\text { Owning my house/condo } \\
\text { (IMPORTANCE) }\end{array}$ & 936 & 1 & 3 & 1.34 & .616 \\
$\begin{array}{l}\text { Living in a home with a large living } \\
\text { space (IMPORTANCE) }\end{array}$ & 920 & 1 & 3 & 2.03 & .755 \\
\hline
\end{tabular}




\begin{tabular}{|c|c|c|c|c|c|}
\hline $\begin{array}{l}\text { Living in a detached single-family } \\
\text { home (IMPORTANCE) }\end{array}$ & 932 & 1 & 3 & 1.50 & .684 \\
\hline $\begin{array}{l}\text { Having a private yard } \\
\text { (IMPORTANCE) }\end{array}$ & 937 & 1 & 3 & 1.39 & .611 \\
\hline $\begin{array}{l}\text { Having privacy from my neighbors } \\
\text { (IMPORTANCE) }\end{array}$ & 937 & 1 & 3 & 1.44 & .570 \\
\hline $\begin{array}{l}\text { Living at the "center of it all" } \\
\text { (IMPORTANCE) }\end{array}$ & 925 & 1 & 3 & 2.58 & .599 \\
\hline $\begin{array}{l}\text { Being near high-quality public schools } \\
\text { (IMPORTANCE) }\end{array}$ & 923 & 1 & 3 & 2.22 & .849 \\
\hline $\begin{array}{l}\text { Living near established, older homes } \\
\text { (IMPORTANCE) }\end{array}$ & 916 & 1 & 3 & 2.28 & .726 \\
\hline $\begin{array}{l}\text { Having access to highways/freeways } \\
\text { (IMPORTANCE) }\end{array}$ & 925 & 1 & 3 & 2.03 & .706 \\
\hline $\begin{array}{l}\text { Having a variety of transportation } \\
\text { options (IMPORTANCE) }\end{array}$ & 931 & 1 & 3 & 1.81 & .707 \\
\hline $\begin{array}{l}\text { Having a commute that takes } 25 \\
\text { minutes or less (IMPORTANCE) }\end{array}$ & 927 & 1 & 3 & 1.68 & .802 \\
\hline $\begin{array}{l}\text { Walking to bus and/or rail stops } \\
\text { (IMPORTANCE) }\end{array}$ & 936 & 1 & 3 & 1.96 & .772 \\
\hline $\begin{array}{l}\text { Having off-street parking at local } \\
\text { destinations (IMPORTANCE) }\end{array}$ & 925 & 1 & 3 & 2.06 & .714 \\
\hline $\begin{array}{l}\text { Having dedicated parking at your } \\
\text { residence (IMPORTANCE) }\end{array}$ & 931 & 1 & 3 & 1.32 & .588 \\
\hline $\begin{array}{l}\text { Having access to parks and } \\
\text { recreational areas (IMPORTANCE) }\end{array}$ & 936 & 1 & 3 & 1.51 & .619 \\
\hline $\begin{array}{l}\text { Walking to nearby places } \\
\text { (IMPORTANCE) }\end{array}$ & 933 & 1 & 3 & 1.64 & .698 \\
\hline $\begin{array}{l}\text { Biking to nearby places } \\
\text { (IMPORTANCE) }\end{array}$ & 928 & 1 & 3 & 2.09 & .789 \\
\hline Valid N (listwise) & 902 & & & & \\
\hline
\end{tabular}


Choice Experiment: Number of Tasks

Two sets of 5 choices? Did the participant allow us to prompt them with an additional 5 tasks?

\begin{tabular}{|l|r|r|r|r|}
\hline & Frequency & Percent & \multicolumn{1}{c|}{$\begin{array}{c}\text { Valid } \\
\text { Percent }\end{array}$} & $\begin{array}{c}\text { Cumulative } \\
\text { Percent }\end{array}$ \\
\hline & 404 & 41.8 & 41.8 & 41.8 \\
Valid E & 105 & 10.9 & 10.9 & 52.7 \\
TRUE & 457 & 47.3 & 47.3 & 100.0 \\
Total & 966 & 100.0 & 100.0 & \\
\hline
\end{tabular}


